Portland State University

PDXScholar

1989

\title{
Cultural relativism in intercultural communication theory : a descriptive and heuristic study
}

Ellen Linnea Trygstad

Portland State University

Follow this and additional works at: https://pdxscholar.library.pdx.edu/open_access_etds

Part of the International and Intercultural Communication Commons

Let us know how access to this document benefits you.

\section{Recommended Citation}

Trygstad, Ellen Linnea, "Cultural relativism in intercultural communication theory : a descriptive and heuristic study" (1989). Dissertations and Theses. Paper 4298.

https://doi.org/10.15760/etd.6182

This Thesis is brought to you for free and open access. It has been accepted for inclusion in Dissertations and Theses by an authorized administrator of PDXScholar. Please contact us if we can make this document more accessible: pdxscholar@pdx.edu. 
AN ABSTRACT OF THE THESIS OF Ellen Linnea Trygstad for

the Master of Arts in Speech Communication presented May $10,1989$.

Title: Cultural Relativism in Intercultural Communication Theory: A Descriptive and Heuristic Study

APPROVED BY THE MEMBERS OF THE THESIS COMMITTEE:


Stephen Kosokoff



Huge M. Maynard

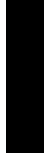

Larry A. Steward

The purpose of this descriptive study was to determine how the concept of "cultural relativism" is used in the current literature pertaining to intercultural communication. This concept is central to much of the work being done on face-to-face intercultural communication, but 
a preliminary review of that literature indicated ambiguity and lack of concurrence among authors' views regarding the concept. This research was designed to describe the range of authors' views on cultural relativism as well as to provide some historical and critical perspective regarding "cultural relativism."

The research data were obtained from the literature of early and current anthropology, and from the area of intercultural communication. A descriptive methodology was employed for obtaining, organizing, and analyzing the data from these three literature groups. Data were examined in terms of four basic categories: authors' definitions, applications, and stated advantages and disadvantages of cultural relativism. The data within each category were organized thematically to facilitate a comparative analysis. The results of the review of the intercultural communication literature substantiated the preliminary findings, namely, that references to cultural relativism in the intercultural communication literature are varied, and generally, inadequately stated. For example, out of the forty-four works reviewed which contained the term "cultural relativism," or a similar term, less than one-third of the authors defined the term, and of these, half were implied, not explicit, definitions. Furthermore, among the authors who did indicate definitions, four different definitions of cultural relativism were found. 
Many similarities were found between the views of the intercultural communication authors and those of the three major early anthropology authors reviewed for this study. In the early anthropology literature, variance was also found among the definitions of cultural relativism, in addition to differences in emphasis regarding its use. It is noteworthy that none of the intercultural communication authors make reference to any historical connections. One of the conclusions of this study is that this is a shortcoming in the intercultural communication literature. This study concludes with a brief review of representative, negatively critical views of cultural relativism in the current anthropology literature. In contrast to the almost blanket support for cultural relativism in the intercultural literature, a lively, often acerbic, debate prevails in the current anthropology literature. Ten works were reviewed for representative criticisms of cultural relativism from anthropology, the implications of which were discussed in the conclusion of this study.

The central conclusion of this study was that, in the intercultural communication literature, cultural relativism needs to be reexamined in light of the goals of the field. Instead of the multiple definitions now being used, a single, clear definition needs to be chosen, based on stated assumptions. Other definitions of the term now being used 
should be assigned different names, to avoid the confusion which now prevails as to exactly which concept an author is employing. A suggested definition of "cultural relativism" appropriate for intercultural communication is offered in the summary of the study. 
CULTURAL RELATIVISM IN INTERCULTURAL COMMUNICATION THEORY:

A DESCRIPTIVE AND HEURISTIC STUDY

by

ELLEN LINNEA TRYGSTAD

A thesis submitted in partial fulfillment of the requirements for the degree of

\author{
MASTER OF ARTS \\ in \\ SPEECH COMMUNICATION
}

Portland State University

(c) 1989 
TO THE OFFICE OF GRADUATE STUDIES:

The members of the committee approve the thesis of Ellen Linnea Trygstad presented May 10, 1989.



Milon J. Bennett, Chair
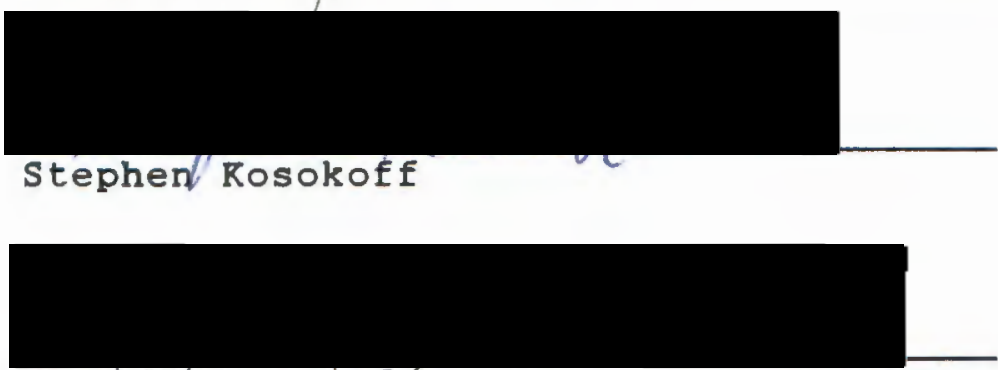

Hugo M. Maynard

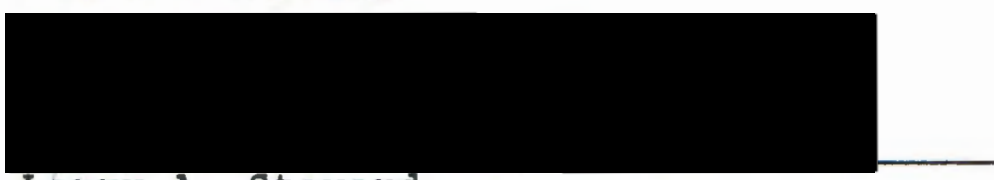

Larry A. steward

APPROVED :

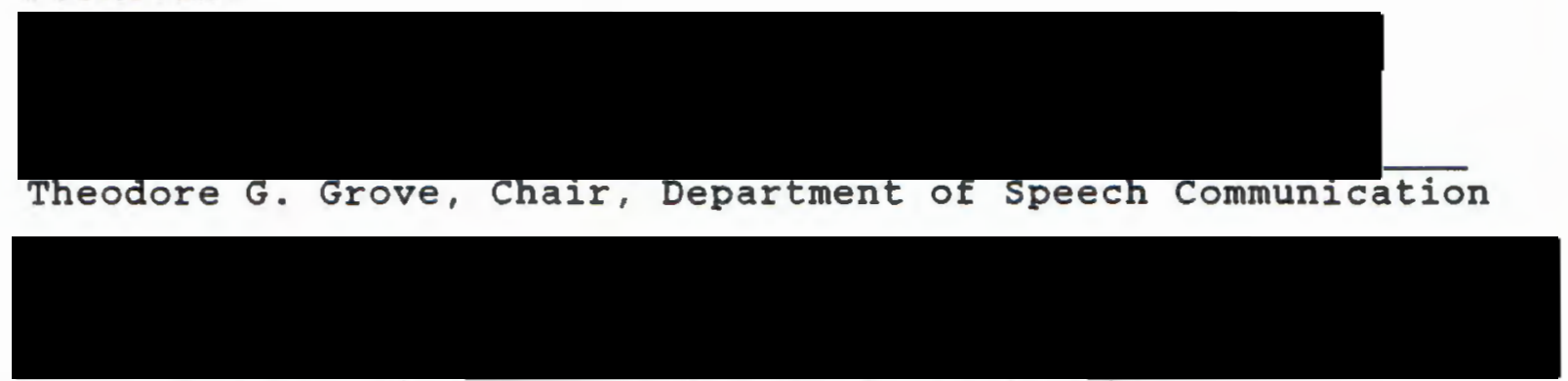

Bernard Ross, Vice Provost for Graduate Studies 
To My Father,

Victor S. Trygstad 


\section{ACKNOWLEDGMENTS}

To all of the many people who have given their encouragement and support for this research endeavor, both friends and family, I wish to convey my deep gratitude.

I would like, especially, to acknowledge my advisor, Milton Bennett, for his most helpful and insightful guidance, and the committee members who oversaw this study, for their interest in, and consideration of, this research.

To my husband, Richard Burke, a heartfelt thank-you for your patience, and your selfless enthusiasm and support for this research undertaking.

To the Intercultural Communication Institute and the Multnomah County Public Library, I would like to extend my sincere thanks for their excellent services and their ready assistance in procuring materials used in this research.

I also wish to express my gratitude to Michael clement and Victoria skakel, for their generous assistance with, and use of, their wonderful computer, without which, this study could never have been written.

Finally, to those faculty members of the speech Communication Department from whom I have taken classes at Portland State University, I wish to convey my deep appreciation for their inspiration and their teaching which 
I have found most helpfuI in the research process of this study, as well as professionally relevant and, personally, very meaningful. 
TABLE OF CONTENTS

PAGE

ACKNOWLEDGMENTS. . . . . . . . . . . . . . . . . . iii

LIST OF TABLES. . . . . . . . . . . . . . . . . . vii

CHAPTER

I INTRODUCTION. . . . . . . . . . . . . 1

Purpose of the study. . . . . . . . 3

Definition of Terms. . . . . . . . 4

Scope of the study. . . . . . . . 6

Methodology. . . . . . . . . . 8

Overview of the Study. . . . . . 16

II CULTURAL RELATIVISM IN EARLY ANTHROPOLOGY. 18

Introduction. . . . . . . . . . . 18

Franz Boas. . . . . . . . . . 21

Boas' Views and the Definitional

Themes. . . . . . . . . . 22

Applications. . . . . . . . . 28

Advantages. . . . . . . . 30

Disadvantages. . . . . . . . . 33

Ruth Benedict. . . . . . . . . 34

Definition. . . . . . . . . . 35

. Applications. . . . . . . . 36

Advantages. . . . . . . . . . 38

Disadvantages. . . . . . . . . . 43 
Melville Herskovits. . . . . . . . 45

Definition. . . . . . . . . . 45

Applications. . . . . . . . . . 48

Advantages. . . . . . . . . . 50

Disadvantages. . . . . . . . 56

Chapter Summary. . . . . . . . 57

III CULTURAL RELATIVISM IN THE INTERCULTURAL COMMUNICATION LITERATURE. . . . . . . . 59

Definitions. . . . . . . . . . 60

Applications. . . . . . . . 65

Advantages. . . . . . . . . 80

Disadvantages. . . . . . . . . . 91

Chapter summary. . . . . . . . . . 94

IV CRITICISMS OF CULTURAL RELATIVISM IN THE CURRENT ANTHROPOLOGY LITERATURE. . . . . 100

Definitions. . . . . . . . . 101

Applications. . . . . . . . 105

Advantages. . . . . . . . . 109

Disadvantages. . . . . . . . . 111

Chapter Summary. . . . . . . . 135

V SUMMARY AND CONCLUSIONS. . . . . . . . . 140

Definitions. . . . . . . . . 143

Applications. . . . . . . . . 150

Advantages. . . . . . . . . . 158

Disadvantages. . . . . . . . 162

Concluding Remarks. . . . . . . 187 


\section{LIST OF TABLES}

TABLE

PAGE

I Cultural Relativism Data Profile. . . . . . 141

I Data Profile Coding Key. . . . . . . . . . .142 


\section{CHAPTER I}

\section{INTRODUCTION}

The concept of cultural relativism is implicit to much of the work presently being done on face-to-face intercultural communication and appears throughout the intercultural communication literature. However, a review of this literature revealed that authors differ in their perspectives on cultural relativity. Because no studies exist which specifically examine the role of "cultural relativism" in the area of intercultural communication, exactly how it is defined and used in this area of study remains unknown. It is also not known how views on cultural relativism in the area of intercultural communication compare with views on cultural relativism in the field of anthropology where it was first established in the social sciences.

The primary focus of this study, therefore, is to gain an in-depth understanding of cultural relativism in the area of intercultural communication theory. In the beginning of this study, there is a brief description of the writings of the early anthropologists who helped establish cultural relativism as a key concept in anthropology. This provides 
some understanding of the historical roots of cultural relativism in intercultural communication theory.

The main body of the text of this study presents the data obtained from the research of the intercultural communication literature pertaining to cultural relativism. Organized thematically, it describes the range of authors' views pertaining to definitions, applications, disadvantages and advantages of cultural relativism.

This paper also summarizes some of the criticisms of cultural relativism in the current anthropology literature. In contrast to the generally positive support cultural relativism is given in the intercultural communication area, a strong challenge to the viability of cultural relativism exists in anthropology. Thus, a brief discussion of representative criticisms from the anthropological literature was included because of the possible implications these criticisms may have for the use of cultural relativism in the intercultural communication area. They help provide greater insight with which to identify possible problems and areas in intercultural communication needing further research.

Intercultural communcation is an applied field related to both the fields of speech communication and anthropology. Thus, an understanding of intercultural communication theory in light of developments in the broader 
theoretical arenas is important. There is, in general, ...a lack of theory integrating the communication and culture concepts and a lack of systematic study in this field (Holmes 1978,18 ).

In particular, "...the important and practical theoretical task...is the identification and clarification of the key concepts of our field" (Becker 1969, 4, quoted in Holmes 1978, 19). In this last decade, efforts have been made to consolidate and systematize the diverse material on intercultural communication for the purpose of developing theory. However, cultural relativism still remains largely unaddressed in the intercultural communication literature. The task of clarifying the concept of cultural relativism undertaken by this study is both relevant and timely. It provides a more precise and comprehensive understanding of a fundamental concept which, to date, remains unclarified in intercultural communication research.

\section{PURPOSE OF THE STUDY}

The purpose of this study is to examine and clarify the concept of "cultural relativism" in the current literature pertaining to intercultural communication. To achieve this purpose, three research questions were identified. 
Research Questions

1. What is the historical context of cultural relativism in early anthropology?

2. How is cultural relativism used in the area of intercultural communication?

3. What are some of the representative criticisms of cultural relativism in the contemporary literature of anthropology?

\section{DEFINITION OF TERMS}

In this study, the following definitions apply:

1. Communication--According to Mortensen (1972, 1521), communication is the assigning of "significance to message-related behavior" such that the communicants attain a shared sense of meaning. The experience is dynamic li.e., we are constantly creating associations, and manipulating and selecting stimuli, physiologically), irreversible and unrepeatable, proactive (total involvement of the individual engaged in communication), reciprocal ("...a mutual influencing process among countless factors, each functioning conjointly so that changes in one set of forces affect the operations of all constituent activity in a total field of experience," and contextual (including both physical setting and the sociocultural situation of the interaction). 
Included in the definition for this study is the concept that communication is approximate:

No one ever sees all, for each abstracts in accordance with his past experience and emerging needs. Where men construe events similarly, they can expect to understand and agree readily; where they construe events differently, agreement is more difficult (Barnlund 1968, 7).

Communication involves approximations of the experiences and meanings of another.

2. Cultural Relativity--One of the early proponents of this concept, Melville J. Herskovits, stated:

The principle of cultural relativism...is as follows: Judgments are based on experience, and experience is interpreted by each individual in terms of his own enculturation (Herskovits 1948, 63).

To Herskovits, cultural relativity referred to the culture-boundness of judgment. Significant variations on Herskovits' definition existed amongst his contemporaries and those who preceded him, and these variations persist today. These are examined in the main text of this study. The term "cultural relativism" will be used in this study to refer generically to the many definitions of the term. Variations as they occur in the literature will be identified as such.

3. Culture--"..the cumulative deposit of knowledge, experience, meanings, beliefs, values, attitudes, religions, concepts of self, the universe, and self-universe relationships, hierarchies of status, role expectations 
spatial relations, and time concepts acquired by a large group of people in the course of generations through individual and group striving. Culture manifests itself both in patterns of language and thought and in forms of activity and behavior" (Samovar and Porter 1976, 7).

4. Current Literature--works written within approximately the last twenty-five years.

5. Face-to-Face Intercultural communication--the interaction between individuals having different cultural backgrounds where cultural behavior and value differences are known to exist. Such communication interaction takes place in each other's presence (Porter and Samovar 1988, 15). The term "intercultural communication" will be used to refer to the field of study itself. When different aspects of the field are referred to, such as the interactive process of face-to-face intercultural communication, the text will indicate this.

\section{SCOPE OF THE STUDY}

To present a profile of "cultural relativism" in the area of intercultural communication, this study focuses on four select topics: 1) authors' definitions of cultural relativism, 2) authors' applications of cultural relativism, 3) advantages of cultural relativism identified by authors, and 4) disadvantages of cultural relativism identified by authors. 
While the main sources of data were authors of works pertaining to intercultural communication, two additional sources were utilized. One is the literature from early anthropology, to which reference was made for information regarding the original views on cultural relativism in anthropology. These early views provide helpful background information. The second is the current anthropological literature, which reflects an active debate on cultural relativism and its viability for the field of anthropology. A summary of some of these criticisms was included in this paper because of the potentially important implications they have regarding the use of cultural relativism in intercultural communication theory.

Due to time and availability restrictions, most of the data is from literature by authors from the United states. Where possible, culturally diverse sources have been included in this study.

As a description of cultural relativism in the area of intercultural communication, this paper is limited in other ways. For instance, the influence of socio-political contexts upon the development of cultural relativism is excluded, as is the historical development of the concept of cultural relativism before this century.

It should be noted that subjects such as "linguistic relativity" and Einstein's "theory of relativity" are quite distinct from the topic of this study and have no bearing 
upon it. The reader should note, however, that terms other than "cultural relativism" have been used in the literature to refer to the concept of cultural relativism, and may appear in this study as well.

Further, because of its descriptive and heuristic nature, it is not the goal of this study to champion any one view on cultural relativism but rather, to present a current profile of the range of views on cultural relativism in the area of intercultural communication. This limited focus of study contributes to the groundwork needed for further research on cultural relativism in face-to-face intercultural communication.

\section{METHODOLOGY}

Description of Research Methodology

A review of the literature on cultural relativism reveals that there are no studies of the specific uses of "cultural relativism" in the area of intercultural communication. A thorough historical and philosophical analysis of cultural relativism in the related field of anthropology, however, can be found in cultural Relativism and Anthropology by Edwin Hatch (New York: Columbia University Press, 1983).

Previous studies can often serve as the basis for new studies (Cooper 1984, 30). However, Hatch's study is too dissimilar in purpose to base the present study on it. The 
book offers historical and critical insight into the concept of cultural relativism helpful for this study, but the historical and philosophical methodologies employed do not serve the descriptive goals of this study. Furthermore, it does not present information about cultural relativism in intercultural communication theory.

Because of the absence of related studies, the methodology for this study was based on the methodology outlined for descriptive studies in Methods for Research (Good and Douglas 1954). The descriptive method is useful because it provides procedures for

$$
\begin{aligned}
& \text {...studies that purport to present facts } \\
& \text { concerning the nature and status of } \\
& \text { anything... a group of persons... a system of } \\
& \text { thought... (Good and Douglas, 259). } \\
& \text { Descriptive studies are useful for providing }
\end{aligned}
$$$$
\text { information on which professional judgments may be based. }
$$$$
\text { The accumulation of data can affect practice due to the }
$$
increased insight afforded by the information (Good and Douglas, 258). Since the goal of this study is to provide information on the "nature and status" of cultural relativism in intercultural communication theory, and to explore the implications of this information for the theory and practice of intercultural communication, the descriptive method is appropriate for this study. 
The methodology of this study has four parts:

(1) collection of data, (2) organization and presentation of the data, (3) analysis of data, and (4) summary, conclusions, and suggestions for future research.

\section{Collection of Data}

The data for this study are from written works. The primary data on cultural relativism consist of authors' views on cultural relativism from the intercultural communication literature. The data from the intercultural communication literature are viewed as representing "intercultural communication theory."

The secondary data utilized in this paper derive from authors' views on cultural relativism found in the anthropological literature. These views are included to add depth of understanding. Such auxiliary data are often used in research to throw light on the conditions or to give additional meaning to the facts (Good and Douglas, 269).

All the data were obtained from original sources. No secondary sources were used for the collection, presentation or analyses of the data, although such secondary sources do exist. The purpose of the use of original material was to enable insights to emerge without previous bias derived from the influence of others' assessments.

Because systematic collection of data is essential, categories were selected in terms of their perceived effectiveness for organizing the data (Good and Douglas, 
538-539). To facilitate the gathering of "specific and definite" data and to present them in a systematic fashion (Good and Douglas, 269), four categories were selected. The most efficient way to gather information about something is to sample representative components of "the whole" of that being studied (Good and Douglas, 357). The four categories chosen for this study as representative of "cultural relativism" are:

1. authors' definitions of cultural relativism

2. authors applications of cultural relativism

3. advantages of cultural relativism stated by authors

4. disadvantages of cultural relativism identified by authors

\section{Organization of the Literature Data}

A preliminary perusal of the intercultural communication literature led to the identification of various themes which tend to occur throughout the literature. These themes were observed to be predominant in the anthropological literature also. Therefore, these themes served as a framework with which to organize the data within each category for all the literature.

This organizational process had several steps. First, the intercultural communication data was obtained for each category (definitions, applications, advantages and disadvantages). Then, within each of the categories, 
authors' views identified as similar in theme were grouped. Topical variations within each theme group were noted. For instance, in the applications category, fifteen of the intercultural communication works were observed to refer to causes of cultural relativism. Within this theme, the causes to which the authors referred divided into two topics: (a) cultural relativism resulting from a formal learning context, and (ㅁ) cultural relativism resulting from an informal learning context. Nine works addressed topic "a" and six addressed topic "b."

The themes which emerged from the intercultural communication data were used to organize the data from the early and current anthropological literature as well. A presentation of all of the data grouped by thematic similarity was seen as more useful than data randomly itemized or inconsistantly organized. This approach of grouping items within categories facilitates economy of thought and helps to bring new properties into focus (Good and Douglas, 493).

While most of the concepts in the current anthropology literature easily fit within the thematic framework, some did not. These were identified accordingly in the early and current anthropology chapters. For example, one of the early anthropology definitions ("subjectivism") did not fit into any of the four definitional themes which had emerged from the intercultural communication literature. 
The basic categorical themes generated from the intercultural literature and used for classifying the data within each category are as follows:

Definitional Themes

1. Cultural Diversity--the "fact" of the diversity of cultures

2. Cultural validity--the "fact" of the validity and equal valuableness of all cultures, or/and cultural values and practices

3. Attitudes Toward Difference--various attitudes toward cultural differences (influencing one's experience of cultural differences) ranging from neutral to positive (i.e., tolerance, respect, non-evaluation, positive evaluation)

4. Contextualization--achieving accurate understanding of other cultures, or aspects of cultures, through contextualization

\section{Application Themes}

1. Causes of Cultural Relativism

2. Consequences of Cultural Relativism

3. Theoretical Dimensions 


\section{Advantage Themes}

1. Facilitation of Internal, Attitudinal Changes

2. Eacilitation of Accurate, Cultural

Knowledge and Understanding

3. Facilitation of External, Interactive Results

\section{Disadvantage Themes}

1. Difficulties of Assumption of Cultural

$$
\text { Relativism }
$$

2. The Avoidance of Ethical Judgments

3. The Permeability vs. Impermeability of

$$
\text { Cultural Boundaries }
$$

The data, organized as previously described according to categories and themes, is presented in three separate chapters. The first describes views on cultural relativism in early anthropology, the second presents the data derived from the intercultural communication literature, and the third provides a brief description of representative views from the anthropological literature negatively critical of cultural relativism.

In the final chapter of the study, the early anthropology, current anthropology and intercultural communication data are compared and discussed, and implications for future study are suggested.

\section{Analysis of the Data}

Comparison is one of the things normally done with descriptive data and provides a way for finding "...additional meaning in the status of any phenomenon" 
(Good and Douglas, 260). The first step in the comparison of data consisted of making a multi-dimensional profile of the data. This summary of the data from the three Iiterature sources was done in chart form (Table 1). Presenting the data in each of the four categories (definitions, applications, advantages and disadvantages), this multi-dimensional profile served as a means for comparing the data.

The procedure was as follows: The categories were entered as horizontal headings, and the themes used to organize the data from all of the literature were listed under the corresponding headings. Then, each work used for collecting data was assigned a symbol to represent that work. Works from the intercultural literature were assigned numbers, and those from the current anthropological

literature were assigned letters. Each of the authors from the early anthropology literature was given one of the following symbols (* \& (d) All of these identifiers were, in turn, entered in the categories under the appropriate themes in accordance with the findings presented in each data chapter.

This procedure resulted in a visual profile of the various views examined in the study. It provided an easy way to compare views among and between each of the three literature sources (since each type of literature was assigned a different type of symbol). It also facilitated 
the identification of correspondences between categories (whether or not, for example, authors having the same definition of cultural relativism stated the same, or different, advantages and disadvantages). The number of authors sharing a view could also be readily seen in graphic form.

In this concluding chapter, significant themes and problems revealed through the data analysis are identified and discussed. Recommendations for areas needing possible further study are presented.

OVERVIEW OF THE STUDY

This study is organized into five chapters. The first provides an introduction to the study. The next chapter gives some historical background regarding cultural relativism by briefly outlining the views held by three key proponents of the concept in early anthropology.

The third chapter presents the views on cultural relativism found in the intercultural communication literature. The fourth presents various critical perspectives on cultural relativism from the current, anthropology literature. This chapter concludes the presentation of data.

The results of the data collection are summarized and analyzed in the fifth chapter They are organized into an 
overall profile of the varying views on cultural relativism discerned through the research.

This final chapter provides an interpretation of the data and a summary of the study. The chapter concludes with a discussion of the implications of the findings of this study on cultural relativism for the theory and practice of intercultural communication. 
CHAPTER II

CULTURAL RELATIVISM IN EARLY ANTHROPOLOGY

\section{INTRODUCTION}

The concept of cultural relativism was adopted and developed in the early twentieth century in Europe and in the United States in the emerging branch of anthropology called cultural anthropology (the study of "culture"). At that time, cultural anthropologists were struggling to establish cultural anthropology as an accepted and credible field of study to both the general public and the established scientific community.

Several of the key issues debated amongst anthropologists in the early decades of this century involved cultural relativism: Euro-American ethnocentrism, cultural conditioning, objectivity, and the idea of culture as an integrated whole.

To provide some conceptual background for the consideration of cultural relativism in this study, a brief overview of these topics is included here, followed by a presentation of the views of the three, early proponents of cultural relativism in anthropology.

As described in the methodology for this study, the data is organized by category. Where several themes and 
topics are reflective of the data, a brief overview and outline is presented at the beginning of each category. Theme numbers (i.e., Theme \#1, Theme \#2) correspond to the respective intercultural communication themes. Topics listed in the outlines are preceeded by lower case letters which correspond to those used in the intercultural communication chapter. For an profile of all the themes and topics, the reader is referred to Table 1 in Chapter $V$.

\section{Overview}

In the early twentieth century, prevailing views in Europe and America about "culture" were dominated by the belief in the superiority of white, European and American cultures (Boas 1938, 5). Other races and cultural groups were generally perceived as insignificant, inferior, and morally deficient. The early twentieth century was still part of the era of massive European and American colonial exploitation which was facilitated (i.e., justified) by the devaluing of people culturally (and technologicaily) different. The ethnocentrism of the public fostered little interest in "lower" cultures.

The efforts and findings, therefore, of cultural anthropologists were met with either disinterest or vehement negativity. The general public either couldn't understand why people would bother to study "inferior," "heathen," "uncivilized" beings or, perceived such study as an inquiry into the bizarre curiosities of the world. 
The concept of ethnocentrism was the means by which anthropologists explained and challenged the prevailing basis of group identification, namely, blood heredity (Benedict 1934, 16), and its fundamental assumption that "race determines mental behavior and culture," a view which Boas, for example, saw as deriving from "strong, emotional values", not fact (Boas 1955, 39). "The recognition of the cultural basis of race prejudice is a desperate need in present Western civilization" (Benedict 1934, 11).

One of the prevailing views in early anthropology was that culture influences ("conditions") its group members (Boas 1940, 261). Though the degree to which this occurs was, and still is, debated, the early proponents of cultural relativism perceived the conditioning influence of culture to be profound.

This concept, however, created difficulties for anthropologists. If one is culture-bound, either completely, or to some degree, can one understand cultures different from one's own, and if so, to what degree? In addition, is there a means for increasing one's capacity to understand other cultures, and if so, what?

The implications of these questions extended to the description, explanation and evaluation of culture and cultural practices. Authors wrote about "objectivity," where one was free, to some degree, from one's cultural conditioning (Herskovits 1948, 78). They also addressed the 
concept of "contextualism," which reflected the assumption that the elements of culture were integrated (Benedict 1934, 46-7), and which provided a methodological means for understanding meaning within cultures.

In the context of these conceptual and methodological concerns, cultural relativism appears in the works of the early anthropologists who attempted to establish the validity of "culture[s]" in the face of an ethnocentric public, who addressed the challenges of defining culture, and who sought to clarify their dual roles as scientists of cultures, and also members of a culture.

The three anthropologists most frequently cited as having fostered and influenced the development of cultural relativism in early anthropology are Franz Boas, Ruth Benedict, and Melville Herskovits. The following is a brief description of their views on cultural relativism as expressed in their written works.

\section{FRANZ BOAS (1858-1942)}

The anthropologist, Franz Boas, is described as "...largely responsible for developing cultural relativism in American anthropology" (Hatch 1983, 38). Interestingly, neither the term "cultural relativism" nor any similar term appears in his works. Hence, no information is presented here which can be specifically claimed to be Boas' views on cultural relativism, per se. 
However, many of the themes of cultural relativism identified in this paper in the intercultural communication literature (summarized in the methodology section of Chapter I) are clearly present in Boas' writings. In the balance of this study, authors' views are organized according to themes, either the intercultural communication themes, or additional ones which were found in the literature reviewed. Because Boas does not identify any of his views as "relativism," the intercultural themes were used to bring into relief Boas' views which are concurrent. This was deemed relevant because one of the goals of this study is to identify concurrence, or lack thereof, between the intercultural literature and that of the founding authors of cultural relativism in anthropology.

\section{BOAS, VIEWS AND THE DEFINITIONAL THEMES}

\section{Overview}

In reviewing Boas' various works, three of the four intercultural communication definitional themes were found:

Theme \#1: Cultural Diversity

Theme\#3: Attitudes Toward Difference

Theme \#4: Contextualization

No reference was found to the second theme of "equal cultural validity." 
Presentation of the Data

Definitional There \#1: Diversity of cultures. Boas addresses this theme extensively. He concludes that there is, for example, no "one" absolute value system. An examination of the so-called "objective" field of science reveals that people think there are absolutes, but we deceive ourselves, he says, into thinking so:

Even in the domain of science the favorite method of approaching problems exerts a dominating influence over our minds. The passionate intensity with which these ideas are taken up, leading to a temporary submersion of all others and to a belief in their value as sufficient basis of inquiry, proves how easily the human mind is led to the belief in an absolute value of those ideas that are expressed in the surrounding culture (1962, 205).

Boas writes that, in fact, the social ideals of other cultures are, in fact,

...so different from our own that the valuations given by them to human behavior are not comparable. What is considered good by one is considered bad by another" $(1962,204)$.

In other words, social ideals and values vary regarding human behavior from culture to culture, and thus, the meanings of human behaviors differ.

Definitional Theme \#3: Attitudes Toward Difference. Boas states that the experiences of an individual "...are largely determined by the culture in which he lives" (1940, 250). He points out that culture conditions us, physically, mentally, linguistically and behaviorily, though, because we grow up within a culture, we tend to be unaware of our 
conditioning $(1940, v)$. Even our "...emotional reactions which we feel as natural are in reality culturally determined" $(1940,635)$.

Boas observes that all people are influenced and biased by their cultures. In research, this colors our understanding of other cultures. One must seek to become free from one's cultural valuations, and approach other cultures in the resulting "objective" state for the purpose of scientific accuracy:

It would be an error to assume that our own social habits do not enter into judgments of the mode of life and thought of alien people. A single phenomenon like our reaction to what we call 'good manners' illustrates how strongly we are influenced $b_{y}$ customary behavior. We are exceedingly sensitive to differences in manners...the valuation of our own manners tinges our description of the alien forms.

The scientific study of generalized social forms requires therefore, that the investigator free himself from all valuations based on our culture. An objective, strictly scientific inquiry can be made only if we succeed in entering into each culture on its own basis, if we elaborate the ideals of each people and include in our general objective study cultural values as found among different branches of mankind (1962, 204-5).

The powerful influence culture has in shaping a person's behavors and thoughts is demonstrated, Boas states, by the great difficulty people experience in suspending their culturally biased way of perceiving and evaluating phenomena (1962, 205-6). Indeed,

We are apt to follow the habitual activities of our fellows without a careful examination of the fundamental ideas from which their actions spring. Conformity in action has for its 
sequel conformity in thought. The emancipation from current thought is for most of us as difficult in science as it is in everyday life. The emancipation from our own culture, demanded of the anthropologist, is not easily attained..." (1962, 205-6).

According to Boas, the more a researcher is aware of cultural diversity, the more objectively a researcher can study culture $(1938,685)$. The degree of objectivity is contingent upon the degree of awareness of diversity. The attempt to suspend one's own cultural values in studying other cultures is necessary because the social ideals of other cultures are different from one's own.

Boas does not adrocate indefinite suspension of value judgment such that une would refrain from all evaluation. Indeed, the study of cultural miltiplicity facilitates the evaluation of our own culture as well as the formulation of generalizations about culture:

The objective study of types of culture that have developed on historically independent lines or that have grown to be fundamentally distinct enables the anthropologist to differentiate clearly between those phases of life that are valid for all mankind and others that are culturally determined. Supplied with this knowledge, he reaches a standpoint that enables him to view our own civilization critically, and to enter into a comparative study of values with a mind relatively uninfluenced by the emotions elicited by the automatically regulated behavior in which he participates as a member of our society.

The freedom of judgment thus obtained depends upon a clear recognition of what is organically and what [is] culturally determined. The inquiry into this problem is hampered at every step by our own subjection to cultural standards that are misconstrued as generally valid human standards. The end can be reached 
only by patient inquiry in which our own emotional valiations and attitudes are conscientiously held in the background. The psychological and social data valid for all mankind that are so obtained are basal for all culture and not subject to varying valuation.

The values of our social ideals will thus gain in clarity by a rigid, objective study of foreign cultures (1962, 207).

Evaluation of our own culture, therefore, according to Boas, is achieved only when one has developed an "open mind" through a studied awareness of the multiplicity of cultures, attaining as great a degree of objectivity as one can. Boas underscores that it is an extremely difficult task, requiring patience, time, and conscious effort.

This theme of "Attitudes Toward Difference" which Boas refers to as objectivity, is prescriptive, in contrast to the first Jefinitional thene which described cultural relativity as the fact of the multiplicity of cultural values. Here, one is informed of "how" to look at culture in terms of one's attitude.

Definitional Theme \#4: Contextualization. Boas advocates that the elements of a culture must be considered in terms of the cultural context:

...the various expressions of culture are closely interrelated and one cannot be altered without having an effect upon all the others. Culture is integrated $(1962,256)$.

We must study cultures as whole units to learn the meaning of behaviors, values, concepts, etc., because, while these cultural expressions may have the same outward appearance in different cultures, they may, in fact, assume very different 
meaning within different cultures: "...The way in which these characteristics manifest themselves depends upon the culture in which the individuals live" (1938, 133).

This definitional theme of cultural relativism is also prescriptive. It instructs us as to how culture should be understood, namely, contextually, because culture is an integrated entity.

However, understanding is not limited to just the examination of cultural elements within cultural boundaries. As previously noted, Boas, believed that "comparative appraisals" might be possible. He argues that the task of anthropologists is to gather "in context" ethnological data first, and only after this is achieved, might generalizations about cultures be made, for example, about possible cultural universals, as well as generalizations regarding which aspects of culture are organic in origin and which are humanly created (1962, 205).

\section{Summary}

Though the definitional themes highlighted here overlap somewhat, they remain distinctly different. The "Cultural Diversity" theme is descriptive. Boas writes, in particular, about cultural values, stating that multiple sets of values exist among cultures because multiple perceptual screens exist. It assumes the process of enculturation. 
The third theme of "Attitudes Toward Difference" is addressed by Boas in terms of objectivity, based on the assumption that the suspension of one's cultural values is possible through the acquired awareness of cultural diversity, to the extent that one is aware of that diversity. This theme is prescriptive, instructing us that to understand other cultures accurately, we must suspend our cuiturai-bound jlidgments.

The Eourth theme of "Contextualisin" is aiso prescriptive, but linlike the third theme, it does not focus on values. Instead, this theme instructs us that any item of culture we seek to understand must be considered within its respective cultural context. This theme is based on the assumption that culture is an integrated structure.

It is difficult to say which of these definitional themes, if any, Boas himself would have termed "cultural relativism," since all three of them are present in his writings.

\section{APPLICATIONS}

\section{Overview}

All three of the intercultural communication application themes were found in Boas' writing. The following topics were addressed within each theme:

Theme \#1: Causes of Cultural Relativism b. Informal Learning 
Theme \#2: Consequences of Cultural Relativism

$$
\begin{aligned}
& \text { c. In Research } \\
& \text { e. Judgment Formation }
\end{aligned}
$$

Theme \#3: Theoretical Dimensions

a. Monocultural vs. Multicultural

Perspective

\section{Presentation of the Data}

Application Theme \#1: Causes of Cultural Relativism.

In terms of the definitional theme of "Attitudes Toward Difference," as can be seen in the previous section, Boas addresses the causes of cultural relativism (application theme \#1). He describes how a person can become increasingly aware of his cultural conditioning, through the patient study of other cultures and the increasing of one's knowledge of cultural diversity. Boas calls this incremental awareness "objectivity," where "..our own emotional valuations and attitudes are conscientiously held in the background" (1962, 207).

\section{Application Theme \#2: Consequences of Cultural}

Relativism. Boas' discussion of both the definitional themes of "Attitudes Toward Difference" and "Contextualism" reveals that he also addressed the application theme \#2 of consequences. He refers to the consequences of each largely in terms of their importance for scientific research of cultural phenomena $(1962,204-5)$. The former involves the 
"open mind" necessary for research (1962, 207) and the latter enables the researcher to accurately determine the meaning of phenomena within culture $(1938,133)$.

Boas' discussion of the "Attitudes Toward Difference" theme also describes the benefits that the findings of anthropology provides generally: "The general theory of valuation of human activities, as developed by anthropological research, teaches us a higher tolerance than the one we now profess" (1955, 225).

Application Theme \#3: Theoretical Dimensions. Much of Boas' writing is focused on clarifying issues of the key questions, assumptions, concepts, theories, and methods of anthropology. He clearly sought to further the development of cultural anthropology as a scientific field of study. His treatment of the definitional themes are part of this clarification endeavor and as such, address application theme \#3 (Theoretical Dimensions) as well.

\section{ADVANTAGES}

\section{Overview}

Boas' support for the concepts represented by the definitional themes is unmistakable. Boas cites several advantages for these concepts. The advantage themes which embrace them are as follows: 
Theme \#1: Facilitation of Internal, Attitudinal Changes

a. Reduces Ethnocentrism

b. Reduces Discrimination

h. Increases Tolerance

i. Counters Western Superiority Notion

Theme \#2: Facilitation of Accurate, Cultural Knowledge and Understanding

a. Helps Understanding of Cultural Behaviors

b. Helps Insight into Diversity of Cultural Truths and Norms

Theme \#3 (Facilitation of External, Interactive Results) is not explicitly addressed in Boas' work.

Presentation of the Data

Advantage Theme \#1: Facilitation of Internal,

Attitudinal Changes. Four of the intercultural communication topics related to this theme were found in Boas' work. One of his books addresses the issues of ethnocentrism extensively, The Mind of Primitive Man, 1938), presenting ethnological data to challenge the assumptions of that position. He says, for example,

It appears that neither cultural achievement nor appearance is a safe basis on which to judge the mental aptitude of races. Added to this is the one-sided evaluation of our own racial type and of our modern civilization without any close inquiry into the mental processes of primitive races and cultures which may easily lead to erroneous conclusions (1938, $30-31)$. 
The topic of discrimination is central to Boas' goals. He develops his case for the validity of the diversity of people, and the lack of justification for judging people's merits on "race." He concludes:

our tendency to evaluate an individual according to the picture that we form of the class to which we assign him, although he may not feel any inner connection with that class, is a survival of primitive forms of thought $(1938,241)$.

Boas' support for the idea that awareness of diversity can lead to an increase of tolerance is evident from his statement that "the general theory of valuation of human activities, as developed by anthropological research, teaches us a higher tolerance than the one we now profess" (1938, 203). He discusses that the value we assign to our own civilization is because we participate in it, but that other traditions may be equally valuable. We have a difficult time realizing this because we have not grown up in those traditions (1938, 202-3).

Another advantage topic found in Boas' writing within this theme is how the awareness of the diversity of cultures counters the Western superiority notion. Evidence of this is pervasive in Boas ' works. The concluding statement of The Mind of Primitive Man demonstrates the degree to which Boas finds this superiority notion important to address:

Freedom of judgment can be attained only when we learn to estimate an individual according to his own ability and character.... Then we shall treasure and cultivate the variety of forms that human thought and activity has taken, and 
abhor, as leading to complete stagnation, all attempts to impress one pattern of thought upon whole nations or even upon the whole world $(1938,242)$.

\section{Advantage Theme \#2: Facilitation of Cultural}

Knowledge and Understanding. Through his focus on the importance of developing the greatest degree of objectivity possible, Boas addresses both topics found in this theme:

(a) facilitation of the understanding of cultural behaviors, and (b) facilitation of insight into diversity of cultural "truths" and "norms."

objectivity, he says, is necessary for carrying out scientific study $(1962,204-5)$. The awareness of the diversity of thought results in a realization that our "truth" is not an absolute truth $(1938,201)$. This frees us to recognize, and possibly appreciate the value in, the variety of thought and behavior of other cultures 11938, 203).

\section{DISADVANTAGES}

\section{Overview}

The intercultural communication disadvantage theme which refers to the difficulty of assuming cultural relativism is specifically addressed in Boas works. Presentation of the Data

Disadvantage Theme \#1: Difficulties of the Assumption of Cultural Relativism. Boas points out only one problem with any of the definitional concepts, namely, the 
difficulty of casting off one's cultural conditioning. He does not say it is impossible; indeed, bicultural and multicultural people existed during his lifetime, though the quantity of literature about them did not parallel that of today. But, he cautions that it is likely to be experienced to a degree, one which he leaves open to the capabilities of the individual seeking to become an "objective," unbiased student of culture(s).

Fox, in the Social Science Encyclopedia, writes that Boas elaborated the "theoretical basis of cultural relativism" and passed this on to his students, one of whom was Ruth Benedict $(1985,28)$. The following section examines her views.

\section{RUTH BENEDICT (1887-1948)}

The importance of Benedict's contribution to the development of cultural relativism, and that of Herskovits, addressed in the next section, is underscored by Hatch, who, in his anthropological study of cultural relativism states that "...the thesis of relativism enjoyed its fullest flowering in the work of Ruth Benedict and Melville Herskovits" (1983, 35).

Among her works, Benedict's views on cultural relativism are stated most specifically in her pioneering 
book, Patterns of Culture. In it, however, she makes only three references to cultural relativism.

\section{DEFINITION}

\section{Overview}

The intercultural communication definitional theme of "Cultural Diversity" is central to Benedict's writing on cultural relativism.

\section{Presentation of the Data}

Definitional Theme\#1: Cultural Diversity. In the introduction to patterns of Culture, Benedict indicates her definition of cultural relativism as the fact of diversity of cultures. She describes "traditional Anglo-Saxon intolerance" of other cultures, and says,

...we have failed to understand the relativity of cultural habits, and we remain debarred from much profit and enjoyment in our human relations with peoples of different standards, and untrustworthy in our dealings with them (1934, 11).

Benedict's second reference to relativism is a description of Wilhelm Dilthey's view regarding the "relativity" of philosophical systems evident in the history of thought. She indicates his view parallels her own view of cultural relativity. Again, she refers to cultural relativity as the idea that cultures are diverse, but she is more specific here, delineating more clearly the nature of "diversity." she says that diversity derives partly from 
the variety of integrated configurations of cultures, none of which is "final" (1934, 52):

The significance of cultural behaviour is not exhausted when we have clearly understood that it is local and manmade and hugely variable. It tends also to be integrated. A culture, like an individual, is a more or less consistent pattern of thought and action....

... The whole, as modern science is insisting in many fields, is not merely the sum of all its parts, but the result of a unique arrangement and interelation of the parts that has brought about a new entity (1934, 46-7).

Cultural relativity, to Benedict, therefore, is the existence of the humanly created, multiplicity of cultures which are diverse in their cultural expressions as well as in the overall cuitural patterns within which these expressions occur.

\section{APPLICATIONS}

\section{Overview}

Two of the three application themes were found in Benedict's work. Because Benedict defines cultural relativism as "cultural diversity," she does not focus on the causes of diversity, but rather, the consequences of this "fact" of multiplicity. She also addresses the importance of a multiplistic viewpoint for anthropological theory. The following themes and topics are discussed in this section: 
Theme \#2: Consequences of Cultural Relativism
a. In Communication
c. In Research
e. Pertaining to Judgment Formation

Theme \#3: Theoretical Dimensions

a. Monocultural vs Multicultural Perspective

\section{Presentation of the Data}

\section{Application Theme \#2: Consequences of Cultural}

Relativism. In Benedict's work, cultural relativism is used in terms of the second intercultural communication application theme: consequences of cultural relativism. Benedict uses cultural relativism in her discussions which describe its importance for improved human relations (communication) and a better understanding of cultures and cultural diversity. She says, for example, that because we fail to understand cultural relativism, we "...remain debarred from much profit and enjoyment in our human relations with people of different standards..." (1934, 11).

The understanding of cultural relativism, and the application of it in social sciences (such as research) is the basis on which we can form judgments on which to base social changes $(1934,278)$.

\section{Application Theme \#3: Theoretical Dimensions.}

Benedict states that anthropology, distinct from other social sciences, includes the study of societies other than 
our own. The anthropologist, therefore,

.... is bound to avoid any weighting of one in favour of the other. He is interested in human behaviour, not as it is shaped by one tradition, our own, but as it has been shaped by any tradition whatsoever. He is interested in the great gamut of custom that is found in various cultures, and his object is to understand the way in which these cultures change and differentiate, the different forms through which they express themselves, and the manner in which the customs of any peoples function in the lives of the individuals who compose them (1934, 1-2).

Benedict's entire book, patterns of Culture, explains how "the relativity of cultural habits" facilitates anthropological theory because of its multiplistic perspective. In particular, she emphasizes the ethnocentric bias that can occur, and the importance of being aware of this bias when considering diverse cuitures.

\section{ADVANTAGES}

\section{Overview}

Concurrence with all of the advantage themes can be found in Benedict's writing, though she does not extensively address theme \#3 (Facilitation of External, Interactive Results). The themes and topics which reflect her views are as follows:

Theme \#1: Facilitation of Improved, Attitudinal

Changes
a. Reduces Ethnocentrism
b. Reduces Discrimination 
d. Increases Enjoyment of Difference

h. Increases Tolerance

i. Counters Western Superiority Notion

Theme \#2: Facilitation of CuItural knowledge and Understanding

a. Helps Understanding of Cultural Behaviors

b. Heips Insight into Diversity of Cultural Trutins and iNorus

Theme \#3: Facilitation of External, Interactive Results

a. Facilitates Intercuitural Functioning

\section{Presentation of the Data}

Advantage Theme \#1: Facilitation of Internal,

Attitudinal Changes. Five of the intercultural

communication topics which occurred within this theme were found in Benedict's writing. In her final reference to cultural relativism in Patterns of Culture, Benedict emphasizes the importance of the recognition and appreciation of cultural diversity as a key to dissolving the fetters of ethnocentrism and achieving increased international understanding and cooperation. It "... would do much to promote a rational social order" (Benedict 1934, 10).

Benedict, however, does not require, in her advocacy of the recognition of cultural relativism, the dissolution of one's judgment regarding culture. She, instead, points 
out the need for refocusing judgment. People must shift

from the prison of ethnocentric judgment, which yields blind biases such as race prejudice based on the ignorance or fear of cultural differences (1934, 9-10) and form judgment based on the awareness of cultural diversity. To avoid discrimination, we need to, therefore,

...become increasingly culture-conscious. We may train ourselves to pass judgment upon the dominant traits of our own civilization. It is difficult enough for anyone brought up under their power to recognize them. It is still more difficult to discount, upon necessity, our predilection for them... The possibility of orderiy progress is shut off because the generation in question could not make any appraisal of its overgrown institutions. It couid not cast them up in terms of profit and loss because it had lost its power to look at them objectiveiy (1934, 249).

In other words, the loss of objectivity means the loss of the ability to step outside of one's own culture and seeing one's own cultural expressions as among many possibilities. Instead, the subjective view of seeing one's culture as the only right way prevails. One remains ignorant and fearful and thus, very likely to have a negative attitude toward cultural difference. Were we to understand cultural relativity, we would both profit from and enjoy cultural difference $(1934,11)$.

Throughout her book, Benedict discusses how an awareness of cultural diversity helps to counter the notion of Western superiority $(1934,7-8)$. In our Western civilization, Benedict says, the degree to which we can free 
ourselves from ethnocentrism and see creative options to the status quo is the degree to which, in turn, we become able to objectively evaluate our own culture $(1934,250)$. This is the basis for making "real improvements in the social order," and the problem of doing so. "... is the most pressing this generation has to face..." (1934, 249).

Benedict concludes her book saying the overall results of all this is an increase in tolerance and new bases of tolerance $(1934,278)$.

\section{Advantage Theme \#2: Facilitation of Accurate,}

Cultural Knowledge and understanding. À sciond advantage of cultural relativism is improved cultural understanding which is achieved when cultures are recognized as varying, integrated patterns. This inciudes the understanding of the whole pattern of a culture which involves perception, beliefs about "truth," and behaviors. The insights afforded by relativism are important for both the anthropologist in research, and for those engaged in fostering social change. The job of the anthropologist is to objectively gather information about cultures (1934, 1-2), having achieved "...that degree of sophistication where we no longer set our own belief over against our neighbour's superstition." (1934, 4) The anthropologist recognizes that cultures are humanly created and, therefore, necessarily diverse. Additionally, the anthropologist understands that the 
diversity of cultural expressions requires one to seek their meaning from within the complex of the cuiture:

If we are interested in cultural processes, the only way in which we can know the significance of the selected detail of behaviour is against the background of the motives and emotions and values that are institutionalized in that culture (1934, 49).

However, in gaining cultural understanding, we can never experience another culture as fully as one who has been brought up in that culture, but increased awareness of cultural diversity affords increased wisdom and tolerance, and an awareness that, just as we perceive our own culture to be significant, so the members of other cultures perceive their cultures to be significant also $(1934,37)$. Social change in a "more sane" direction requires that

We need intimate understanding of their experiences, so that we shall learn to discriminate between what is truly sociaily dangerous and what is only another method of arriving at a socially desirable goal. The kinds of strength which the people of each area could use in a world organized for peace can only be those to which they have been bred. If we insist that they imitate another kind of strength, they will be powerless to contribute. If we, the people of the world, are ever to achieve a world organization which promises mutual benefits, we must be scientifically prepared to know the strength which different nations of the world can utilize to this end $(1946,164)$.

The recognition of the diversity of cultures, with their varying integrated patterns, facilitates the cultural understanding on which to base such social changes.

Research based on accurate cultural understanding will 
enable us to recognize the variety of cultural strengths with which the peoples of the world have to work.

\section{Advantage Theme \#3: Facilitation of External,}

Interactive Results. Benedict refers to improvements in social relations which result from cultural relativism, implying interactive results, but does not describing them, per se:

Social thinking at the present time has no more important task before it than that of taking adequate account of cultural relativity. In the fields of both sociology and psychology the implications are fundamental, and modern thought about contacts of peoples and about our changing standards is greatly in need of sane and scientific direction... We shall arrive then at amore realistic social faith, accepting as grounds of hope and as new bases for tolerance the coexisting and equally valid patterns of life which mankind has created for itself from the raw materials of existence (1934, 278).

\section{DISADVANTAGES}

\section{Overview}

Benedict mentions two disadvantages regarding cultural relativism. One, the difficulty of assuming cultural relativism, is embraced by one of the intercultural communication themes. The second, which refers to the phenomenon of "reverse ethnocentrism," falls outside the intercultural communication themes, and is, therefore, designated as an "additional disadvantage." 
Fresentation of the Data

Disadvantage Theme \#1: Difficulties of issumption of

Cultural Relativism. Benedict explains that people fail to realize that

The great diversity of social solutions that man has worked out in different cultures... are all equally possible on the basis of his original endowment" $(1934,14)$.

She explains that it is difficult to understand cultural relativity ("the relativity of cultural habits") because the process of cuitural conditioning tends to make people ethnocentric $\{1934,5-6)$. People perceive their own cultures as the standard, and the norm, for ail cuitures because either they devalue other cultures, or they are ignorant of the existence of cultural alternatives.

Benedict defines culture as the ideas and standards that members of a culture have in common (1938, 16). She states emphaticaliy that the failure to be culturally relative must be overcome. While it is evident that Benedict believes that ethnocentrism and its potential negative impact on other cultures can occur anywhere (1934, 11), she focuses her appeal on contemporary western societies, saying they need to become aware of the diversity of cultural forms to become more appreciative of and tolerant of other cultures $(1938,16)$.

Additional Disadvantage: Reverse Ethnocentrism. It is interesting that Benedict makes a point of saying that appreciation of difference does not mean "a romantic return 
to the primitive" $(1938,20)$. She says that one or another culture may appeal to people amidst an "era of heterogeneous standards and confused mechanical bustle" (1938, 20). However,

...it is not in a return to ideals preserved for us by primitive peoples that our society will heal itself of its maladies. The romantic Utopianism that reaches out toward the simpler primitive, attractive as it sometimes may be, is as often, in ethnological study, a hindrance as a halp $(1333,20)$.

MELVILLE HERSKOVITS (1895-1963)

In his book, The Development of Anthropological Ideas, Honigmann states that among the anthropologists who defended cultural relativity, none did so more "vehemently" than Melville Herskovits (1976, 260-61).

\section{DEFINITION}

\section{Overview}

Herskovits' definition of cultural relativism was not encompassed by the intercultural communication themes. Therefore, it is referred to here as a "definition" to indicate that it fell outside the thematic framework.

\section{Presentation of the Data}

Additional Definition: Subjectivism. Herskovits refers to his definition of cultural relativism as follows:

The principle of cultural relativism derives from a vast array of factual data, gained from the application of techniques in field study 
that have permitted us to penetrate the underlying value-systems of societies having diverse customs. This principle, briefly stated, is as follows: Judgments are based on experience, and experience is interpreted by each individual in terms of his own enculturation $(1948,63)$.

Herskovits' definition constitutes a new definition-subjectivism. Its distinction from Themes \#1 and 2 are obvious. It differs from Theme \#3 because Herskovits is referring to all inner experiences--perception, cognition, and evaiuation $(1958,267)$, not just conscious attitudes toward difference. Herskovits definition also differs from Theme \#4. While it does have a contextual element in it, in contrast to "contextualism," where a person consciously sees aspects of culture in terms of the respective cuitural context, it refers to the influence of cuitural context upon people and their perceptions.

Herskovits explains that "cultural relativism" has a "sure, psychological foundation," identified by Sheriff as the concept of "frame of reference" (1948, 65). This is the psychological basis of social norms, internalized by individuals during enculturation, and comprising the measure against which an individual perceives reality (whether something is, for example, "normal" or "abnormal," "right" or "wrong") (1948, 66):

Even the facts of the physical world are discerned through the enculturative screen, so that the perception of time, distance, weight, size, and other "realities" is mediated by the conventions of any given group $(1948,64)$. 
Thus, though a physical reality exists, cultural relativism is the "fact" that judgments of reality are reiative to the cultural "frame of reference." Necessarily, what may be "normal" or "good" in one culture, may be "abnormal," or "bad" in another $(1948,66)$. Because cultural frames of reference are the product of contacts between individuals (1948, 66), they have no ultimate origin other than the interaction of the individuals. They are all historical and human developments $(1948,64)$. Further, they can change: "...The summation of behavior we call culture is flexible, not rigid, and holds many possibilities of choice within its larger framework" (1948, 64). The lack of an absolute set of values against which all others are measured is a basic assumption of cultural relativism.

Herskovits makes a point of stating that to understand cultural relativism, one alust differentiate between absolutes and universals $(1948,76)$. Although there nay be no absolutes, universais, inductively deduced, can be identified. For example, though there is no one absolute set of standards, the existence of standards can be found in every society. Morality is, thus, an example of a "universal" (1948, 76). 


\section{APPIICATIONS}

\section{Overview}

Herskovits states three basic applications of relativism: methodological, philosophical, and practical (1951, 24). He does not address how one becomes relativistic (Theme\#1). His views are encompassed by the following :

Theme \#2: Consequences of Cultural Relativism

c. In Research

e. Pertaining to Judgment Formation

Theme \#3: Theoretical Eimensions

a. Monocuitural vs iuiticuiturai Ferspective

Presentation of the Data

Application Theme \#2: Consequences of cultural

Relativism. Herskovits' discussions pertain primarily to research, and the implications of judament formation in research. When cultural relativism is lised as a method of inquiry, one strives to achieve, he says,

...as great a degree of objectivity as possible...one does not judge the modes of behavior one is describing, or seek to change them. Rather, one seeks to understand the sanctions of behavior in terms of the established relationships within the culture itself, and refrains from making interpretations that arise from a preconceived frame of reference $(1951,24)$.

In other words, one is able to do research as free of bias as possible. A researcher, in recognizing his or her own 
subjectivism, is sensitive to possible value judgments and thus seeks to exercise objectivity, "a primary requirement of our scientific endeavors" (1951, 25).

There are also impications of relativism which extend to how research findings are to be considered, namely, "within the frame of reference set by the culture we are studying...analyzed in terms of its relevance to the total structure of cultural form..." (1951, 26).

Herskovits suggests that a third implication of the fact of relativism (subjectivism) is the recognition of cultural diversity $(1951,30)$.

Cultural relativism in "practice" (in contrast to "research") is the application of the philosophical principles of relativism "derived from the method, to the wider, cross-cultural world scene" (1951, 24). Cultural relativism, "on the level of application, stresses the importance of allowing, rather than imposing acceptances of cultural elements newly experienced" (1951, 30).

\section{Application Theme\#3: Theoretical Implications. In}

his reference to philosophical applications, Herskovits highlights the theoretical dimensions cultural relativism can address. It (relativism) "...concerns the nature of cultural values, and, beyond this, the implication of an epistemology that derives from a recognition of the force of enculturative condition in shaping thought and behavior" (Herskovits 1951, 24). Herskovits strongly indicates that 
anthropologists have to squarely face questions such as "Whose standards?" (1958, 270) and "Whose objective reality?" (1958, 271) when they are involved in researching other cultures.

It is clear from his works that Herskovits saw relativism as challenging and guiding the assumptive foundation of anthropology, generating a specific set of questions and infiuencing the riethodology with which they can be addressed, particularily, in terms of the study of cultural values $(1951,24)$.

...an important factor in its [cultural
relativism's] development is the increasingly
felt need to expand the base of formal
philosophical thought so as to include the
entire range of human cuiture, rather than to
continue its focus on the Graeco-Roman
tradition which, from the point of view of the
total cultural inventory of mankind, has
limited its resources and its findings (1958,
266).

\section{ADVANTAGES}

\section{Overview}

Herskovits addresses, primarily, Themes \#1 and \#2 from the intercultural literature. As can be seen from the following outline, fewer of the intercultural communication topics are addressed in Herskovits' work than in the work of either Boas or Benedict, the omissions being those topics which refer to interpersonal interactions. This seems to reflect the distinction Herskovits makes between the anthropologist involved in the intellectual process of 
research, and the anthropologist in the role of citizen, interacting in society. Herskovits' views are organized as follows :

Theme \#1: Facilitation of Internal, Attitudinal Changes
a. Reduces Ethnocentrism
h. Increases Tolerance
i. Counters Western Superiority Notion

Theme 2: Facilitation of Cultural Rnowledge and Understanding
a. Helps Understanding of Cultural Behaviors
b. Helps Insight into Diversity of Cultural Truths and Norms

\section{Presentation of the Data}

\section{Advantage Theme \#1: Facilitation of Internal,}

Attitudinal Changes. Herskovits states that one of the advantages of cuitural relativism is that it brings into focus the "...validity of every set of norms for the people whose lives are guided by them, and the values these represent" (1948, 76). The recognition and affirmation of multiplicity encourages understanding and tolerance between people of different cultures, in contrast to the judgmentalism and destruction which expectations of conformity to one's own code can foster $(1948,77)$. 
Herskovits makes clear, however, that tolerance as applied to research is somewhat different than tolerance in social contexts:

The answer to the problem raised by practical relativism remains one which cannot be resolved on the philosophical level. It must be repeated, there is no living in terms of unilateral tolerance, and when there is the appeal to power, one cannot but translate enculturated belief into action (1958, 271).

A second benefit of relativism is that, through the awareness of the variety and significance of the diversity of cultures, cultural relativism helps us to lift ourselves "..out of the ethnocentric morass in which our thinking about ultimate values has for so long bogged down" (1948, 78). In so doing, it affords us a Eresh perspective on our own culture. We attain a differert kind of objectivity $(1948,78)$.

Herskovits differentiates between two kinds of ethnocentrism. The first is that of people from cultures which "...have a gentle insistence of the good qualities of one's own group, without any drive to extend this attitude into the field of action" (1948, 69). This form of ethnocentrism facilitates "individual integration and social adjustment" through exclusive identification with one's group.

This contrasts with the ethnocentrism of EuroAmericans, for example, where the tradition is to devalue or negatively evaluate cultural expressions which are different 
from the home cuiture, and to expect that they must be changed to match those of the home culture $(1348,69)$. The notion of "progress," its application in Euro-American tradition for dividing cultures into "inferior" and "superior," and the subsequent drive to change others to be like Euro-americans, is part of the problem of Euro-American ethnocentrism:

What we too often fail to recognize is that superiority of this demonstrable kind will not necessarily convince a person from another culture that an art foreign to his own is also preferable, or that monotheism is better than poiytheism....Acceptance of European beliefs and values, coupled with the withholding of opportunity to achieve an equitable way of life under them - the most common form, over the world, of the contradictory situation that ensues on the imposition of Euroamerican controis - induces bewilderment, despair, and cyncism $(1948,69)$.

Ethnocentrism, such as that of the Euro-American tradition, rationalized and made the basis of programs of action detrimental to the well-being of other peoples, gives rise to serious problems $(1948,68)$.

It is clear that Herskovits perceived cultural relativism as a concept rooted in Euro-American tradition addressing the Euro-Aamerican problem of ethnocentric zeal. He pointed out that both the dualism inherent in the concept (absolute/no absolutes) and the scientific methods upon which the concept is based, derive from Euro-American culture $(1948,76-77)$. However, he states that cultural 
relativism offers new conceptual direction:

In a culture where absolute values are
stressed, the relativism of a world that
encompasses many ways of living will be
difficult to comprehend $(1948,78)$.

Supported by ethnographic data, relativism shifts the focus from the idea of the singular authority of any one culture to the multiplicity of humanly created significance assigned by cultural members to their respective cultures.

Additionally, because cultures are not closed systems, even within the entity of a "culture," values may vary just as, in the lives of succeeding generations, values and behaviors can change $(1948,64)$. Cultural relativism points out this variability, and at the same time, fosters insight into the commonalities of the human experience:

Cultural relativism which stresses the universals in human experience as against ethnocentric concepts of absolute values, in no wise gives over the restraints that every system of ethics exercises over those who live in accordance with it. To recognize that right, and justice, and beauty may have as many manifestations as there are cultures is to express tolerance, not nihilism. As anthropology's greatest contribution, this position puts man yet another step on his quest of what he ought to be, in the light of the facts, as we know them, about what in his unity, no less than in his diversity, he is (1948, 655).

\section{Advantage Theme \#2: Facilitation of Accurate,}

Cultural knowledge and Understanding. Cultural relativism, applied as a method, is a means for understanding and describing behavior: "... one seeks to understand the sanctions of behavior in terms of the established 
relationships within the culture itself, and refrains from making interpretations that arise from a preconceived frame of reference" $(1958,24)$. This is applicable in the study of cultures where"...one seeks to attain as great a degree of objectivity as possible" (1972, 32).

Relativism, thus, affords the benefits of contextualism, which is essential for the accurate understanding of cultural difference $(1948,65)$. This difference extends to the perceptions of people, and their interpretations of reality $(1958,267)$. Herskovits specifies that the relativistic student of eulture does not seek to judge or change, only to observe and understand (Herskovits 1951, 24).

A second methodological benefit is the self-reflexive ability which the relativistic researcher can exercise. The scientist is aware of the influence of culture upon judgment, and thus can take note of both the conditions influencing that which he is studying, and the cuitural conditions influencing himself $(1948,76)$.

It is noteworthy that Herskovits, like Boas (1962, 207) and Benedict $(1934,250)$, refers to this ability of "objectivity" as quantitative, such that one can have greater or lesser degrees of it. He implies one is less, or more, objective depending on the extent to which one refrains from making interpretations based on one's frame of 
reference, and, in turn, succeeds in making interpretations based on a new frame of reference.

\section{DISADVANTAGES}

\section{Overview}

The disadvantage Herskovits cites is not encompassed by the intercultural communication themes. Hence, it is not referred to here as a "theme" but rather, as a "disadvantage."

\section{Presentation of the Data}

\section{Additional Disadvantage \#1: The IIIogical Logic of} Cultural Relativism. Herskovits draws attention to the different uses of cultural relativism and warns that, when distinctions are not drawn between the methodological, philosophical, and practical aspects of cultural relativism, confusion can result. His concern is that there will be a confusion of logic between levels. He identifies as an example of this confusion those "instances of the rejection of relativism on philosophical grounds, by writers who attempt to reconcile the principle of absolute values with the diversity of known systems" (1972, 34, footnote). Herskovits, thus, perceives that, depending on its use, the implications of cultural relativism, defined by him as the culture-boundness of judgment, change.

Another example of the problem of shifting levels involves the findings of science versus the applications of 
the findings. This problem of "scientist as citizen"" Herskovits seems to readily admit, is a dilemma "not only being faced by anthropologists, but by all scientists and, indeed, by scholars in the humanities as well" $(1958,30)$. This problem cannot be resolved on the philosophical level, however. The scientist exercises judgmental restraint, but as a citizen, "there is no living in terms of unilateral tolerance...one cannot but translate enculturated belief into action" $(1958,30)$.

\section{CHAPTER SUMMARY}

It is clear that Boas, Benedict, and Herskovits concur extensively on their anthropological assumptions regarding cultural relativism. Boas' work is so comprehensive that it encompasses a multitude of views regarding cultural relativism including: the multiplicity of cultural values, the problem of objectivity, and the understanding of cultures. Because Boas did not specifically use the term "cultural relativism, his own definition, if he had one, remains unknown.

Benedict's definition of cultural relativism focuses on the "fact" of the existence of cultural multiplicity. Her application of the concept is to counter ethnocentrism and create tolerance of cultural differences.

Herskovits' definition is much more narrow, focusing on the culture-boundness of judgment formation. He bases 
his definition on the multiplicity of cultures, which he treats as an assumption, unlike Benedict who employs the idea of the cultural diversity as her very definition. Both Benedict's and Herskovits' definitions are descriptive, but their applications are prescriptive.

It is interesting to observe that all three of these anthropologists were dedicated to alleviating what they perceived as the negative evaluation of cultural differences and its resulting abuses. All three sought to bring to the fore a recognition of what they saw as the universal dignity of humanity. Herein lies what they perceived to be the overall advantage to cultural relativisin.

The early anthropologists refer to three different disadvantages of cultural relativism. Both Boas and Benedict discuss the difficulties of assuming cultural relativism. Benedict aiso points out that problems can occur for those anthropologists who experience reverse ethnocentrism. Herskovits briefly mentions the problems that can occur if the different uses of cultural relativism are not kept logically distinct.

In the next chapter, the definitions, applications, advantages and disadvantages of cultural relativism will be examined in the current literature of intercultural communication. 


\section{CULTURAL RELATIVISM}

\section{IN THE INTERCULTURAL COMMUNICATION LITERATURE}

The data obtained to providing information about cultural relativism in the intercultural communication literature were the result of an extensive literature search. 148 books, journal articles and papers were ultimately selected as the most likely works to contain reference to cultural relativism. From these 148, 44 works were selected to comprise the body of intercultural communication literature upon which this study is based. For brevity's sake, where these forty-four works are referred to as a whole, the phrase "ICC references" will be used.

The criterion for selecting the forty-four works was quite straightforward. Any intercultural communication work containing the term "cultural relativism," or some close variation thereof, was included. The purpose of this criterion was to screen for those works in which cultural relativism is specifically signified as such by the authors.

This restriction was seen as important because many of the works in the intercultural literature do not contain the term "cultural relativism," but they do include concepts 
which might be termed "cultural relativism." Because of the absence of a concept label (i.e., "cultural relativism") in these works, there was no way of knowing if these authors would themselves view these various concepts in their writing as "cultural relativism."

Once the body of ICC literature was established, it was subsequently examined for the four categories of data delineated previousiy in the section on method:

1. authors' definitions of cultural relativism

2. authors' applications of cultural relativism li.e. using cultural relativism in a discussion about methods for improving communication skills or how cultural relativism can be developed through training)

3. advantages of cultural relativism presented by the authors

4. disadvantages of cultural relativism presented by the authors

\section{DEFINITIONS}

\section{Overview}

The definitions of cultural relativism found in the sample consist of those stated explicitly by the authors or, ones which are clearly implied by the surrounding text. of the $\mathbf{4 4}$ works containing the term "cultural relativism" (or related term), only 13 works (30\%) actually contain 
definitions of cultural relativism 18 stated, 5 clearly implied).

A description of the range of definitions found is presented in the following paragraphs. Variations within each group which emerged are identified. The distribution of definitions within the themes was found to be as follows:

Theme \#1: Cultural Diversity (3 works)

Theme \#2: Cultural Validity (2 works)

Theme \#3: Attitudes Toward Difference (4 works)

Theme \#4: Contextualism (4 works)

\section{Presentation of the Data}

Definitional Theme \#1: Cultural Diversity. Gudykunst and Kim explicitly state that cultural relativism is "the fact of cultural diversity" (1984, 203). Two other works clearly imply this definition. Pedersen refers to cultural diversity when he describes the "relativist framework" in which cultures are differentiated from one another by divergent attitudes, values and assumptions..." (1974, 55). Howell emphasizes the "fact" of diversity when he says, in his definition, that

..everything we live by is relative. Somewhere on Spaceship Earth is a culture which finds our treasured values to be unwholesome and gives high priority to goals and practices we reject $(1977,8)$.

Definitional Theme \#2: Equal cultural Validity. Two of the definitions in the ICC literature explicitly address 
this theme. Bochner defines cultural relativism as

...the doctrine that all practices are valid if they are sanctioned by the indigenous norms and traditions of their society $(1981,14)$.

In a similar vein, Tai, who presents her definition three times, says cultural relativism is the view that other cultures are just as valid as our own $(1986,28)$, that it means "...no one culture is better or worse than any other..." (1986, 88), and also that "...all cultures are equally valuable..." (1986, 88).

The obvious commonality between these definitions is the reference to the universal, equal vaiidity of all cultures. Bochner, however, confines his definition to the validity of cultural practices, whereas Tai refers to whole cultures. Further, Bochner states the validity of said practices derives from the societies to which they belong. Tai states no source of validity, though she implies that it is an inherent characteristic of culture.

Definitional Theme \#3: Attitudes Toward Difference. Four of the definitions in the sample correlated with this definitional theme. Stewart, Danielson and Foster explicitly define cultural relativism as: "...a perspective which recognizes that differing sets of values and assumptions exist..." (1979, 44).

M. Bennett, using the term "ethnorelativism", says this means "different cultures are perceived as variable and viable constructions of reality" $(1986,64)$. 
He uses the term "ethnorelativism" to clearly express cultural relativism as the opposite of ethnocentrism (1936, 46). He defines ethnocentrism as: "...'assuming that the world-view of one's own culture is central to all reality'" (1986, 33). Further, ethnocentrism, in contrast to ethnorelativism, involves experiencing cultural difference as "threatening" (1986, 46).

Ethnorelativism, as the opposite to ethnocentrism, is the "assuming" that "reality" varies with culture or, to put it another way, that one is aware of, and accepts, the existence of different cultural realities. It involves "...stages of greater recognition and acceptance of difference..." (1986, 27). Furthermore, these perceived differences, unlike in the various ethnocentric stages, are experienced as "non-threatening" (1986, 46).

In two works, implied definitions were found. Wendt refers to cultural relativism as the understanding, respect and tolerance of other cultures $(1982,583)$. Mayer refers to cultural relativism as a perceptual process where a person is "ready to accept the potentiality of numerous frames of reference.... and is able to vouch for the workability of each frame of reference" (1980, 34).

Definitional Theme \#4: Contextualization. Four of the works in the sample addressed this theme. Three explicit definitions were found. Sitaram and Haapanen 
present the following definition:

... cultural relativism... the study of the values of others within the framework of that culture rather than in comparison with our own values $(1979,150)$.

Sitaram and Cogell define cultural relativism similarly, referring to it as a "method" of studying values 11976 , 177) .

Samovar and Porter also define cultural relativism in terms of contextualization, but, instead of values, they refer to concepts of right and wrong, valued in a particular culture as "truth." These "...should be meaningful to us only in the relative sense of what is accepted or believed within a given context" (1976, 12).

Tzeng doesn't give an explicit definition of cultural relativism. However, in his discussion of relativism, he says that "judgment (or adaptation) of a given (absolute) conception" of a culture must be made within the context of that culture rather than in comparison to one's own culture $(1983,245)$.

The commonality of these four definitions is that concepts and/or values are identified as needing to be understood or made meaningful only in relation to their respective cultural contexts. 


\section{APPLICATIONS}

\section{Overview}

Authors of works in the intercultural communication Iiterature sample use cultural relativism in their discussions in many different ways. The thematic range of applications, and the topical variations within each thematic group, are noted as follows:

Theme \#1: Causes of Cultural Relativism (15 works)

a. Cultural relativism resulting from a formal learning context (9 works)

b. Cultural relativism resulting from an informal learning context ( 6 works)

Theme \#2: Consequences of Cultural Relativism (23 works)

a. Applications pertaining to the communication process (13 works)

b. In Professions Involving Face-to-Face Interactions ( 5 works)

c. In Research (2 works)

d. Pertaining to Culture Shock ( 1 work)

e. Pertaining to Judgment Formation (1work)

Theme \#3: Theoretical Dimensions ( 6 works)

a. Monocultural vs Multicultural speech Perspective (2 works) 
b. Human Rights and Intercultural Theory

(1 work)

c. Viability of Cultural Relativism ( 3 works)

Presentation of the Data

Application Theme \#1: Causes of Cultural Relativism.

The fifteen works encompassed by this theme divide into two topics--formal learning and informal learning.

A. Formal Learning

Nine works utilize cultural relativism in discussions pertaining to formal learning. Four variations within this group were identified: measuring relativism, teaching/training outcomes, training models, and ethical questions.

1. One author refers to measuring relativism. Tzeng, in his discussion of intercultural training, describes how the use of a certain data collection format ("Atlas") "...may pose as an objective criterion for assessing the trainee's progress in developing cultural relativism on various issues" (1983, 244-5).

2. Five authors refer to cultural relativism as a teaching/training outcome. Furnham and Bochner state that in training:

The aim is to compare and contrast two cultures, look at various behaviours from the perspective of each society, and thus develop a sensitivity to and awareness of cultural relativity, leading to the view that very few human values, beliefs and behaviours are absolute and universal and that what a 
particular individual believes to be true and good will depend on the norms prevailing in that person's society, norms that other societies may reject $(1986,237)$.

J. Bennett discusses training outcomes which educators generally anticipate will result from self-awareness training, one of which is cultural relativism (1985, 164).

Mayer uses cultural relativism (termed "ethnorelativism") in contrast to ethnocentrism to provide further insight into ethnocentrism. He says that ethnorelativism can be taught, and tested for $(1980,35)$.

Howell presents cultural relativism in the context of exploring whether or not intercuitural communication can be taught in the classroom. Relativism, he emphasizes, is a key insight resulting from the study of intercuitural communication $(1977,8)$.

Harris and Moran, in discussing managers with crosscultural sensitivity, explain that cross-cultural experiences and formal cultural study can result in cultural understanding, which makes us aware that behavior and culture are relative $(1979,202-3)$.

3. Two authors describe training models for developing cultural relativism. M. Bennett uses cultural relativism ("ethnorelativism") in the context of a theoretical model which depicts an "ethnocentrismethnorelativism" continuum, useful for training, to "...guide the sequencing of concepts and techniques to match 
some typical progression of development in students" (1986, 28).

Stewart, Danielson and Foster discuss the "American/Contrast American" simulation model for intercultural communication training and the importance of depicting American culture accurately in the model. This is because developing cultural self-awareness (i.e. awareness of one's own cultural assumptions and values) is the basis for developing the perspective of cultural relativism (1979, 44).

4. One work by Paige and Martin focuses on ethical guestions associated with the development of cultural relativism in training/teaching contexts:

It is our view, therefore, that it is not the normal condition of human beings to be culturally relativistic, appreciative of contradictory belief and behavioral systems, or nonjudgmental when confronted with alternate cultures....The ethical issue at question becomes the degree to which the trainer is aware of the expectations for personal change inherent in cross-cultural training programs and is prepared to assist the learner who begins to suffer stress and anxiety as a result of training. We are not arguing against training directed at promoting personal change... (1983, 44).

They discuss the ethical issue of trainer responsibility toward trainees, and say this is critical because training can be "...potentially threatening, even damaging..." because it challenges one's own cultural ways $(1983,44)$. 


\section{b. Informal Learning}

six works describe cultural relativism as resulting from unstructured or informal culture-learning. Three variations occur within this group: exposure to teaching methods and content of intercultural communication, exposure to other cultures, and mediation.

1. Asuncion-Landé indicates cultural relativism is an indirect result of exposure to the methods and content of intercultural communication teaching and research. She says this as important implications for bilingual and bicultural education:

The content and methods employed in research and in teaching intercultural communication make one aware of the relativity of one's own group's standard $(1975,66)$.

2. Three works discuss how cultural relativism may result from a person's exposure to another culture.

Barnlund and Nomura, in discussing cultural adjustment within a new culture, point out that cultural relativism may result from conceptual learning about a culture, but this may not always occur because cultural relativity is not easily acquired. Experiential learning in addition to intellectual learning may be needed as well (1985, 360-361).

Brislin, in describing the effects of sojourns, says one of the effects is "an understanding of cultural relativity" (1981, 104).

Adler, in discussing mediators, says that cultures are a source of renewing a relativistic perspective for 
mediators. He explains that a "multicultural person" needs to "...rely heavily on cultures to maintain his own relativity" (1974, 370).

3. Two authors say relativism results, or should, from mediation. McLeod emphasizes that

...mediating activities should result in some kind of benefit for the two cultures between which he is mediating. The success of the mediating person must be measured in terms of his effect on the people of the two or more cultures with which he is Eamiliar... (1981, $50)$.

She says one of the effects of mediation should be the acquisition of a relativistic outlook by the people involved in the mediating.

Bochner, in his discussion of mediation, discusses how the "disengaged" (versus the "engaged") mediator helps others form culturally relativistic attitudes (1981a, 306). Application Theme \#2: Consequences of Cultural

Relativism. Authors addressed cultural relativism as it pertained to consequences in five areas: (1) in communication, (2) in professional work, (3) in research, (4) pertaining to culture shock, and (5) pertaining to judgment formation. The references to cultural relativism in twenty-one works are encompassed by this theme (48\% of the ICC Iiterature). 


\section{a. Consequences in communication}

Fourteen works employ cultural relativism in discussions of how it affects and facilitates the intercultural communication process in various ways.

1. Szalay presents cultural relativism as the key process factor which distinguishes intercultural from domestic communication. It involves a bridging of differences through cultural self-awareness, a knowledge of the other culture, and adaptation to the other's cultural frame of reference. This facilitates effective communication (1974, 2).

2. Gudykunst discusses how predictions are part of the communicative behavior. He says the accuracy of such predictions about the other communicator are influenced by how we draw distinctions, "i.e., are they made ethnocentrically or from a 'cultural relativist' position?" (1977, 25). Gudykunst says that cultural relativism increases prediction accuracy and thus, facilitates intercultural communication interactions.

3. Samovar and Porter say that "...to be guilty of ethnocentrism is to doom intercultural communication to failure" (1988, 388). For effective communication to occur, one needs, among other things, to have "...a universalistic, relativistic approach to the universe $(1988,388)$.

4. Pusch describes cultural relativism as one of the skills needed for effective functioning in a multicultural 
environment. She refers to it as something you can learn to "accept". It is one of the aims of intercultural training to help facilitate this acceptance. (1981, 95).

Cultural relativism leads to ("suggests") several

other concepts: (1) cultures cannot be judged from an absolute moral or ethical reference point; (2) evaluations are relative to their context of origin; (3) No values, Ethics or morals of a culture can be "judged as inherently superior or inferior to another's" $(1981,4)$.

But, why these derive from "cultural relativism" and, in turn, exactly how cultural relativism, as distinct from the concepts it "suggests", is effective in the communication process is not clear.

5. Brislin, Landis, and Brandt state that a "...move toward a relativism in such perceptions..." of appropriate roles and norms would facilitate more situationally appropriate behaviors. This, they suggest, is "...critical for long-term effectiveness in intercultural situations..." $(1983,6)$.

6. Samovar and Porter discuss how cultural relativism helps facilitate communication through more accurate judgments about social reality, whereas absolute values can distort such judgments, and thus, impede communication $(1976,12)$. 
7. M. Bennett identifies cultural relativism as essential for the development of empathy in the intercultural communication process $(1977,163)$.

8. Sitaram and Hapanen identify cultural relativism as the "solution to ethnocentrism", and thus, the path to better intercultural communication. Ultimately, the solution to ethnocentrism is communication that is "...free of ethnocentrism as well as relativism." No further definition is given by these authors of this use of "relativism." They do say that this level of communication "beyond relativism" involves sharing the best aspects of cultures for others to borrow and become enriched by 11979, 158-59) .

9. Sitaram and Cogell see ethnocentrism as probably a major barrier to intercultural understanding because it distorts the meaningfulness of values. He discusses the problems created by ethnocentrism (i.e., judging others. values by one's own cultural standards), and states that cultural relativism may be the answer to the problems of ethnocentrism $(1976,176-77)$. By implication, there is a positive affect on communication because ethnocentrism is reduced, or eradicated.

10. Tai employs cultural relativism in a number of ways. It is primarily used in her discussions on improving intercultural communication interactions. She sees cultural relativism as a way of overcoming ethnocentrism. She also 
mentions it with regard to cultural differences and how cultural relativism helps in bridging differences in intercultural cultural communication $(1986,29)$. Particularly noteworthy is her discussion of the relevence of cultural relativism for a Japanese approach to intercultural communication $(1986,87-8)$.

11. Barna discusses stereotyping and how this is one of the stumbling blocks to successful intercultural communication interactions. In educational settings, one way of overcoming stereotyping may be to give examples of cultural relativism. However, the overcoming of stereotyping may still be difficult (1975, 294).

12. Gudykunst and Rim state that cultural relativism Eacilitates better cross-cultural understanding in communication situations $(1984,5)$.

13. Gudykunst and Rim's second reference to relativism is found in their explanation of their concept of "communication distance" and speech patterns, where they describe how cultural relativism is part of a continuum of attitudes (ethnocentrism--cultural relativism) (1984, 97). Of special note is their discussion of the different kinds of relativism which, because there are a variety of terms and definitions, creates much confusion about cultural relativism. They differentiate between "cultural relativism" and "ethical relativism" and then, identify several sub-categories of "ethical relativism" (1984, 201). 
Interestingly, their reference to ethical relativism matches that which some of the other authors in the ICC Iiterature call "cultural relativism."

14. Bochner, in discussing mediation, says that emphasizing cultural relativism, and studying of different cultures, helps dispel the myth of western superiority $(1973,34)$. He says it should be one of the key foci of intercultural education $(1973,36)$.

b. Consequences in Professional Work

Cultural relativism is discussed in five works in the context of how it helps various professionals whose work involves face-to-face intercultural communication.

1. Hofstede $(1983,89)$ discusses cultural relativism in the context of foreign management practices, and how cultural relativism leads to more effective management.

2. Stewart discusses how cultural relativism helps foreign student advisors become more effective in their work with foreign students (1972, 14).

3. Pedersen discusses the two polarized schools of theory in the mental health profession, one assuming a fixed description of mental health, applicable to all cultures, the other based on cultural relativism where "...each sociocultural context defines its own norms of mental health" $(1974,55)$.

4. Barnlund discusses the importance of collaboration among communication specialists for ethicial dialogue, and 
how such collaboration depends on relativism. Such collaboration is made difficult though, because "...the cultures which might make important contributions to such an ethical dialogue are far from equal in power and influence..." (1978, 11).

5. Bochner discusses the importance of cultural relativism to the process of mediation, and how it is a "necessary" trait for a mediator (1981b, 3; 1981c, 14).

c. Consequences in Research

Cultural relativism is discussed in two works in relation to intercultural communication research.

1. Hofstede discusses how ethnocentrism impedes cross-cultural research whereas, in contrast, cultural relativism is necessary for it $(1978,390)$. Relativism affords greater "...tolerance for people and groups with deviant ideas" $(1978,395)$.

2. Hofstede here uses cultural relativism as the basis for his comparative research on work values and the quality of work life (1984, 389).

\section{d. Consequences Pertaining to Culture Shock}

One work refers to cultural relativism in terms of how it seems to lessen culture shock. Taft says cultural relativism is the reason why a multicultural person is less likely to suffer culture shock than a monocultural person. A multicultural person "...probably has already learned to accept the relativity of cultures" (1981, 79-80). 
e. Consequences Pertaining to Judgment Formation

Smart advocates the need for an individual to become aware of one's own relativity, and then, get beyond it to a creative synthesis of cultural ways. This doesn't mean one gives up evaluation. Rather, evaluation is temporarily held back to gain understanding to avoid the premature judging of others $(1968,25-6)$. Ultimately, he hopes the results will be "...that people will form wiser judgments through their cross-cultural contacts but without forcing others to agree" $(1968,25)$.

Application Theme \#3: Theoretical Dimensions. Six works utilize cultural relativism in terms of various theoretical dimensions. They divide into three types of applications.

a. A Monocultural vs Multicultural Speech Perspective

1. Owen (1971) addresses communication accuracy vs distortion in the speech communication field. He says the adoption of cultural relativism would enable the field to improve by becoming multiplistic--recognizing the situational and cultural basis of ocmmunication behaviors and competence. This contrasts with the present-day, monocultural approach in the speech field, dominated by a white, middle class communication perspective lOwen 1979, $1-3)$.

According to Owen, few have recognized the need to study "...the cultural relativity and 'situational 
appropriateness' of communicative behavior..." (1979, 1). He says that many communication skills are culture-specific $(1979,3)$. Skills generally prescribed in communication classes reflect white, middle class values and behaviors, making the others not having this background appear communicatively incompetent. "...virtually all of the authors writing about interpersonal competence have made the error of prescribing appropriate roles and behaviors based on the dominant culture's values" $(1979,3)$. "Adopting a posture of cultural relativism..." would help communication education be more pluralistic rather than monocultural $(1979,3)$.

2. Barna says that many axioms throughout social science are culture bound and relative, even when crosscultural data are used $(1979,6)$. She raises the question of whether or not the use of "culture-bound, relative" theoretical orientations is ethical, particularily in the teaching of intercultural commmunication. She suggests that such teaching maxims used "...as if they are valid for all cultures" should be scrutinized (1979, 11).

3. Wendt identifies cultural relativism as part of the intercultural perspective $(1982,583)$ and explores whether or not a universal idea such as human rights is consistent with the intercultural communication perspective. He concludes that since this perspective renders "...understanding, respect, and tolerance of other 
cultures..." as having universal application (1982, 583), it is consistant with "human rights" which involves a universal regard for human life (1982, 586-7):

mas long as intercultural communication
theory contains the universal respect for
differences, that viewpoint has to incorporate
human rights $(1982,587)$.

4. Isomura and stewart explore the question of the viability of cultural relativism. They ask whether or not cultural diversity and relativism are idealistic or realistic concepts, in terms of the world today. Stewart says that some people assume that communication and industrialization "unravel diversities of cultures" (1976, 115). He says he does not see there is necessarily a link between these and a loss of pluralism. He compares human societies to flora and fauna which have diversified because of response to a homogeneity of environmental conditions. He sees societies similarly maintaining their integrity and thus, maintaining cultural diversity (1976, 116).

5. E. Glenn (with C. Glenn) disallows the validity of cultural relativism for application in the modern-day world. He discusses how relativism applies to distinct, independent cultures. However, because cultures are no longer isolated, "ethical cultural relativism" is no longer viable:

The recognition of the cognitive autonomy of culture implies a relativistic approach to ethics. However, ethical cultural relativism can stand only in the context of cultural independence and the lack of contact between 
cultures with different moral standards. This, obviously, is not the case nowadays (1981, $317)$.

6. Ferguson discusses how cultural relativism is not relevent for culture learning.

Cultural relativism has become a bad 'word', largely as a result of this particular unit. Actually, it was beside the point in the unit, as it is beside the point in culture Learning... We do not here aver that the student must learn that within each culture the values and attitudes of a given moment are absolute or that they are of no concern to us.... The aim, then, is empathy and understanding, not to go out and change another culture, nor, on the other hand, to simply nod our heads and say, "Good for them."

What is more important is to learn how other peoples express themselves as they do and to understand why they act as they do...the aim of culture learning... [is] international and intercultural understanding, communication and harmony (1977, 9-10).

\section{ADVANTAGES}

\section{Overview}

Out of the total of 44 works, 36 works (82\%) associate only advantages with cultural relativism. Several works mention more than one advantage. Six authors (17\%) refer to cultural relativism as a viable concept as well as including observations as to limits or problems they perceive with it. one author says it is not relevant to culture learning. Another says it used to be useful, but is no longer, given the integration of cultures that has occurred.

The advantages which authors present regarding cultural relativism grouped into three themes. The topics 
which the data addressed within each theme are listed accordingly.

Theme \#1: Facilitation of Internal, Attitudinal Changes ( 13 works)

a. Reduces ethnocentrism ( 4 works)

b. Reduces discrimination ( 1 work)

c. Helps overcome stereotyping (1 work)

d. Increases enjoyment of difference ( 1 work)

e. Helps development of empathy ( 1 work)

f. Facilitates acceptance of behavioral variety (1 work)

g. Helps provide greater figure/ground elasticity ( 1 work)

h. Increases tolerance of, and openness to, people of other cultures (2 works)

i. Helps to correct mistaken notion of Western superiority (1 work)

Theme \#2: Facilitation of Cultural knowledge and Understanding ( 4 works)

a. Facilitates understanding of cultural behaviors ( 3 works)

b. Facilitates insight into diversity of cultural "truths" and norms (1 work) 
Theme \#3: Facilitation of External, Interactive Results (21 works)

a. Facilitates Functioning in Intercultural

Situations ( 9 works)

1. Systematic bridging of differences (1 work)

2. Effective functioning in a multicultural environment ( 1 work)

3. Fosters successful intercultural communication ( 1 work)

4. Necessary for effective culture learning and competence ( 1 work)

5. Fosters accuracy of perceiving communication norms contextually ( 1 work)

6. Fosters accurate and meaningful sense of truth (via contextualism) (1 work)

7. Evaluation of situations contextually (multicultural man) (1 work)

8. Adaptation to different context (multicultural man) (1 work)

9. Helps accuracy of prediction of communication behaviors ( 1 work)

b. Ethical Advantages (2 works)

1. Facilitates context-sensitive teaching and research (1 work) 
2. As part of intercultural communication theory, renders theory in support of "human rights" (1 work)

c. Facilitates Cultural Multiplicity (2 works)

d. Facilitates Professional Work Involving Face-to-Face Interaction ( 8 works)

Presentation of the Data

Advantage Theme \#1: Facilitation of Internal, Attitudinal Changes.

a. Mayer $(1980,35)$, Sitaram and Cogell (1976, 176$177)$ and Sitaram and Haapanen $(1979,159)$ say cultural relativism helps reduce ethnocentrism. Tai states this is appropriate not only for Westerners, but for the Japanese as well, because ethnocentrism is a major impediment for the Japanese in intercultural communication interactions (1986, $87-8)$.

b. Asuncion-Landé says cultural relativism helps in the reduction of social and economic discrimination, an important goal in bilingual and bicultural education (1975, $66)$.

c. Barna says that, in educational settings, giving examples of cultural relativism may be one way to overcome stereotyping, though this may not be easy. She identifies stereoptyping as one of the "stumbling blocks" to intercultural communication $(1976,294)$. 
d. Howell identifies cultural relativism as advantageous because it leads to enjoyment of difference which he sees as a necessary foundation for intercultural communication skill building $(1977,8)$.

e. M. Bennett says that cultural relativism is a necessary step for the development of empathy which, in turn, increases understanding of cultural differences (1977, $163)$.

f. Brislin, Landis, and Brandt see cultural relativism as involving a move away from

...seeing the world in terms of moral and behavioral absolutes. Thus, appropriate and necessary behaviors would become more situationally (culturally) specific so that the individual could accept a greater variety of such behaviors both in others and in himself. We would suggest that these changes are critical for long-term effectiveness in intercultural situations... $(1983,6)$.

Relativism helps create acceptance of behavioral variety.

g. Barnlund and Nomura explain that an advantage to cultural relativism is that it "...may cultivate the greater figure/ground elasticity that is essential for crosscultural rapport" $(1985,360)$.

h. J. Bennett identifies the benefit of cultural relativism as the increase in tolerance of, and openness to, people of other cultures, attitudes which, she says, are valuable in succeeding in living abroad $(1985,166)$ and in increasing cultural effectiveness (1985, 162). 
M. Bennett says that the "construing of difference" (ethnorelativism) is necessary for intercultural sensitivity and the overcoming of ethnocentrism:

The key to ethnorelativism is the idea of "process." Perceiving behavior, values, and identity itself as a process of constructing reality overcomes ethnocentrism by reducing reification and the assumptions of absoluteness, centrality, and universalism that usually accompany reification $(1986,64)$.

i. Bochner says one of the benefits of cultural relativism is that, through educational programs, it help to correct the mistaken notion of Western superiority (1973, 34).

Advantage Theme \#2: Facilitation of Accurate, Cultural Knowledge and Understanding.

a. Gudykunst and Kim say cultural relativism facilitates cultural understanding of behaviors.

"Becoming more culturally relativistic, on the other hand, can be conducive to understanding.....Cultural relativism suggests the only way we can understand the behavior of others is in the context of their culture" $(1984,5)$.

b. Furnham and Bochner say that sensitivity to and awareness of cultural relativism can provide insight into the diversity of cultural truths and norms $(1986,237)$.

c. Hofstede states that cultural relativism is necessary for doing comparative cultural research. Where one is ethnocentric, value systems and assumptions are culture-bound, and hence, biases the research. Using a relativistic approach, "...the researcher should be prepared 
to question all culture-bound value systems and assumptions, even his own" $(1978,390)$. Cultural relativism, as the opposite to ethnocentrism, affords a more "empirical" approach $(1978,397)$.

d. Hofstede implies that cultural relativism provides a basis for obtaining accurate, cultural data about cultures. In seeking information through his research about "quality of life" in various cultures, he presumes the "cultural relativity of values" where "...what one considers good or bad is dictated by one's cultural context" (1984, 389).

Advantage Theme \#3: Facilitation of External, Interactive Results.

a. Facilitates Functioning in Intercultural Situations

1. Szalay says cultural relativism involves systematic bridging of differences based on (a) selfawareness, (ㅁ) knowledge of other's culture, and (ㄷ) shift of frame of reference $(1974,2)$. This is essential:

To be effective, communication has to be adapted to the cultural background and experiences of our partner or audience. This adaptation is a fundamental requirement that lies at the very core of the intercultural communication process $(1974,2)$.

This bridging process, he says, is distinct from that in domestic communication $(1974,2)$.

2. Pusch says that cultural relativism helps effective functioning in a multicultural environment. A 
communication style that transcends cultural barriers includes a number of abilities and attitudes including cultural relativism (1981, 95).

3. Samovar and Porter say the mode of communication behavior which fosters successful intercultural communication is not only void of ethnocentrism, it requires willingness, empathy, tolerance and a "universalistic, relativistic approach to the universe" $(1988,388)$.

4. Paige and Martin point out that in spite of the possible problems that a few trainees may experience with cultural relativism, it is nonetheless necessary for effective culture learning and competence. They also state it is among those "...most frequently posited personal qualities associated with authentic intercultural competence" $(1983,43-4)$.

5. Owen identifies a culturally relativistic approach to communication as necessary for effective communication, research and teaching. It involves accurately perceiving communication norms through contextualization $(1979,3)$. The study of communication becomes more "grounded" because it is based on actual communcication interaction rather than on theory and skills pre-determined, generally, on a single, cultural view (in particular, that of the dominant, white, middle-class) $(1979,8)$.

6. Samovar and Porter say cultural relativism is a means for obtaining an accurate and meaningful sense of 
truth as viewed in a particular culture because it is considered contextually. If truth is assumed to be true for al1 people, it becomes distorted (1976, 12).

7. Adler identifies two benefits of cultural relativism in terms of multicultural people: they can evaluate situations contextually and they can themselves adapt to different contexts, taking on new cultural identities $(1974,370)$.

\section{According to Gudykunst, the accuracy of} predictions that are a part of communicative behavior is seen as facilitated by cultural relativism (1977, 25).

9. Taft says that if a person has accepted the relativity of cultures, he/she is less likely to suffer culture shock $(1981,79-80)$.

\section{b. Ethical Advantages}

1. Barna raises the question of whether or not the use of "culture-bound, relative" theoretical orientations is ethical, particularily in the teaching of intercultural communication $(1979,6)$. An example would be when teachings maxims are used "...as if they are valid for all cultures" (1979, 11). She implies that the recognition of cultural relativism would afford a more ethical, context-sensitive, approach to research and teaching.

2. Wendt says "...as long as intercultural communication theory contains the universal respect for differences, that viewpoint has to incorporate human rights" 
(1982, 587). This viewpoint is central to the relativistic perspective of intercultural communication (1982, 583). It's advantage is that it supports the "human rights" perspective.

c. Facilitating Cultural Multiplicity

1. Isomura and stewart discuss the viability of cultural relativism as a"realistic" happening in the world. Stewart concludes that he sees cultural diversity (which they associate with cultural relativism) as continuing in spite of increased global communication. His statement implies he sees this as positive, though he does not say why $(1976,115)$.

2. Mcleod says if relativism were common, "...a continued diversity of life-styles, values, and approaches to human problems would be guaranteed" (1981, 51).

d. Advantages for Professions involving Face-to-Face Interactions

1. Barnlund says cultural relativism is necessary for communication specialists who do cross-cultural collaboration (1978, 11).

2. Pedersen says cultural relativism provides a multiplistic-type foundation which helps to facilitate effective directions in cross-cultural counseling. In contrast, the unilateral mental health approach impedes effective counseling and client understanding (1974, 55). 
3. Stewart says that cultural relativism makes foreign student advisors more effective in working with foreign students $(1972,14)$.

4. Hofstede says that cultural relativism leads to more effective management and "...better ability to manage intercultural negotiations and multicultural organizations like the United Nations, which are essential for the common survival of us all" (1983, 89).

5. Bochner says that mediation, based on relativism, benefits cultures mutually. He describes the mediator as a "cultural relativist," and says,

The essence of the mediating function is to shape the exchanges between the participting societies so that the contact will benefit both cultures, on terms that are consistent with their respective value systems (1981b, 3).

6. Relativism helps facilitate beneficial culture contact. Bochner states "cultural relativism of values" as one of the key attributes of "mediating man" (people he describes as important through serving as links between diverse cultural systems) (1973, 35).

7. Bochner says that in mediation, cultural relativism is one of the

...precious skills that are so badly needed, because of their unique contribution is to help steer mankind through a middle course, where the benefits of technology can be gradually extended to all human beings, without at the same time creating a bland, homogenized and inflexible world $(1973,36)$. 
8. Harris and Moran state that cultural relativism is advantageous because it increases the effectiveness of the cross-cultural manager $(1979,203)$.

\section{DISADVANTAGES}

\section{Overview}

Nine disadvantages regarding cultural relativism were identified in the ICC literature. All but two of the disadvantages stated by authors reflect perceived limitations of cultural relativism. Two of the authors state that cultural relativism is simply not viable. The data was organized according to the following themes:

Theme\#1: Difficulties of Assumption of Cultural Relativism ( 5 works)

Theme \#2: The Avoidance of Ethical Judgments (2 works)

Theme \#3: The Permeability vs. Impermeability of Cultural Boundaries (1 work)

Presentation of the Data

Disadvantage Theme \#1: Difficulties of Assumption of

\section{Cultural Relativism.}

1. Barnlund and Nomura state that a disadvantage of cultural relativism is that it is not easily acquired (1985, 360). It may require experiential, as well as intellectual, involvement $(1985,361)$. 
2. Bochner says that one of the problems of cultural relativism is that many people have difficulty sustaining non-evaluation. The difficulty is such that relativism ...can be expected to serve only as a limited guide to action in the practical world of affairs....

People vary in the strength of their committment to a doctrine that avoids making value judgments about the practices of other societies $(1981,14)$.

3. Smart, in pointing out that relativism provides a wonderful challenge, also says it can be a traumatic experience $(1968,25)$.

4. Brislin describes cultural relativism as one of the effects of a sojourn experience. However, upon returning home, a sojourner may experience difficulty relating to people who have had no cross-cultural experience. They may perceive these people as narrow-minded and, in crosscultural programs, they have little or nothing in common with these people upon which to build relationships (1981, 316-7). Brislin thus implies that a person who has become culturally relative can feel isolated from others not having a similar relative approach.

5. M. Bennett describes several stages of the development of a culturally relativistic perspective. One of these stages can lead to neutrality or even negativity toward intercultural communication education. This he calls "non-developmental pluralism"--the ability of a person to be culturally sensitive to only specific cultures. The person, 
instead of having a general adaptability to any culture, has a limited ability to be culturally relative $(1986,56)$.

6. M. Bennett describes various stages of cultural relativism which he has identified as paralleling the internal acquisition of cultural relativism. They represent levels of intercultural sensitivity which correspond to a person's level of comprehension and experience of cultural difference. "However, the concept of fundamental cultural difference is also the most problematical and threatening idea that many of us ever encounter" (1986, 27-28). Training for increasing one's intercultural sensitivity must be done "with the greatest possible care" because of this difficulty of accepting cultural difference $(1986,27)$.

Disadvantage Theme \#2: The Avoidance of Ethical Judgments.

1. Gudykunst and Kim say that cultural relativism can be used as an "alibi" for not making necessary ethical judgments which must be made $(1984,203)$. They imply this is "wrong."

2. Ferguson says that cultural relativism is neither an disadvantage nor an advantage. Rather, it is irrelevent. The goal of culture learning, he says, is to learn empathy and understanding, not cultural relativism. It is "...not to go out and change another culture, nor, on the other hand, to simply nod our heads and say, "Good for them" $(1977,10)$. In other words, Ferguson views cultural 
relativism as involving the affirmation of cultures, and he feels that such evaluation has no part in culture learning. Disadvantage Theme \#3: Permeability vs Impermeability of Cultural Boundaries. E. Glenn (with C. Glenn) indicates that cultural relativism is not useful anymore because culture contact exists now. Formerly, when cultures were independent, cultural relativism was useful (1981, 317).

\section{CHAPTER SUMMARY}

It is clear from the data obtained from the literature sample that cultural relativism is neither defined nor used in a consistant fashion in the intercultural communication literature. Major differences were found to exist between authors' definitions, applications, and stated advantages and disadvantages. A wide range of variations within these differences were found as well.

\section{Definitions}

In light of the fact that great discrepancy of opinion exists as to the definition of "cultural relativism", it is noteworthy that less than one third of the authors presented definitions of "cultural relativism." Clearly, the remaining two-thirds of the authors, through their definitional omission, create ambiguity regarding their view of cultural relativism.

It is also interesting to note that of the definitions which were found, two refer to characteristics of cultures 
(diversity and equal validity), while two refer to internal human experiences (attitudes and factual knowledge).

\section{Applications}

The applications divided into three main uses of cultural relativism, namely, in discussions pertaining to causes of cultural relativism (15 works--34\%), in discussions pertaining to consequences of cultural relativism ( 23 works--52\%), and in discussions of cultural relativism as it pertains to theory ( 6 works--14\%).

Discussions pertaining to causes of cultural relativism involve either formal or informal learning contexts. The formal learning discussions (9 works) include one discussion of how cultural relativism might be measured, five discussions on how cultural relativism is an outcome of training, descriptions of two training models for developing relativism, and one discussion of cultural relativism as an ethical dimension to intercultural communication training programs.

The informal learning discussions ( 6 works) range from addressing cultural relativism as a result of exposure to intercultural communication teaching and research, to that which results from contact with another culture, to involvement with cross-cultural mediation.

Discussions pertaining to consequences of cultural relativism (1) address results in the communication process 
itself (13 of the works), (2) identify professional fields in which cultural relativism is beneficial ( 6 works),

(3) describe the importance of cultural relativism in crosscultural research (2 works), (4) discuss cultural relativism in terms of culture shock (1 work), and (5) present relativism as a means for better cross-cultural judgment formation (1 work).

Six discussions pertained to theory. Two authors discuss how cultural relativism provides a more accurate, multicultural dimension to speech communication. One author looks to cultural relativism in intercultural theory to justify "human rights." Three explore the viability of cultural relativism as a concept--one affirms its usefulness, one says it is not useful and one says it is irrelevent to culture learning.

\section{Advantages}

In the ICC Iiterature, 36 different advantages are associated with cultural relativism. Thirteen of the works (36\%) referred to advantages of cultural relativism in terms of its facilitation of internal, attitudinal changes which increase a person's tolerance of cultural differences. Among these thirteen works, a range of attitudinal changes related to increase of tolerance was found. This includes (1)reduction of ethnocentrism, (2) reduction of social and economic discrimination, (3) overcoming of stereotyping, (4) enjoyment of differences, (5) development 
of empathy, (6) acceptance of behavioral variety, (7) greater figure/ground elasticity, (8) increase in tolerance and openness to people of other cultures, and (9) the correction of the "mistaken notion" of western superiority.

In contrast to how people perceived, four works (10\%) cite the advantages of cultural relativism as intellectual knowledge about cultural behaviors and the diversity of cultural truths and norms.

Nine works (25\%) refer to advantages in interactive situations such as the (1) systematic bridging of cultural differences, (2) more effective functioning in a multicultural environment, (3) successful intercultural communication, 4) effective cliture learning and competence, (5) accurate perception of communication norms, (6) accurate and meaningful sense of "truth" contextually, (7) contextual evaluation of situations and ability to adapt to different contexts, (8) accuracy of communication behavior predictions, and (9) reduced likelihood of suffering culture shock.

Two works describe ethical advantages of cultural relativism, two state it facilitates cultural pluralism, and eight works discuss advantages for professional work involving intercultural communication interactions.

\section{Disadvantages}

Nine disadvantages were referred to in the ICC literature. Seven works made reference to the difficulties 
associated with the assumption of cultural relativism.

These included the following: (1) relativism is not easily acquired, (2) it is difficult to carry out non-evaluation because people's abilities differ in the degree to which they can do this, (3) cultural relativism can be traumatic, (4) people who view things relativistically can feel socially isolated in their different frame of reference, people may develop only a limited form of relativism which is culture-specific, not a general attitude ("nondevelopmental pluralism"), and (6) people differ in their ability to accept "cultural difference."

Finally, one work says cultural relativism is sometimes used as an alibi for not making ethical judgments, which the author says must be made.

In addition to these seven disadvantages from authors who are, however, clearly in support of cultural relativism, two authors rejected relativism. One author says it is no longer viable because the world is too interconnected now. Relativism was only useful when cultures were isolated from each other. The other says relativism is not relevant. He says the goal of culture study is to learn, not to change cultures or approve cultures.

Overall, $95 \%$ of the authors clearly support cultural relativism as a viable concept. Most authors refer to it in the context of face-to-face interactions, though some reference to its use in research is made. 
All the authors refer to cultural relativism as an end to itself which has resulting ramifications for intercultural communication in some way. However, Smart (1968) and Sitaram and Haapanen (1979) speak of relativism as a useful stage which ideally needs to be transcended, resulting in wiser judgments (Smart) and a higher level of communication where the best of cultures are recognized and shared (Sitaram and Haapanen). These results parallel those associated with "constructive marginality" which constitutes the final stage of ethnorelativism on Bennett's intercultural sensitivity model (1986).

Potentially parallel ideas such as these, named with differing terminology, or implied or assumed and not named at all, seem to pervade the literature on cultural relativism in the intercultural communication area. An attempt has been made here to explore the literature within the limits of the four categories (definitions, applications, etc.). However, comprehensive detective work to follow up on apparent contradictions, or misleading similarities, and to ferret out underlying assumptions of the various authors, could not be done within this one study. Here, a limited number of authors' ideas are presented as reported by the authors themselves. It is for further studies to dig deeper. 
CHAPTER IV

\section{CRITICISMS OF CULTURAL RELATIVISM}

\section{IN THE CURRENT ANTHROPOLOGY LITERATURE}

As the result of a review of the current anthropological literature, a number of works were found which critically analyzed cultural relativisn in terms of its role and viability within the field of anthropology. The analyses and arguments utilized in these works are generally detailed and lengthy. However, in this chapter, the criticisms of cultural relativism will be summarized only. Should the reader wish to gain an in-depth understanding of any of the criticisms, he/she is encouraged to refer to the source material directly.

The problems regarding cultural relativism summarized in this chapter reflect the general trend of criticisms currently prevailing in anthropology. The works from which they derive were selected after a fairly comprehensive literature search, and comprise the main body of critical works in the current anthropological literature. 
DEFINITIONS

Overview

As was found in the intercultural communication literature sample, authors of the current anthropology Iiterature do not concur regarding the definition of cultural relativism. Out of the ten works examined, seven contain explicit definitions, one contains an implied definition, and two of the works refer to cultural relativism as a term which signifies a family or cluster of ideas instead of a single concept.

To be consistent with the format of data presentation of this study, definitions were grouped by theme. Three themes from the intercultural literature were reflected in some of the current, anthropology definitions:

Theme \#2: Equal Validity of Cultures (2 works)

Theme \#3: Attitudes Towards Difference ( 3 works)

Theme \#4: Contextualism ( 3 works)

Two additional definitions were found as well:

1. The Contingency of Customs and Beliefs ( 1 work)

2. Relativism as a Plurality of Concepts (1 work)

\section{Presentation of the Data}

\section{Definitional Theme \#2: Equal Validity of Cultures.}

Kuttner presents two terms. He defines "radical cultural relativism" (he also terms this "radical ethical relativism") as not just a "restraint on ethnocentric bias," 
which is "reasonable and necessary," but the refraining from ethical judgment $(1970,22)$ and "..holding that all cultures express equally valid ethical principles" (1970, 222). The second term, "cultural relativism", reflects theme \#3, described in the next section.

Hartung concurs with the definition of Kuttner's first term, but refers to it as "cultural relativity." Hartung says that cultural relatlivism "...asserts that any set of customs and institutions, or way of life, is as valid as any other" (1954, 118).

It is interesting to note that Kuttner perceives cultural relativism in terms of ethical principles, whereas Hartung's definition has a broader scope, namely "any set of customs and institutions, or way of life."

\section{Definitional Theme \#3: Attitudes Toward Difference.}

Jarvie says that "cultural relativism" means there is "...no way of rationally justifying standards that transcend the boundaries of time society and culture...no rational justification for ranking societies morally, cognitively or cultural1y" (1975, 344).

Ruttner defines his second term, "cultural relativity," as "reserving judgment on alien societies" (1970, 220). This definition reflects the theme of "attitudes toward difference."

Hippler, in spite of his strong criticism of cultural relativism, fails to explicitly define it. He implies, 
however, that he perceives relativism as meaning that there are no standards which identify what is "optimal" for humans (1981, 396), nor are there standards which can be applied cross-culturally (1981, 395).

Definitional Theme \#4: Contextualization. Beattie defines relativism as the understanding of the meanings of the representations of other cultures in terms of their own contexts "...that is, relatively to other aspects of the cultures of which they are a part" $(1984,14)$. He identifies two "levels" of such relativism:

1. epistemological relativism--This refers to the fact of conceptual difference between cultures, "...the totally different way of thinking about, apprehending experience, a logic of a different order from our own (whoever 'we' may be)..." (1984, 14). "Absolute, extreme relativism" is defined here as "...claiming that truth is entirely relative to context..." (1984, 15);

2. cultural relativism--This refers to the abstaining from using the conceptual categories of our own culture "...in the attempt to understand the categories and classifications, the ways of thought, of other cultures..." $(1984,18)$.

The definition of another author, stein, also reflects the contextualism theme, but it has a different emphasis. He says relativism means "cultures are to be understood as unified wholes that can and must be accounted for in terms 
of themselves ("emic"), not in terms of any external frame of reference ("etic"). The "doctrine of relativism" describes each culture as "unique and self-contained," and views as spurious cross-cultural comparisons intended to explain culture by means of "underlying common denominators". (1986, 159)

Turner describes relativism as the attempt to understand and evaluate other cultures on the other cultures' own terms $(1982,76)$.

\section{Additional Definitions}

1. The contingency of Customs and Beliefs. DimenSchein defines cultural relativism as "the contingency of customs and values" $(1977,41)$. The fact of cultural diversity is implicit in this definition, but not the whole of it. Dimen-schein, in her discussion, makes it clear that she sees relativism as the variability of the circumstances which create the diversity of customs and values.

2. Relativism as a Plurality of Concepts Clark does not perceive cultural relativism as a term with a single definition. To him, "Obviously 'relativism' is not the name of a specific and consistent set of doctrines, but the family resemblance between a number of ideas is sufficient to warrant the label" (1970, 553, reference note \#1). He focuses in his discussion on one of these ideas which says "...that a conceptual scheme fashioned in and applicable to 
one particular culture cannot meaningfully be applied to an alien culture." $(1970,545)$

Nowell-smith also refers to cultural relativism as a cluster of ideas rather than a single concept:

Indeed, it seems to be more of an atmosphere than a doctrine, and for this reason I sha11 examine four propositions which seem to me to contain the essence of the doctrine rather than discuss particular formulations to be found in the literature $(1971,1)$.

These propositions are as follows:

1. There are no absolute, universal moral rules or values; all rules and values are relative to something.

2. The mores of a society are necessarily right for that society.

3. One ought not to make cross-cultural moral or value judgments.

4. One ought to conform to the mores of his society $(1971,2)$.

\section{APPLICATIONS}

\section{Overview}

The ten, current anthropology works for this study were selected to present a range of criticisms regarding cultural relativism in the current anthropological literature. Though references to causes and consequences occur in the arguments presented, the process of questioning the viability of cultural relativism as an anthropological construct places the discussions within Theme \#3. 
Theme \#3: Theoretical Dimensions (10 works)

$$
\begin{aligned}
& \text { a. Cultural Relativism as not Viable ( } 6 \text { works) } \\
& \text { b. Cultural Relativism as Viable in a Limited } \\
& \text { Way only ( } 4 \text { works) }
\end{aligned}
$$

\section{Presentation of the Data}

Application Theme\#3: Theoretical Dimensions. All of the current anthropology works discuss the viability of cultural relativism for anthropology. Six works disallow the viability of cultural relativism altogether. However, four of the works do include brief reference to ways of defining and/or using relativism which are viewed as viable.

The various topics which the criticisms address are described in the following.

a. Cultural Relativism as lot Viable

Stein (1986), Hartung (1954), Jarvie (1975), Hippler (1981), Turner (1982), and Clark (1970) all present cultural relativism as not viable.

Stein does a psychological analysis of the anxiety problems he perceives regarding cultural relativism which ultimately keep anthropologists from fully understanding their subject matter.

Taking a philosophical approach, Hartung and Jarvie explore philosophical problems of logic and "rationality." focusing particularily on the ideas of "tolerance" and moral judgments. 
Hippler, in replying to a challenge to one of his previous articles, focuses on relativism and its lack of criteria for evaluating cultures as the core issue needing to be addressed.

Turner, in his overall discussion, seeks to establish a universal value system for anthropology. To develop his position, he examines both cultural relativism and ethnocentrism, and argues that their "particularistic" value systems are inappropriate for the field of anthropology. "Anthropology, particularily its applied forms, needs a universalistic value positicn" (1982, 76). He discusses as an alternative to relativism a universal "ecosystem" of values.

Clarke also criticizes the particularism of relativism. However, he does so within a different topic, namely, the inadequacy of the "basic needs" concepts for a "science of culture."

b. Cultural Relativism as Viable in a Limited Way

$\underline{\text { Only }}$

Beattie (1984) presents his criticisms of cultural relativism (primarily, the unavoidability of ethnocentrism) within his overall discussion of the problem in social anthropology of understanding other cultures. He does indicate, however, that relativism serves as a reminder to anthropologists about the difficulties and problems of cultural bias regarding terms and concepts $(1984,9)$. He 
implies degrees of relativism, and focuses his criticisms on the problems of "extreme" relativism.

Kuttner (1970), like Hartung and Jarvie, does a philosophical analysis of the problems of "tolerance" and moral judgments. However, his approach parallels that of Beattie in considering relativism in degrees, where "extreme" relativism is not seen as viable, but a modified relativism has value as a restraint against bias (1970, 221).

Nowell-Smith (1971) uses a philosophical approach also, but focuses on the topic of moral judgments. She gives a detailed discussion of how relativism is generally not viable because of its faulty logic. She does include a very brief, contrasting description of relativism as an empirical thesis (as opposed to "moral" or "conceptual") which she sees as a possible viable use of cultural relativism $(1971,15-16)$.

Dimen-Schein (1977) refers to relativism in her book The Anthropological Imagination. In three short sections, she distinguishes between cultural relativism as a methodology and cultural relativism as a moral system, and highlights problems therein. Her criticisms are focused on relativism used as a moral system. However, she explains, where relativism is limited to methodology, or used only as a reminder about cultural bias, it can be useful $(1977,41)$. The author descibes an ongoing inner tension between 
cultural bias, awareness of cultural bias, and our changing ideas. This, she indicates, fosters a healthy relativism $(1977,42-3)$.

\section{ADVANTAGES}

\section{Overview}

As can be seen in the previous section, only four authors perceived possible applications of relativism which resulted in positive results in research.

Theme \#2: Facilitation of Cultural Understanding

$$
\begin{aligned}
& \text { a. Helps Understanding of Cultural Behaviors } \\
& \text { b. Helps Insight into Diversity of Cultural } \\
& \text { Truths and Norms }
\end{aligned}
$$

Presentation of the Data

Advantage Theme \#2: Eacilitation of Cultural

Understanding.

a. Helps Cultural Understanding

Beattie $(1984,9)$ and Ruttner $(1970,221)$ refer to cultural relativism as a reminder of cultural bias. Bias can distort the data one collects. Thus, the accuracy of one's results is enhanced if one is aware of possible bias. They see this advantage resulting from a limited or modified relativism only (as opposed to an "extreme" form). Implicit here is the idea of a continuum of degrees of relativism. Reduction of bias helps one obtain more accurate information about culture. 
Dimen-Schein also refers to relativism as a corrective for bias, but only when one does not seek to "reconcile our culturally given ethocentric morality with the anthropological demand for detachment." These, she says, occur separately. The greater one's detachment, the greater one's ability to be relativistic. Relativism "keeps us humble by reminding us, quite reasonably, that our own way of life is not the only or the best way to live" (1977, 4143).

b. Helps Insight into Diversity of Cultural Truths and Norms

Nowell-Smith and Dimen-Schein state that cultural relativism, as a method, can be useful.

Nowell-Smith states that relativism can facilitate the empirical study of morals. One could address, descriptively, questions such as "How do people get their moral ideas?" and How do moral ideas arise and change? $(1971,15-16)$.

In a similar, but broader vein, Dimen-Schein implies that contextualism, as a general methodological directive of cultural relativism, directs our attention to specific questions which help us gain insight into fundamental, cultural differences such as truths and norms. "Since cultures vary according to circumstances we must discover what those circumstances are and what pattern they produce" $(1977,41)$. 


\section{DISADVANTAGES}

\section{Overview}

Two of the intercultural communication disadvantage themes were were found among the criticisms of cultural relativism in the current anthropological literature. Five disadvantages were found which fell outside the thematic framework.

Because the criticisms are organized thematically, authors having several criticisms may be referred to within several different thematic groups. The intention of this organization was to presert the range of criticisms in the Iiterature, not a summary of the authors' works, per se. The range of themes are as follows:

Theme \#2: The Avoidance of Ethical Judgments (4 works)

a. Alienation from One's Own Cultural Value System (1 work)

b. Prevention of Cross-Cultural Ranking ( 3 works)

Theme \#3: The Permeability vs. Impermeability of Cultural Boundaries (2 works)

Additional Disadvantages found in the Current Anthropology Literature:

1. The Illogical Logic of Relativism (4 works) a. Circular Reasoning ( 3 works) b. Faulty Linear Reasoning ( 1 work) 
2. The Justification of Personal Acts ( 2 works)

3. Reality as a Discoverable Entity vs. Reality as a Cultural Construct ( 1 work)

4. Particularism vs. Universalism (2 works)

5. Reverse Ethnocentrism (3 works)

\section{Presentation of the Data}

\section{Disadvantage Theme \#2: The Avoidance of Ethical}

Judgments. Three authors address this theme--kuttner, stein and Hippler. The reference to relativism used as an alibi for not making judgments, though in the intercultural communication literature, was not found in the current anthropology literature reviewed. However, two additional topics were found, as indicated below.

\section{a. Alienation from One's Cultural Value System}

Kuttner's first criticism is that extreme cultural/ ethical relativism alienates one from one's own cultural value system. Such relativism "has passed the mark set by utility and has a crippling effect on progress" (1970, 221). The subject of ethics is of great importance to anthropology for it is "... an expression of the highest activity a culture can manifest" $(1970,221)$. He continues:

Failure to evaluate at this level is not just heroic neutrality, but a retreat from the standands of one's own culture. Ethics are not neutral. Adherence to an ethical system requires choice and partisanship. Reserving judgment is not an example of objectivity but an indifference to the implicit values of the 
observer's culture. Radical ethical relativism carries with it many damaging notions... (1970, 221).

Kuttner describes two problematic consequences of extreme relativism in everyday life:

1. "It first of all questions the ability of any participant in a culture objectively to defend the ethical values of his own society" (1970, 221).

2. "It suggests that agreement between cultures on ethical matters cannot be reached by rational methods if different patterns have already evolved" (1970, 221).

Ruttner refers to the goal of tolerance maintained by relativists and argues that one can have allegience to one's cultural ethical system without being intolerant of alien systems. Furthermore,

Science may not discover absolute truths, but our ethical truths have a longer history and a wider acceptance than any other prevailing system. The trivialities of Africa and the introspective mysticism of Asia have not enriched our lives to the degree that our culture has enriched the societies of others $(1970,222)$.

Kuttner concludes his discussion:

Scientists ought to be loyal to their cultures, even if tolerant of other societies. The fact that we are studying them, and not they are studying us, ought to foster the idea that we have moved a bit further up the ladder of social organization than the others....we should not pretend that other life-styles are immune to the same searching analysis we devote to our imperfection $(1970,224)$.

Ruttner's arguments are exemplary of the confusion between "cultural relativism" and "ethical relativism." For 
example, he uses the terms "radical cultural relativism" and "ethical relativism" interchangably. Apparentiy, to Kuttner, the term "cultural relativism" does not embrace moral issues but, somehow, an "extreme" degree of relativism does.

\section{b. Prevention of Cross-Cultural Ranking}

Kuttner's second criticism is that relativism prevents cross-cultural, hierarchical ranking of values. He states that relativism "denies the universality of any ethical theme, and thereby elevates to equal importance all ethical themes" (1970, 221).

It is noteworthy that Kuttner makes a point of stating that he is not suggesting that "...radical cultural relativism bars the scientist from making a system of classification of ethical beliefs" $(1970,221)$. But, he feels it prevents placing ethical systems into a hierarchy, and clearly, he does not agree with this.

Stein concurs with this criticism, although he refers to cultures at large, not just ethical beliefs. Like Hartung, he says that relativism permits the discovery of differences via the cross-cultural comparative method, but he points out that, to him, relativism has the restriction that "differences found between cultures must not be used to disrupt the status equality that prevails between cultures (though the modern West is an exception, since it must be shown to be less equal...)" $(1986,164)$. In this last 
comment, he presents his view that relativism has an inappropriate bias against the modern west.

Hippler argues that, in the realm of research, cultural relativism fails "to explain the world and especially to explain the differential capacity of different cultures to change and adapt..." $(1981,394)$. He says that relativists have "...apparently abrogated the capacity for judgment concerning what they view" $(1981,334)$. He emphasizes that it is necessary for anthropologists to ask questions about human potential and the problems of attaining maturity, individually and culturally. This requires "standards of maturity and growth" which relativism denies through its rejection of a cross-cultural approach:

The inevitable outcome of a refusal to apply theory cross-culturally is solipsism, and this is precisely what anthropology has fallen into. (1981, 395)

In contrast to the "tedious butterfly collecting that characterizes our present relativist paradigm" (1981 395), Hippler proposes a criterion for evaluation, where cultures are considered "better or worse depending upon the degree to which they support innate human capacities as those emerge" (1981, 395) .

Cultural relativism is a dead letter. If we do not wish our discipline to remain in the depths of sterility inherent in relativistic nonsense, or to express the continual adolescent rebelliousness of Marxism, we must be willing to address afresh our sacred totems (1981, 396). 
Hippler emphasizes that the explanatory inadequacy of relativism "has led to an increasing adoption of Marxist thought in anthropology" (1981, 394). It is clear from Hippler's comments ("the continual adolescent rebelliousness of Marxism" and "its high nonsense content") that Hippler is not overenthousiastic about Markism. Still, because it allows for the cultural evaluation relativism rejects, he sees it as the lesser of two evils:

Marxist thought, whatever its high nonsense content, is at least not relativistic and in addition satisfies both the needs of many anthropologists to attack their own culture while at the same time recognizing the reality of fundamental and far-reaching differences in capacities from culture to culture $(1981,394)$.

Marxism, thus, is viewed as better than relativism because it at least allows for, and provides, a basis for ethical judgments.

\section{Disadvantage Theme \#3: The Permeability vs}

\section{Impermeability of Cultural Boundaries. Two authors'}

criticisms reflect this theme. Beattie argues that relativism draws fixed boundaries around cultures and requires a person to be wholly within the boundaries of one, or another, culture, to achieve understanding.

Understanding requires shifting cultures in order to shed cultural bias which prevents understanding. Beattie makes two arguments:

1. There must be some commonalities among cultures or communication could not happen at all. 
2. He says it is impossible for a person to completely shed a culture.

Beattie argues that whereas extreme epistemological relativism claims truth is relative, this cannot be wholly so, or we would be unable to bridge cultures at all (1984, 15).

Beattie presents relativism in the context of a discussion on understanding other cultures, in particular, in terms of understanding ideas and beliefs. He analyzes understanding in terms of facts, social actions, and conceptual systems. Cultural relativism is examined, and criticized in terms of conceptual systems--"what people think"--concepts, beizefs, meaning.

Unlike actions which one can see, ideas and beliefs must be inferred $(1934,10)$. The author asks two key questions about cross-cultural understanding of ideas and beliefs, one associatied with the term "epistomological relativism" and the other, with the term "cultural relativism." Since Beattie says these are simply different levels, both are included in this summary. He asks:

Can we say anything valid at all about the concepts and beliefs systems, symbolic or otherwise, current in cultures other than our own? ...Can the meanings...be adequately understood in 'our', that is in the anthropologist's, terms? or do they have to be understood entirely in their own contexts, that is relatively to other aspects of the cultures of which they are a part $(1984,14)$ ? 
"Epistemological relativism" addresses the question of whether there are "...totally different ways of thinking about, apprehending, experiencing, a logic of a different order from our own" (1984, 14). "Cultural relativism" refers to the using of "...categories particular to our own culture in attempting to understand those of other cultures" $(1984,14)$.

Beattie states that extreme relativism

(epistemological) "...appears to be claiming that truth is entirely relative to contezt" (1984, 15). Beattie counters this, stating that for commication to occur at all, some common assumptions must exist:

Truth and falsity, as qualities of statements about what is, cannot be wholly relative to the cultures or languages in which the statements are made. Even though there is room for discussion as to what the minimum of such indispensable shared assumptions might be, without the 'bridgehead' they provide we should all be inescapably constrained to cultural solipsism (1984, 15).

Extreme relativism creates a dilemma: there is no way to understand another culture without totally abandoning one's own, in order to avoid ethnocentrism. But, Beattie says, "..this is an impossibility, if only because the thought that we think can only be our thoughts, not 'theirs'" (1984, 17). The author argues that admittedly, our knowledge of another culture may be tainted by our own, but we can still learn something (1984, 17). 
Whereas extreme epistemological relativism postulates truth as exclusively culture-bound, cultural relativism involves abstaining from using our cultural categories for understanding. Again, the author presents extremists as saying we must abstain $(1984,18)$. The author, however, disputes this, saying that

...ethno- or sociocentricism is scarely avoidable, and certainly the problems posed by our ineluctable subjectivity are formidable.... The scholar who sets the search for truth above all other values can sometimes 'fight against his ideologies'. He may even win the battle, though, as we have seen, his victory is unlikely to be either clear-cut or complete $(1984,20)$.

Beattie clearly acknowledges relativism to a degree. But, he rejects an extreme form of relativism which, according to him, isolates cultures, excluding the possibility of crosscultural understanding because it excludes the possibility of assumptions common to all humans. According to Beattie, some commonalities which facilitate the bridging of cultures through communication must exist.

While extreme epistemological relativism requires the abandoning of one's culture to understand a different culture, Beattie argues that one cannot, in fact, do so. We are who we are. To this extent, our cultural boundaries are fixed (within us). This, however, does not prevent all understanding. We can understanding something, even if tainted with our cultural biases (Beattie 1984, 17). 
Dimen-schein offers two arguments regarding

boundaries. First, she says that fixed boundaries do not exist:

If there is no overt statement that cultures actually lack visible boundaries, it becomes possible to think of each culture as if it were a solid smooth ball, spinning off by itself, eternally the same. Such objectification prevents us from seeing that fieldwork initiates or continues a process in which two ways of life mutually change one another. The culture concept, as constructed, cannot encompass change and has therefore led us to misunderstand primitive societies as well as our own.

In this sense, the corcept of culture is not true to the real world of relationships whose character is processual, not static $(1977,51)$.

Hence, Dimen-schein is saying that "culture" is an arbitrary concept which has a limited function. Second, because there is no reality of separate cultures, the issue of "separate but equal" value systems versus the ranking of value systems would dissolve. Only "as long as each culture is kept separate and bounded in theory, each nation can be likewise seen as separate and ethicaliy accountable to no one but itself" $(1977,53)$.

Additional Disadvantages Cited in the Current Anthropology Literature

1. The Illogical Logic of Relativism. Three authors criticisms are encompassed by this theme--Kuttner, Hartung, and Nowell-smith. 


\section{a. Circular Reasoning}

Kuttner says that those who advocate an extreme relativism err "...by postulating a priori each system to be equally valid. This is in itself an ethical judgment, which relativism forbids us from doing" (1970, 223). Kuttner seems to take "equally valid" to mean "equally good." From this follows the equally erring prescription of "tolerance" which the author says means that "...it is just as valid to be intolerant as to be tolerant" $(1970,223)$. He indicates this is illogical.

Kuttner softens his criticism somewhat, saying that the inhibitions of extreme relativists about uttering ethical judgments "were washed away very rapidly when Fascist ideology expressed opinions not in harmony with the personal beliefs of liberal anthropologists and sociologists" $(1970,223)$. This change of position resulting from World war II is reflected, fortunately, in current texts which "..now make it clear that cultural relativity does not mean we should be indifferent to the quality of other ethical systems."

Unlike Kuttner, Hartung's criticism of the "flawed logic" of cultural relativism is not qualified at all. He says cultural relativism is ethnocentric and moral for it claims we should be "tolerant." Hartung says this statement is illogical because it itself is a moral statement. 
Hartung criticizes cultural relativism on two points:

1. It deprives us "of any rational grounds for the making of decisions" and,

2. "...its recent expositions, especially those formulated by anthropologists, are ethnocentrically and surreptitiously moral" (1954, 125).

He challenges the leap of logic from the "undeniable, obvious and trite fact of cultural variation" to the conclusion of cultural relativism, namely, in his view, "equal validity" of cultures and that "there is no possible intercultural standard for the evaluation of cultural variations" (1954, 120).

He notes that one can conclude from cultural variation that man can live under a variety of conditions. However, this does not mean all customs are equally valid, "even though each culture may think of itself as the best" (1954, 121). The author says that the injunction of tolerance of all cultural ways, inherent in relativism, is "...simply an ethnocentric extension of our own liberal tradition" (1954, 121). It is not based on scientific analysis "based upon a comparison of all cultures against a set of moral criteria equally applicable to all cultures" $(1954,121)$. It elevates the liberal view, saying it ought to be followed, and in this sense, it is ethnocentric.

Furthermore, that moral diversity exists does not mean that all moral systems are equally valid, nor that an 
intercultural standard might exist or be developed against which these differences can be judged (1954, 121-2):

This plea for tolerance of all customs makes ethical concepts, for the individual, completely a matter of personal taste and preference... Tolerance and equal validity also seem to imply that no moral concepts, regardless of their derivation, can possibly be given any logical or empirical authority over the conventions of any individual" $(1954,122)$.

Hartung, thus, argues that the logic of relativism is faulty.

Hartung, like Kuttner, also argues that "tolerance" is a suspect dimension of relativism, because:

The factual description of cultural variation is no basis for either tolerance or condemnation unless the moral relevance of this variation has been referred to a standard which applies to all (1954, 124)

Hartung concludes that not only does tolerance deprive us of "rational grounds for making choices and decisions," but it also affirms all ways of life as equally valid, even those which are intolerant. The relativist cannot logically insist that people be tolerant; this claim is instead itself an ethnocentric, moral judgment (1954, 125).

Turner also says that the reasoning of relativism is circular:

Cultural relativism has been attractive because of its supposedly value-free nature. On closer examination, however, the assertion that social science requires a value-free approach turns out to be itself a value judgment (1982, 77).

Turner says that some relativists talk about "higher 
values" such as self-determination:

..not one of the leading proponents of cultural relativism can be consistent on this point. Nor can anyone else, for the position ultimately leads to universalistic type statements, which are inconsistent with relativism $(1982,77)$.

Thus, those relativists who try to maintain their neutrality and also avoid justifying attrocities such as the consequences of Nazi Germany end up doing so by taking a values position.

\section{b. Faulty Linear Reasoning}

Nowell-Smith's basic argument is that cultural relativism is a confused collection of moral concepts, injunctions and prohibitions pertaining to intra and crosscultural judgment formation which is largely unsupportable. Cultural relativism"...is seldom set out in detail, still less defended by argument, it is difficult to discover precisely what the doctrine is, or even what sort of a doctrine it is..." $(1971,1)$.

Nowell-Smith identifies four propositions as the core of relativism and explores each, and the relationship of each, in detail. The following are examples of the arguments presented.

Proposition 1: "There are no absolute, universal moral rules or values; all rules and values are relative to something" (1971, 2). Nowel1-Smith makes two arguments against this. First, nowhere has it been shown that there 
are no rules people ought to adhere to even though, in practice, they do not adhere to them $(1971,3)$.

The second criticism argues that if one takes the position that rules appropriate for one culture may not be appropriate for another, one takes a utilitarian stance since 'appropriate' implies an end or purpose which the rule is supposed to serve. However, utilitarianism then becomes a universal basis for morality, for "the diversity of rules in different conditions presupposes a uniformity of ends such as health or survival" $(1971,3)$. But, relativism rejects that there is any such basis, and therefore, cannot consider the diversity of moral rules in terms of appropriateness.

Proposition 2: "The mores of a society are necessarily right for that society" (1971, 2). Nowell-Smith here argues that this proposition is unsupported because ...there are societies living in similar conditions but having different practices, so that it would be difficult to argue that each of them has the right practices. Secondly, there are some customs the appropriateness of which depends on belief in empirical falsehoods... (1971, 4).

Proposition 3: "One ought not to make cross-cultural moral or value judgments" $(1971,2)$.

Proposition 4: "One ought to conform to the mores of his society" $(1971,2)$.

Basically, Nowell-Smith says that since proposition 2 has been shown to be false, Propositions 3 and 4 which 
supposediy follow from it, are, therefore, also false (1971, 4).

In sum, Nowell-Smith finds relativism as it is usually presented, theoretically unacceptable. "This doctrine is more pernicious even than moral scepticism since, unlike scepticism, it can be put into practice" $(1971,16)$. Cultural relativism cannot logically serve as an alternative to making judgments. The fact of diversity does not logically lead to nonjudgmentalism.

2. Justification for Personal Acts. Dimen-Schein says that a problem of the use of relativism in the area of individual morality is that it fails to address the conditions of choices of individuals. Cultural relativism "contains moral and methodological premises about cultures; it is not a moral justification for individuals" $(1977,42)$. The use of relativism to justify individual acts is not effective because relativism addresses issues of cultures, not individuals $(1977,41)$. There is a confusion of levels (group/individual).

Hartung's criticism of cultural relativism as a personal moral justification has a different focus. He says relativism deprives us of rational grounds for making decisions. Society's ethics no longer have authority over the individual; ethical concepts become a matter of personal taste (Hartung, 122). Clearly, Hartung, finds this inadequate. 
3. Reality as a Discoverable Entity vs Reality as a Cultural construct. Jarvie's overall criticism is that "omni-tolerant relativism" takes away the possibilitiy of critical debate over questions of truth and morality which pertain to a discoverable reality. "Tolerance, to be rational, must be allied with criticism and debate (1975, 352).

First, Jarvie establishes that it appears that the problem of relativism is "thrust upon us by social and cultural, moral and cognitive diversity" $(1975,345)$. It appears to be

...a reaction peculiar to us [presumably 'westerners']...many traditional societies contain and cope with diversity without becoming open-minded, critical or tolerant, still less relativistic $(1975,345)$.

Furthermore, it appears to be not about cross-cultural facts, theories or morals per se, "but the criteria we bring to bear on substantive issues" $(1975,345)$. Relativism casts criteria as culture-specific, with no "...clear way to transcend localized views" $(1975,344)$. Jarvie argues:

If a statement is declared true in one culture and false in another, then either one culture is mistaken, or each one has a different criterion of truth, and such criteria cannot be ranked. $(1975,344)$

The relativist position involves, according to Jarvie, several problems. The first entails a confusion of knowledge and belief. Relativists focus on two questions, "What do we know?" and "How should we behave?" $(1975,346)$. 
"Because the questions are interpreted individualistically/ socially rather than transcendentally," the relativist sees answers only in terms of human beliefs and opinions (1975. 346) which are derived from and bound to "the culture which has nurtured us; they have, as it were, no possible jurisdiction beyond those cultural units" (1975, 345).

Jarvie says, however, that while, admittedly, people are caught in cultural and linguistic "nets," there is, nonetheless, a world "which is the way it is and not another way" $(1975,347)$. In other words, while people's answers may only approximate reality, all answers are not necessarily equally correct. For example, "localized mathematics, localized science and localized morality are simply not mathematics, science and morality in the sense we intend and to which we aspire" $(1975,347)$. Relativism errs because :

...knowledge is not a special state of belief any more than morality is a special kind of opinion. What we think of as moral or immoral is not on that account moral or immoral. Moreover, our view of what is moral or immoral may itself be judged true or false. This is not just a tricky piece of self-referring argument, but a decisive reason for not muddling belief and opinion, truth and goodness. Only because we can make these moves are we able to argue and debate the issues of truth and goodness $(1975,348)$.

Acknowledging the existence of a real world, even if our faculties can only approximate it, provides, through debate, a "basis for rational comparison" of differences, acknowledging "the diversity the relativist makes so much 
of," in the effort "to put them to the acid test" (1975, 348). Relativism, according to Jarvie, through its limiting view of context-bound beliefs, sidesteps debate, and the recognition of the discoverable world $(1975,351)$.

A second confusion is the "muddling up of social tolerance with epistemological tolerance." on the one hand, Jarvie says, relativists employ a double standard when tolerance for difference is accompanied by affirmation of multiple truths:

It is fine to be socially tolerant of other views and their holders; wretched to declare them equally true in their own way when they are nothing of the sort (e.g. one may be aimed at destroying the other). On the contrary, we have a sort of moral duty to engage in critical debate on serious issues, not to fudge them $(1975,350)$.

The crux of the problem is not the possibility of justification of value and cognition judgments. It is the exercising of critical debate about them. Jarvie's final criticism of relativism is that the adoption of

...the principle of universal charity towards all and all that they do and believe is condescension of the worst kind; it takes away the one feature which makes concrete the unity of mankind, viz., its shared rationality, its ability to engage in critical debate over questions of truth and morality $(1975,352)$.

Jarvie says ethnocentrism is unavoidable, but rather than a criticism, he sees this statement in concert with the relativistic view. "All human beings are products of their cultures, so will their answers be" $(1975,346)$. However, 
he says because there is a real world, we can discover it (1975, 351).

Cultural relativism fails to be a practical concept. "No one can actually live by it leven anthropologists--for if they do they become amoral)" $(1975,348)$. He charges that the "passion with which it is preached, especially ethically" is the indication that it cannot be lived out $(1975,348)$.

3. Particularism ys Universalism. Two authors' works reflect this theme, Clark (1970) and Turner (1982).

Clark's fundamental criticism of cultural relativism is that it is not appropriate for a discipline which seeks to have a scientific base (i.e., a means for generalizing). He defines relativism in terms of contextualism, and argues that because "terms cannot be applied, salva veritate, to different societies, then not even cross-cultural descriptions can be generated, let alone general laws" $(1970,545)$. This is not conducive to a "science of culture".

The purpose of Clark's discussion is not to argue the problems of relativism, per se. His overall argument is against the usefulness of two types of criteria, "basic needs" and "basic problems," which have been set forth as the accepted basis for establishing general, universal laws about cultures. However, in anthropology, 
tendency to reject the once popular set of theories and beliefs associated with the name of 'relativism' (1970, 545).

While clark disagrees with two of the attempts in current theory to find "the underlying similarities of superficially different cultures" (1970, 545)) for the purpose of making cross-cultural descriptions and identifying general laws, neither does he offer an alternative. But, it is clear that he concurs with the move away from relativism as a necessary requirement for the development of theory within a "science of culture."

Turner argues that the contextualism of cultural relativism is manifested, among applied anthropologists, as a "live and let live" credo which "when applied to behavior that has global ecological implications, is becoming increasingly anachronistic in a world of limited resources" (1982, 79). The particularism of relativism needs to be replaced by a more effective, anthropological, value position which has a broader basis such as a universal ecosystem.

Turner views anthropologists as "social engineers" who help develop standards for cultural evaluation and change $(1982,77)$. He rejects the relativist position which, in perceiving cultural evaluation as only appropriate in terms of that culture's beliefs and practices, restricts outsiders from criticizing the goals of that culture $(1982,76)$. 
Furthermore, relativism, "...instead of making it possible for someone to escape ethnocentrism, may only involve exchanging one kind of ethnocentrism for another kind" $(1982,77)$. He argues that the practice of anthropologists becoming cultural insiders to shed the "ethnocentric viewpoint of outsiders" merely means taking on the ethnocentrism of that culture and thus, bound within a particularistic framework.

4. Reverse Ethnocentrism. "Reverse ethnocentrism" refers to the negative evaluation of one's own culture, and the positive evaluation of other cultures (Bennett, 1986 , 28). It aptly describes the criticisms rendered by three authors, Turner (1982), Hippler (1981), and Stein (1986). Anthropology has made, Turner states, ...important contributions to the development of universalism in many areas, but thus far it has made little progress toward universalism in values. The lack of progress has not been due so much to an absence of alternatives as to a distate for dealing with value judgments, particularly its own (1982, 78).

Turner says anthropologists "romanticize non-Western cultures while criticizing the industrial ones from which anthropologists come" (1982, 77). With the exception of using cultural relativism "for initial fieldwork among a group of people," Turner warns that cultural relativism can lead to serious "unresolvable difficulties" for the anthropologist $(1982,76)$. 
Similarily, relativists practice, Hippler says,

...a kind of nonrelativistic relativism where anything and everything done in or by some nonWestern culture is viewed as good or at least neutral with clear judgmental and nonrelativistic emphasis, and everything done in or by Western society is seen as bad. That is, we have come to say, "all cultures are equal, except for Euro-American ones which are inferior and evil" (1981, 394).

However, according to Hippler, the truth is generally the reverse situation:

...Euro-American culture is vastly superior in its flexibility, tolerance for variety, scientific thought, and interest in ernergent possibilities to any primitive society extant. (1981, 395)

The many repeated tests based on Piaget's observations, Hippler writes, support the higher growth and maturation of Euro-American societies.

He says relativists have tremendous anxiety of such results, fearing, he says, misuse of them for the support of "racist theories or as excuses for oppression" (1981, 395). To ignore the importance of exploring questions of human potential is not, Hippler says, objective or useful (1981, 396).

Stein also refers to the role anxiety plays in an extensive critique. He lambasts cultural relativism with the argument that relativism serves a psychological role for anthropologists, one which buffers them from anxiety:

As an anxiety-reducing ideology, relativism holds that no universal common denominators can be found, thereby preventing any increase in anxiety.... Relativism has thus grown to be 
anthropology's paramount defense against arriving at an understanding of its subject matter while purporting to be doing so. only as the self-mystifying shroud of relativism is lifted and dispelled can truth about man be pursued $(1986,174)$.

In studying and "tolerating" other cultures,

anthropologists are experiencing wish fulfillment of aspects of themselves which are not safe to express in their own "modern" societies $(1986,171)$.

The escape from anxiety is achieved through reverse ethnocentrism. Stein describes three different situations in which relativists positively evaluate other cultures, and negatively evaluate their own.

The first pertains to the transformation of quilt feelings about Western ethnocentrism and scientific imperialism:

Among relativists, guilt feelings are transformed via projection into accusation of others who are ethnocentric. At a more primitive level, the relativist symbolizes his inner splits through a dualistic system that portrays the modern west as evil and the primitive as innocent $(1986,169)$.

The second involves status anxiety:

The pluralistic world of the primitive becomes the idyllic world of ascribed status (officially at least) dominates modern western life.... In the projectively constitutive "family of man," all become equal siblings where there is no rivalry, no parental favoritism or neglect....The primitive becomes the ideal self...one that will always mirror the anthropologist's specialness $(1986,164)$. 
The third situation is that of separation anxiety:

The idealization of the past, the celebration of tribal wholeness, and the nostalgia for lost cohesion (projectively identified with the "primitive," are distinctive features of doctrinal relativism $(1986,172)$.

Anthropologists use relativism as a way of addressing the experience of "emotional separation from their family of origin" $(1986,172)$.

Stein describes the relativist as devaluing western culture and prizing "primitive culture" through the doctrine of relativism to solve these "anxieties."

CHAPTER SUMMARY

The current anthropology works reviewed for this study were found to vary as to definitions, applications, advantages and disadvantages of cultural relativism.

\section{Definitions}

Three of the four intercultural communication themes were found, as well as two additional definitions. Definitional Theme \#2 (Equal Validity of Cultures) encompassed two works, and Theme \#3 (Attitudes Toward Difference) and Theme 4 (Contextualism) each encompassed three works. Two additional definitions were found which were not encompassed by the intercultural themes: "The Contingency of Customs and Values" and "Relativism as a plurality of Concepts." 
It is interesting that two of the authors (Beattie and Kuttner) indicate that relativism is a continuum of greater and lesser degrees of relativism. The other eight authors seem to refer to relativism as a single conceptual entity.

\section{Applications}

In examining the discussions of the viability of cultural relativism, six works were found to focus on explaining why it is not viable, and four describe the conditions in which relativism could be considered not viable, and the limitations within which it could be seen as useful.

\section{Advantages}

of those works which outline limited uses, three authors refer to relativism as beneficial as a reminder of cultural bias. Two works refer to the usefulness of cultural relativism as a method.

\section{Disadvantages}

The review of these ten anthropological works generated a wide range of criticisms of cultural relativism. The limitations of this study prevented a comprehensive search of all the anthropological literature for a complete accounting of all the different criticisms, and the number of anthropologists which rally behind each. However, the criticisms include here are representative of the general critical trend. 
This trend seems to include criticisms of every manifestation of cultural relativism in human behavior. Cultural relativism is not seen as having just problems of logic, or a weakness in one of its concepts. The perceived problems are conceptual, attitudinal, methodological and moral. In other words, relativism has been criticized as a thought construct, as an attitude, as an action-process, and as an action having implications in a social context.

The conceptual difficulties identified include dispute over the definition of "reality" (it is argued that it is a discoverable entity, as opposed to a humanly created one), and the definition of the concept of "culture" (i.e., what are the boundaries of culture and how do they affect our theories).

An even deeper, more fundamental conceptual challenge to the logic of relativism points to the heart of the structure of cultural relatvism as unsound. Both circular reasoning and faulty linear reasoning are given as arguments against its viability.

In turn, some authors use the faulty logic point to argue that the attitude of "tolerance," one of the key goals of relativism for some, is a questionable goal. Authors also criticize relativists for allegedly negatively evaluating their own cultures while positively evaluating other cultures. 
The methods which result from the thought and attitudes of the relativists are challenged on several fronts. One is that relativism is lacking as a method because it does not allow for the ranking of cultures, or the establishing of evaluative criteria with which to compare and rank information. Relativists are also seen as failing to universalize which, it is argued, is necessary for the methodology of a science.

A number of the critical issues brought out by the authors focus on the problems of cultural relativism as a moral philosophy. Some authors negate cultural relativism entirely on this basis. Others describe cultural relativism as valid as a conceptual tool, but not as a moral guide.

The criticisms in anthropology have generated a lively debate. Works supporting cultural relativism, as well as ones which specifically rebutt the criticisms of cultural relativism, are prevalent in the anthropological literature. Though a discussion of these remain outside the scope of this particular study, the reader is referred to the following for a view into the other side of the debate: Bidney (1979), Bose (1969), Bourdillon (1986), Geertz (1984), Hanson and Martin (1973), Jimenez (1981), Neki (1976), Opler (1968), Pastner (1982), Reser (1981; 1982) and Taylor (1969). 
These authors, supportive of cultural relativism, reflect a cultural range. Bose and Neki are connected with professional institutions in India; Bourdillon teaches at the University of Zimbabwe; Jimenez is published in a journal from Poland, Reser is connected with the University of Queensland, and Bidney, Geertz, Hanson and Martin, Opler, Pastner, and Taylor are connected with American academic institutions. 
CHAPTER V

\section{SUMMARY AND CONCLUSIONS}

This chapter examines the intercultural communication data in light of the findings pertaining to cultural relativism obtained from the early and current anthropology literature. Explanations for various correlations and discrepancies between the literature groups are offered and, where relevent, there is discussion as to how the different fields of study might assist one another in addressing various issues.

The format for presenting the conclusions of this study is consistent with the previous chapters. Observations and issues are addressed in relation to each respective category (definitions, applications, advantages and disadvantages), and organized by theme. Each point discussed focuses on how the intercultural literature compares to the early and current anthropology literature, and includes a brief discussion of the possible reasons for the concurrences, or lack, thereof.

A visual, multi-dimensional profile of all of the data is presented in Table I. Table II, which immediately follows Table I, provides the coding key for the various works from 


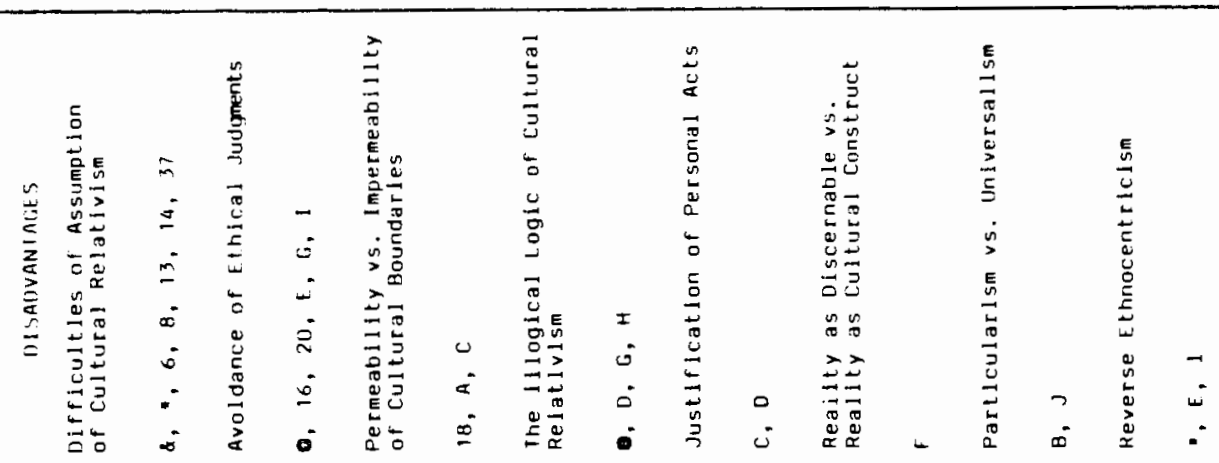

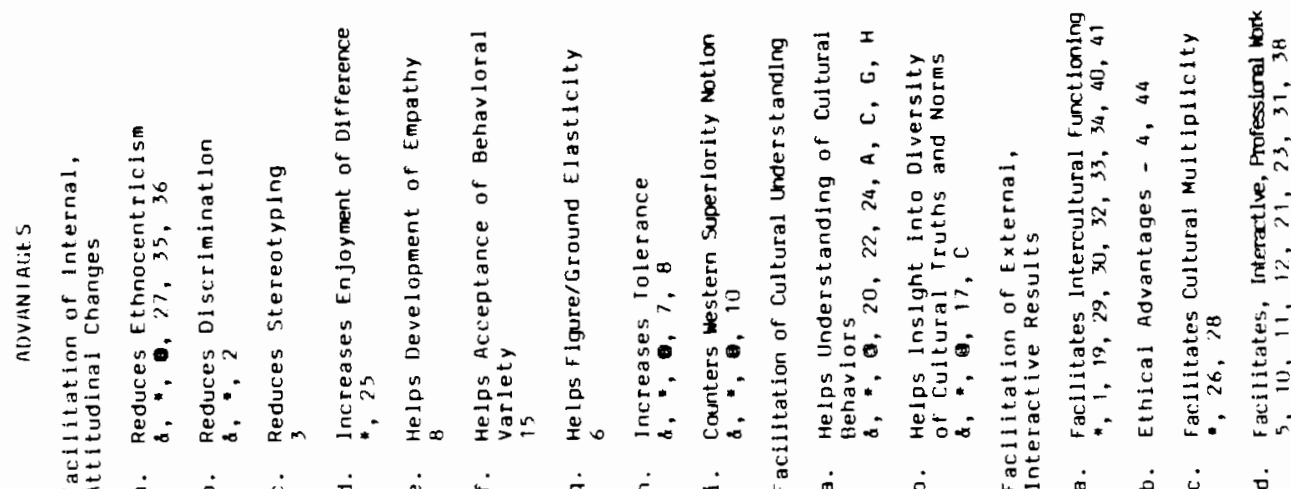

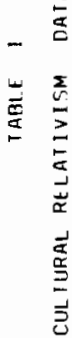

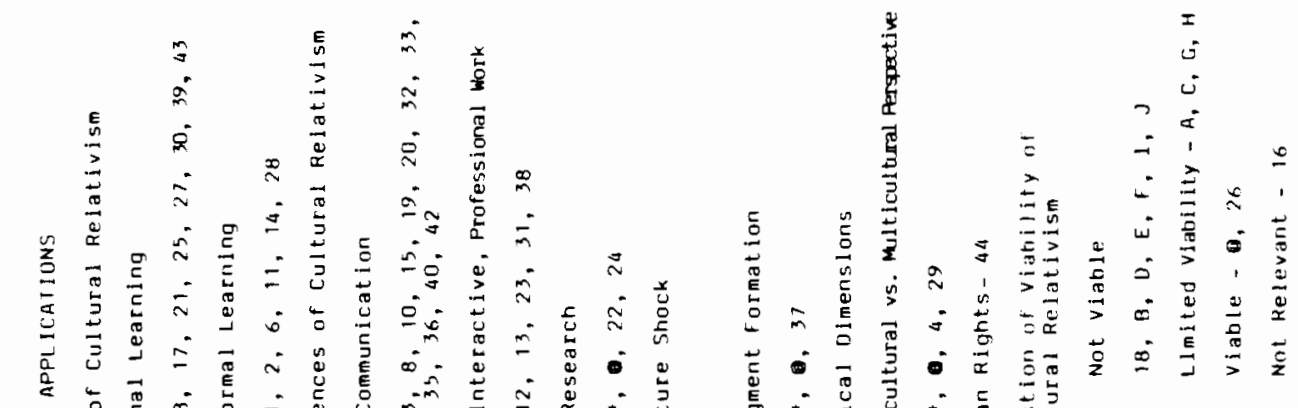

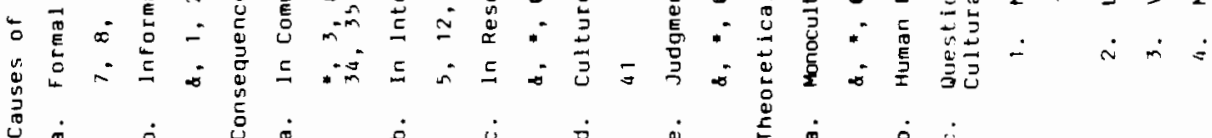

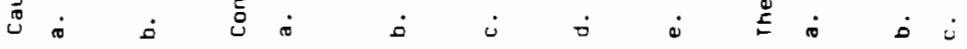

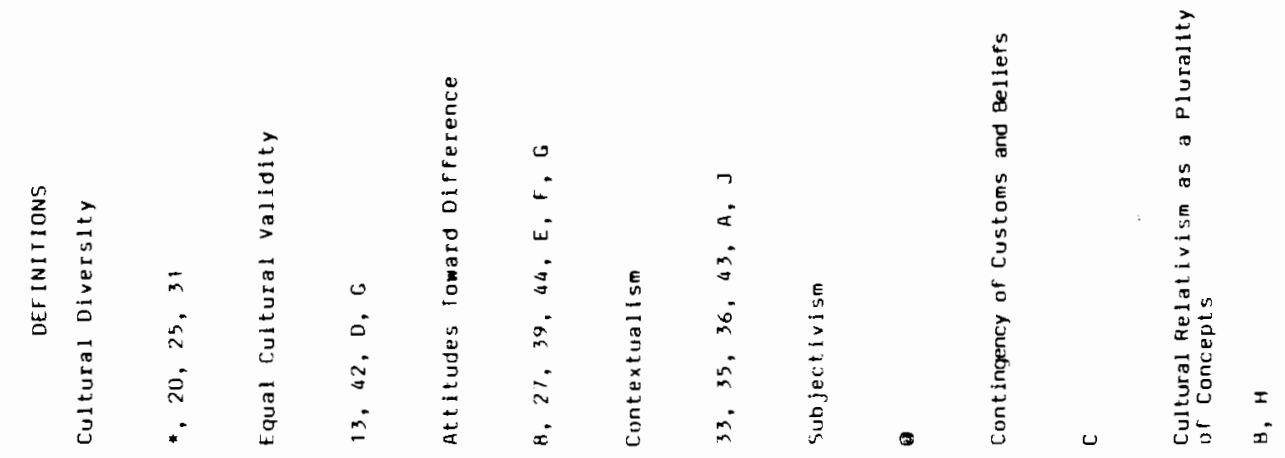




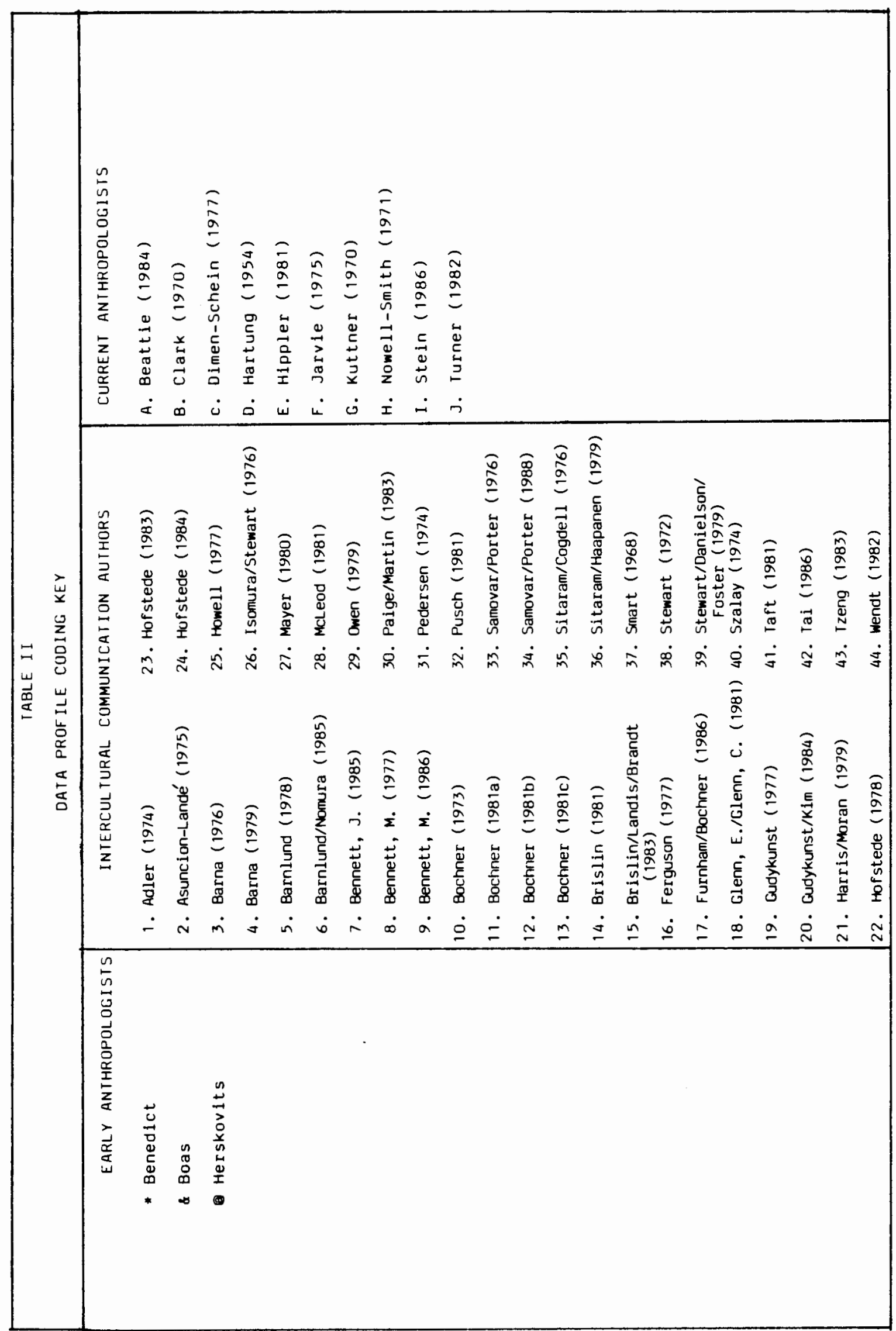


which the data was obtained. Thus, for example, references in Table I to Ruth Benedict's writing are represented by a "*" (see column 1 of Table II), and the symbol "20" in Table I refers to Gudykunst and Kim (1984) (see column 2 of Table II).

The profile graphically portrays the thematic framework generated from the intercultural communication literature and is used, in this study, to organize the data in all three literature groups. The items of data in the early and current anthropology literature which were found to fall outside this framework have been listed in the profile as well for comparative purposes. Definiton \#5 is from the early anthropology literature, as is Disadvantage \#8. Definitions \#6 and 7, and disadvantages \#4-7, are from the current anthropology literature.

\section{DEFINITIONS}

\section{Overview}

One of the most striking findings of this study is the number of different definitions of cultural relativism found in the all of the literature reviewed. Definitions were found to be stated in all of the current anthropology literature reviewed whereas only a small percentage of the intercultural communication authors provided definitions. In the early anthropology literature, two of the three "founders" of cultural relativism in anthropology had 
different definitions. The third early anthropology author, Boas, who has been acclaimed as the earliest proponent of relativism in anthropology, was found to not even use the term "cultural relativism."

\section{Discussion of the Findings}

Definitional Theme \#1: Cultural Diversity. Of the three early anthropologists, only Benedict (1934) explicitly defines cultural relativism as "Cultural Diversity". None of the current anthropologists state this definition, but it was found in three of the intercultural communication works.

Benedict's choice of definition likely reflects the focus of her application of cultural relativism. Much of her work was devoted to making people aware of the different consequences of positive and negative evaluation of cultural differences. The pressing need she felt for the "consciousness raising" regarding cultural diversity stemmed from the extent to which she perceived Euro-American cultures exercising their power based on erroneous, ethnocentric premises about cultures.

This definition is probably absent from the current anthropology literature reviewed for this study because cultural diversity has been so fully incorporated into the current anthropology theory (very likely thanks to Benedict), that it is no longer seen as having significant conceptual use. Perhaps, also, in contrast to Benedict, anthropologists assume the concept is prevalent in the world 
at large, or, if not, they may not see the role of anthropologists as one of doing "consciousness raising" of the public.

of the percentage of intercultural communication authors who actually defined cultural relativism, one-fourth use the definition of "cultural diversity." This may reflect a theoretical inheritance from Benedict. It also may reflect an emphasis on drawing attention to diversity. Much of the work in intercultural communication is devoted to helping people adjust to and understand different cultures. One of the major barriers identified in the intercultural communication literature is the degree to which people seem to lack an awareness, and understanding, of cultural differences.

\section{Definitional Theme \#2: Equal Cultural Validity. A} second definition found for cultural relativism, "Equal Cultural Validity," presents somewhat of a historical puzzle. Not one of the three early anthropologists espouse this concept, either as a definition for cultural relativism or as a theoretical assumption. Yet, two of the current anthropology authors and two of the intercultural communication authors present this definition.

It is very possible that several concepts in the early literature have been misinterpreted, in particular, Benedict's discussions of cultures as human constructions, all equally possible, and therefore, having no inherent good 
or bad qualities. This is rot the same as saying that all cultures are "equally valid", in other words, "equally good," a concept Benedict would undoubtedly have disputed. Indeed, she describes how people have to critically examine their cultures and advocate changes when directions taken by cultures are seen as harmful for mankind. Her emphasis is that people have the potential to choose and influence directions for their cultures, and rather than going along with the status quo, should actively do so.

Definitional Thene \#3: Attitudes Toward Difference. A

large percentage of both the current anthropology and the intercultural communication authors' definitions were encompassed by definitional Theme\#3. Again, no definitional concurrence exists with the early anthropologists. However, unlike definitional Theme \#2, this concept is present in their works. This connection may well reflect an indirect historical connection between the theory of the early anthropologists and more recent views on cultural relativism.

"Attitudes Toward Difference" certainly reflects the intercultural communication focus on communication interaction, and the role that internal attitudes have upon communication behaviors and experiences. The intercultural communication emphasis is on a person's construal and evaluation of cultural "differences." The more a person can perceive, and accept (though not necessarily like) cultural 
differences, the more successful will be his or her intercultural communication experiences.

The three current anthropologists do not develop this definitional theme in terms of an internal, attitudinal process which influences interactions. Rather, they refer to it as a stance of non-judgment toward cultural phenomena. In one case, it is considered judgmental restraint; in two others, it is a statement of the absence of standards which makes one unable to judge.

The difference in orientation between the intercultural communication and current anthropology definitions reflects the emphases of the two respective disciplines. The former is more concerned with facilitating intercultural interactions, and the latter focuses, instead, on evaluating, comparing and ranking information.

\section{Definitional Theme \#4: Contextualism. This}

definitional theme, like theme \#3, also is present as a concept in the early anthropology literature, but not utilized as a definition by any of the three authors reviewed for this study. Thus, it too, indicates possible a possible theoretical, historical link.

Four of the intercultural communication authors' definitions are encompassed by this theme. Two refer to the study of values in terms of the respective culture's context. One focuses specifically on concepts of right, wrong, and truth as meaningful only if considered 
contextually. One takes a broader view, and says concepts in general need to be understood contextually.

The definitions of the two current anthropologists are somewhat different. One says it means not using our own conceptual framework to understand the categories, classifications and thoughts of another culture. While this is implicit in the intercultural definitions, it reflects the author's concern with personal restraint pertaining to intellectual processes.

The second anthropologist's definition refers to relativism as the viewing of cultures as unique, unified wholes, thus underscoring the author's view of relativism as emphasizing the self-contained aspect of individual cultures.

The difference between the definitions of the two literature groups seems to reflect, again, the intentions of the authors. While the intercultural communication authors are concerned with the information results achieved from contextualization, the two current anthropologists emphasize two different premises upon which they perceive relativism to be based - personal restraint and the characteristic of cultures as self-contained wholes. Each of these premises, in turn, becomes the object of each anthropologists' criticism.

Additional Definitions from the Anthropology Literature. Three, current anthropology definitions did not 
coincide with the intercultural communication themes. However, the concepts of two of the three can be found throughout the early anthropology and intercultural communication literature. These are the definitions of "Subjectivism" and "Contingency of Customs and Beliefs."

Perhaps the reason Herskovits' definition of "Subjectivism" (1948) is not found in the intercultural communication area is that subjectivism is very likely considered, now, as obvious and, therefore, seen as failing to provide substantive theoretical direction where previously it represented new conceptual ground.

"The Contingency of Customs and Beliefs" seems to serve as a basic assumption in the writings of the early anthropologists and the intercultural communication authors. It is difficult to say why the idea of the ever-changing, human creations of "cultures" has not been not used in these areas as a definition. Perhaps, it represents too great a conceptual leap for the uninitiated. Or, the early anthropology authors and intercultural communication authors may have found it more important to their work to draw attention, through their definitions, to the fundamental concepts underlying this definition.

The third additional definition in the current anthropology, "Cultural Relativism as a Plurality of Concepts," is not present at all in either the early anthropology or intercultural communication literature 
probably because people were, and are, not aware of the confusion of the term. But the concern with the plurality of concepts now connected with cultural relativism brings to the fore the need for clarification.

\section{APPLICATIONS}

\section{Overview}

Two significant findings occurred from the examination of the applications of cultural relativism in the three literature groups. First, many similarities were found between the early anthropology literature and that of intercultural communication. Second, the criticism focus of the current anthropology literature was found to barely exist in the early anthropology and intercultural communication literature.

The extent to which the current anthropology criticisms reflect anthropology as a whole cannot be determined, because the works reviewed for this study were intentionally chosen for their critical viewpoint. However, the ease with which critical works could be found among the current anthropology literature indicates that cultural relativism is a significant issue in anthropology.

In contrast, the lack of critical focus in the other two literature groups indicates a lack of critical concern regarding cultural relativism. There seems to be, instead, overwhelming and unquestioning support in the early 
anthropology and intercultural communication literature for cultural relativism. The possible reasons for this discrepancy are discussed in the "Theme \#3" section to follow (Theoretical Dimensions).

\section{Discussion of the Findings}

Application Theme \#1: Causes of cultural Relativism. One-third of the intercultural communication authors refer to cultural relativism in terms of how it could be acquired or further developed. This large percentage of authors indicates the perceived significance of cultural relativism for the intercultural communication process.

of the early anthropologists, only Boas describes the process involved in acquiring cultural relativism. Neither Benedict nor Herskovits address this theme, probably because their definitions refer to relativism as pre-existing states which cannot be "caused" (cultural diversity and subjectivism).

None of the current anthropologists refer to this theme. Perhaps, this is because their focus is to discuss what is wrong with cultural relativism, not what causes it.

Application Theme \#2: Consequences of Cultural Relativism. None of the current anthropologists directly discuss the consequences of cultural relativism. The few consequences that were referred to as advantages are considered in the following section. The primary purpose of the current anthropology articles is not to address the 
consequences of relativism but rather, to describe the theoretical issue of whether or not the concept is even viable in, and of, itself (Theme \#3).

Most of the intercultural communication authors and all of the early anthropology authors do discuss consequences. Not surprisingly, most of the intercultural communication discussions pertain to the topic of consequences in communication. Of the three early anthropologists. Benedict refers to communication in a general way, in her references to improved social relations. Whereas Boas and Herskovits describe benefits for theory and research methodology, Benedict emphasizes the influence of cultural relativism in interactive situations.

None of the early anthropologists discuss interactive professional work whereas six of the intercultural communication authors do. This may reflect the fact that the use of cultural relativism in interactive situations wasn't specifically addressed in professional work until the intercultural communication area developed.

The discussion of research is the primary application of cultural relativism in the early anthropology works, reflecting the research emphasis of the field. Although one would expect a research emphasis in intercultural communication, only a few works were found to discuss cultural relativism in terms of research. This may be a serious lack in the literature, and one which should be 
addressed. Perhaps, because most intercultural communication authors see cultural relativism as having an interactive role, they do not feel it has a research role. However, this is unlikely, given that communication researchers can hardly avoid human interaction.

A connection between cultural relativism and culture shock is described by only one intercultural communication author. This may suggest an application of cultural relativism that could be further explored in the intercultural communication field. Or, perhaps other intercultural authors have rejected this application. From the literature reviewed, this is difficult to determine. The absence of this topic from the anthropology references again suggests the difference in focus between the two fields. However, given the fact that anthropologists do live in different cultures, and interact with people from those cultures, the experience of culture shock is probably not uncommon amongst anthropologists. Therefore, implications of cultural relativism for culture shock may be an important topic for anthropologists to explore further.

The final application topic which emerged in this theme, the role of cultural relativism in judgment formation, was a central topic to all of the early anthropologists. Only one intercultural author addresses this topic, and none of the current anthropologists do. 
Why does only one intercultural communication author see cultural relativism as integral to judgment formation, while no others (in the study) elaborate on this? Judgments in intercultural communication situations are perhaps referred to most frequently in references on "ethical relativism". Though some of these appear identical to some of the cultural relativism references, they were not included in this work because the focus here was to delineate "cultural relativism." The topic of ethical relativism remains for another study.

Application Theme \#3: Theoretical Dimensions. The three early anthropologists dedicated much of their work to describing how cultural relativism influences the theoretical base of anthropology and what methodological implications result. One of the characteristic features of their approach was their emphasis on taking other cultural perspectives into account at the point at which anthropologists sought to determine the meaning of cultural behaviors.

This approach is typical of intercultural communication methodology as well. However, two of the intercultural communication authors advocate a more extensive integration of multiculturalism in intercultural communication theory. They use cultural relativism as the basis for their arguments in advocating that communication theory must itself become pluralistic in its criteria. The 
occurrence of this topic in both the early anthropology and intercultural communication literature suggest possible historical connections in their views on theory.

The use of cultural relativism to develop a multicultural base for theory is not an application in the current anthropology literature reviewed for this study. The focus of each selection reviewed for this study is to point out what's wrong with cultural relativism. It would be interesting, however, to find out if some of the anthropological literature not reviewed in this study discuss this topic, to determine if there are any parallels between the intercultural commuication area and current anthropology regarding a need for a multicultural theoretical base.

One intercultural comminication author uses cultural relativism in intercultural commication as a theoretical justification for his human rights arguments. While the idea of the dignity of all humankind is pervasive throughout both Boas' and Benedict's works, they did not specifically address human rights. They did refer to problems they perceived as resulting from imperialism, but not in terms of human rights.

However, the early anthropologists' use of cultural relativism as a reason for changing attitudes toward cultural differences is very like the basis for some of the human rights discussions today (e.g., Annaim 1987; Donnely 
1984; 1985). It is difficult to say whether or not Boas or Benedict would have agreed with this application. Further research would need to be done to see if some of the anthropologists who advocate the use of anthropology for social change also write about human rights and cultural relativism.

The viability of cultural relativism, the final topic which emerged among the application themes, was the primary focus of all of the current anthropology articles (by design of the study), and the focus of only a few of the intercultural commuication and early anthropology authors. The ease with which the current anthropology works could be found suggests that cultural relativism is a significant issue in anthropology. Conversely, the almost complete lack of discussions on relativism in the early anthropology and intercultural communication literature suggests a high degree of acceptance of, or at least nonconcern with, cultural relativism.

The liveliness of the debate on relativism in anthropology today poses the question of whether, perhaps, there shouldn't be some critical query in intercultural communication. It is possible that because the different areas have different goals, cultural relativism may be useful in one area, and not the other. For example, comparison and ranking of data is done in anthropology, but not in intercultural communication which focuses primarily 
on the description and facilitation of intercultural commication interactions. As revealed in an examination of the various criticisms on cultural relativism in the current anthropology literature, some authors see cultural relativism as impeding the goal of comparing and ranking data. In contrast, almost all the intercultural communication authors see cultural relativism as important in facilitating intercultural communication interactions. According to this line of thinking, anthropology has one use, intercultural comunication another.

However, the case is not so clear cut because anthropologists do engage in intercultural interactions. Thus, the question faces them as to whether cultural relativism is indeed important for assisting these interactions.

Three intercultural communication works contain very brief references to the viability of cultural relativism. One says it is irrelevent to culture study because approval of all cultures is not the goal of culture learning. Other intercultural communication authors may agree, but this could not be determined from this study because of the dearth of elaboration of views on cultural relativism. This argument is present among the current anthropology criticisms, however.

One intercultural communication author says that relativism was useful when cultural boundaries were 
distinct, but lost its usefulness when cultures in the modern world became so interconnected. This idea is further pursued in the discussion of disadvantage Theme \#3 which follows.

Herskovits is the only early anthropology author who makes a point of discussing the viability of cultural relativism. He is the only author among the early anthropology and intercultural communication authors who acknowledges in his writing that critical debate over cultural relativism exists. Though outside the scope of this study, an examination of how his arguments fit into the debate in anthropology might help initiate some discussion about cultural relativism in intercultural communication.

\section{ADVANTAGES}

\section{Overview}

The advantages of cultural relativism perceived by the intercultural communication authors ranged from internal benefits comprised largely of greater openess toward, and tolerance of, cultural differences, the facilitation of more accurate, less biased, knowledge about culture, and actual interactive results in the form of improved communication and the support of culture difference.

The early anthropologists addressed these same themes as well, although their emphasis was on how cultural relativism helps facilitate more accurate cultural knowledge 
and how it helps curb bias in research. The Eew advantages cited in the current anthropology literature reviewed for this study do not refer to internal or interactive results. Like the early anthropologists, they reflect a research orientation, emphasizing the curbing of bias and certain methodological applications.

\section{Discussion of the Findings}

\section{Advantage Theme \#1: Facilitation of Internal,}

Attitudinal Changes. The attitudinal changes resulting from cultural relativism which were found in the intercultural communication literature are varied and include the reduction of ethnocentrism, discrimination and stereotyping, the increase of the enjoyment of difference, the increase of empathy, an improved ability to accept behavioral variety and to shift figure/ground concepts, the increase of tolerance, and the negating of the notion of Western superiority.

Some of these changes perceived as resulting from cultural relativism are described in the early anthropology 1iterature. Others, such as stereotyping, empathy and figure/ground elasticity, are not discussed in the early anthropology literature in relation to cultural relativity. The broader range of results identified in the intercultural 1iterature may reflect later theoretical developments.

The topics found in Herskovits' writing are fewer still, probably because his focus is research, not human 
relations. Thus, for example, he does not refer specifically to discrimination, whereas Boas and Benedict do.

Advantage Theme \#2: Facilitation of Cultural knowledge and Understanding. All of the early anthropology authors, three of the intercultural communication authors, and one of the current anthropology authors cite cultural relativism as necessary for the understanding of cultural behaviors. It is interesting that all of the early anthropology authors see cultural relativism as central to cultural understanding. This, again, seems to stem from their commitment to cultural relativism and its usefulness. Of course, since most of the current anthropolgists included in this study negate cultural relativism altogether, their lack of reinforcement on this advantage is understandable. However, it is difficult to determine why there are so few references to this topic in intercultural communication. It may be that this advantage is assumed as obvious, or it may reflect inadequate discussion of cultural relativism on the part of most intercultural communication authors.

The one current anthropologist who was found to agree with this advantage suggests the heuristic potential of cultural relativism for generating questions which arise because of a multiplistic outlook. This helps the understanding of cultural behaviors because it helps draw 
attention to certain questions which then influence the direction of study.

A second topic pertaining to cultural understanding also received scant attention from the intercultural communication and current anthropology literature, but was fully embraced in the early anthropology literature. This topic, pertaining to insight into diversity of cultural truths and norms, differs from the understanding of cultural behaviors in its focus on a culture's views of reality and morality. All of the early anthropology authors saw cultural relativism as facilitating this insight. Only one author in each of the other literature groups referred to this advantage. Perhaps this reflects a prevailing attitude today that these are obvious to perceive, and not in need of attention in the literature. Or, perhaps most of the authors in these two groups perceive truth and morality as not varying from culture to culture. It seems likely that the answer lies somewhere in between these speculations, but a more definitive answer would require more research into the views of both literature groups.

\section{Advantage Theme \#3: Facilitation of External,}

Interactive Results. Most of the intercultural communication authors refer to one or more topics pertaining to this theme. Only one early anthropologist describes this advantage. None of the current anthropologists do. This distribution, no doubt, results from the different emphases 
of anthropology and intercultural communication. However, because anthropologists do engage in face-to-face intercultural interactions, the area of intercultural communication may have an approach involving cultural relativism which could be beneficial to anthropologists. However, given the cursory treatment of cultural relativism in the intercultural literature, more elaboration of their views on cultural relativism is needed for the consideration and possible benefit of other social scientists.

\section{DISADVANTAGES}

\section{Overview}

Three disadvantage themes were found in the intercultural communication literature. Only the first was found to have much support from the intercultural communication and early anthropology literature. One additional disadvantage was cited in the early anthropology literature and four were found in the current anthropology literature.

\section{Discussion of the Findings}

The comparison of the data from each of the literature groups pertaining to the disadvantages is presented under each of the respective headings.

Disadvantage Theme \#1: Difficulties of Assumption of Cultural Relativism. As can be seen in Table 1, there is support in the early anthropology literature for the 
intercultural communication disadvantage theme \#1 which describes the difficulty of becoming relativistic. This thematic correlation between the intercultural communication authors and the early anthropologists again suggests a similar theoretical orientation between these two literature groups. For example, authors in both groups point to the tenacity of the enculturation process and the difficulty of shedding one's ethnocentrism, as impediments to assuming cultural relativism.

Benedict (1934) talks about the fear of difference as one of the emotional factors behind ethnocentrism and how, in contrast, appreciation of cultural differences helps one be more tolerant. In the intercultural communication literature, Bennett (1986) also discusses this. By means of his model of intercultural sensitivity, he describes different levels of acceptance of cultural differences which people can experience. He, and most (but not all) of the intercultural authors base their approach for reducing ethnocentrism on the idea of increasing awareness of, and tolerance for, cultural differences. Bennett, like Benedict, says that, in contrast to ethnocentrism, cultural relativism involves a positive attitude toward differences. This use of the word "positive" refers to a comfortableness with, and, therefore, a lack of fear of, the experience of "difference." (A negative attitude, according to these two authors, would involve Eear of difference.) This contrasts 
with the evaluative interpretation of "positive" which results in the idea that "differences" must be perceived as "good."

The current anthropologists do not refer to this theme of "difficulty of assumption" at all. This may be partly because six of the ten authors, using different criticisms, declare cultural relativism nonviable altogether. of the four authors who qualify their criticisms with descriptions of limited forms of relativism which might be viable, none are concerned with the process of how relativism is acquired. Hence, they don't discuss any difficulties associated with acquiring relativism.

This is another example of where perspectives from intercultural communication on cultural relativism might be fruitful for current anthropologists, by providing an understanding of how people develop more positive attitudes toward difference. However, this perspective from intercultural communication would be useful for only some of the anthropologists who support relativism. As demonstrated by the current anthropology authors included in this study, discrepancies exist as to what is meant by cultural relativism. Thus, a process-oriented, intercultural communication perspective might not be helpful for anthropologists (or intercultural communication people) who define relativism as "contextualism." As discussed in the intercultural communication definitions, "contextualism" as 
a definition of cultural relativism is not an attitude; it is a method of obtaining information. Reducing fear of differences would not necessarily help anthropologists become culturally relativistic if they perceived relativism to be the examination of cultural behaviors and values in terms of cultural context.

Disadvantage Theme \#2: The Avoidance of Ethical

Judgments. The second theme of "The Avoidance of Ethical Judgments" was not found in any of the early anthropological Iiterature. In fact, all three authors support judgment. Both Boas and Benedict refer to the need for culture change. They see anthropologists as instrumental in providing a data base on which "beneficial" judgments could be made.

Boas (1962), with his orientation for thorough data collection, advocates social changes, but not immediate ones. He first wanted in-depth data from a wide range of cultures in order to determine possible universals on which to base evaluation. His caution against the use of any one particular value system as the measure for all, is clearly meant as a temporary step until enough cultural data was collected.

Benedict (1934) describes a pressing need for culture change, especially among Euro-American cultures which she perceives as dangerous in their ethnocentrism. She refers to the ethnocentric potential of any culture, but identifies that of the Euro-American cultures as especially problematic 
because of its power-base. This is clearly an ethical judgment. Her advocacy of tolerance as an approach to cultural difference does not make Benedict view all difference as "good."

Herskovits (1958) makes a point of distinguishing between the anthropologist as researcher, and the anthropologist in society. The former tries to be as objective as possible, while the latter must necessarily act. He views the role of anthropologists as descriptive information gatherers, not social change agents. Thus, Herskovits saw the use of ethical judgments as changing depending on the role of the anthropologist.

Several of the current anthropology authors, who perceive cultural relativism as involving the view that all cultures are equal, say that such a view prevents the evaluation and ranking of data. They feel that this impedes the comparison of data. Herskovits (1958) challenges these critics who want critera with which to evaluate and asks "Whose criteria?" and on what basis are these criteria to be selected?

Like Herskovits, the current anthropologist NowellSmith (1971) applies cultural relativism to research. She says moral injunctions do not logically follow from cultural diversity and that research should be empirical, not evaluative. She suggests that cultural relativism be used 
to address such questions as how values differ crossculturally, and why people see them as valuable.

Where do the intercultural communication authors stand in this controversy pertaining to research methodology? Are researchers expected to do descriptive work from as nonevaluative a perspective as they can or, should they have criteria against which to compare and rank data?

Hofstede is one of the few who offers even brief insights into the assumptions underlying methodology. He is very definite when he states that cultural relativism is essential for empirical research. It helps restrain bias because one questions one's values and assumptions (1978), and it facilitates the obtaining of more accurate information about culture (1984).

Because the general premise of restraining evaluation in interpersonal interactions prevails in the intercultural communication area, it is likely to be operational as part of the research methodology as well. Furthermore, the primary focus of intercultural communication is to discern differences (and similarities, according to some authors) between communication behaviors of people from different cultural backgrounds, not to compare and rank data. Hence, the conflict apparent in the anthropology methodology as to whether or not to evaluate data does not appear in the intercultural literature. 
However, that discussion can be found in the anthropological literature pertaining to methodology, and the assumptive base of methodology, is important to note. Such discussion is present in both the current and early literature reviewed. In contrast, little discussion was found in the intercultural communication literature as to how research is conducted, and why it is conducted that way. (In contrast, the intercultural literature addresses extensively the question of how intercultural interactions should be optimized, and what intercultural communication training should comprise. But it begs the question of how the data on which theory and training is based was obtained.)

The assumptive base of research methodology should be clearly stated in the literature of an area of study. especially when it is an applied area which draws from several fields as intercultural communication does. Earlier in this discussion, the need for a description of the historical and theoretical sources of concepts was identified. Here, we find yet another lack of clarification, namely, of the research methods and goals of intercultural communication.

\section{Disadvantage Theme \#3: The Permeability and} Impermeability of Cultural Boundaries. The third disadvantage theme which emerged from the intercultural literature pertains to cultural boundaries. This theme was 
not found in the early anthropology literature. Only a few authors refer to it in the intercultural literature. Glenn (1981) says the change in the usefulness of cultural relativism has been contingent upon the existence of distinct cultural boundaries. Formerly, boundaries were quite distinct, but through increasing culture contact, much interdependence and culture blending has occurred. As a result, relativism no longer applies. It is unclear what Glenn means by this. Does he define relativism as contextualism, such that behaviors, for example, can no longer be considered in relation to the cultural context because this context is no longer clearly confined by boundaries? Or, does he mean that the idea "all cultures are equally valid" no longer applies, because distinct cultures no longer exist? Does he mean, perhaps, that people are not culture bound any more because cultural boundaries are more fluid?

Bennett (1986) takes a different tack. One of the basic assumptions of his "ethnocentrism-ethnorelativism" continuum, which serves as the basis for his intercultural sensitivity model, is that how people construe cultural boundaries influences their intercultural sensitivity, and reflects their level of cultural relativism. Thus, for example, someone who is fully ethnocentric has firmly fixed cultural boundaries. At the opposite end of the scale, at 
the stage of "constructive marginality," a person who is fully relative consciously reconstrues cultural boundaries. The key difference between these two views on cultural boundaries seems to be that Glenn sees boundaries as real, and as something which can change with time by means of historical events. Bennett sees cultural boundaries as conceptual, based on attitudes toward cultural differences. At one end of his continuum, some people construe cultures to be "us" and "them." Differences are seen as fixed. At the other end of the continuum, people are capable of conceptually reorganizing and recreating cultural boundaries, and participating in them.

These questions relate to those raised in the current anthropology literature. Beattie (1984) reflects Glenn's assumption of fixed reality. He describes what he perceives to be the fixed cultural boundaries of cultural relativism and says that, according to this relativistic formula, communication cannot occur unless a person completely shifts to the cultural context of the other person. He argues, however, that between these fixed cultural contexts, people somehow do communicate. Therefore, some kind of boundary permeation must occur, even if we can't get rid of our ethnocentrism.

Dimen-Schein (1977) is closer to Bennett in assuming that cultural boundaries are a mental construct. She says that because there are no actual, "fixed" cultures, there is 
no "separate but equal cultures" problem, nor is there a problem of ranking cultures because, in actuality, there are no cultures to be considered equal or to be ranked.

The general impression from the majority of the intercultural literature is that culture is viewed as a fixed entity, as Glenn and Beattie suggest. However, Bennett is not alone among authors in describing reality as a construct. Perhaps many other intercultural authors reflect this position, but they either do not state the assumptions they have which support their particular view of "culture", or they are not specific to what extent they see reality (and hence, "cultures") as construed.

It would be informative for theory clarification in intercultural communication if a study were done which determined assumptions such as this by both authors and practitioners of intercultural communication. Lack of such fundamental definition leaves ideas wide open for both misinterpretation, criticism, or both, regarding cultural relativism.

Additional Disadvantages Found in the Current Anthropology Literature

1. The Illogical Logic of Cultural Relativism. In the current anthropology literature, several authors fault cultural relativism for inconsistant or inadequate reasoning. What are the implications of this criticism for intercultural communication? 
First, before one takes the logic outlined in the anthropology criticisms and holds it up against the logic of cultural relativism used in the intercultural communication literature, two questions should be considered. First, is the logic used by the current anthropologists the same as that which operates in the reasoning of cultural relativism used in the intercultural area? Second, should this anthropology logic be the same as the reasoning pertaining to cultural relativism which is used in intercultural communication?

The first question is difficult to consider because of the lack of discussion in the early anthropology and intercultural communication literature to draw on. Exceptions are found in the writing of Herskovits and Bennett. They are fairly thorough in presenting assumptions, defining terms and outlining how cultural relativism operates within their overall conceptual frameworks.

Other than a brief reference by Herskovits, no discussion of the possible faults in the logic of cultural relativism appears anywhere in the early anthropology or intercultural communication literature reviewed in this study.

Herskovits' (1958) allusion to the logic of cultural relativism does not criticize the logic itself. Rather, he cautions that misuse of cultural relativism will lead to 
conceptual error. He says that if the different applications (methodological, philosophical, and practical) are not kept distinct, unfounded criticism, and/or unnecessary confusion can result. In other words, he suggests that cultural relativism as a methodology is not the same as cultural relativism as a philosophy, or as used in a practical context.

Regretfully, Herstovits does not elaborate upon his caution. The problem of shifting applications is, however, pursued further in Nowel1-Smiths' article. But nowhere, in the early anthropology or intercultural communication literature, is the logic of cultural relativism actually examined, beyond what Herskovits and Bennett have offered. Hence, the question of how the logic between anthropology and intercultural communication compares must remain unanswered for now.

The second question of whether or not the logic of cultural relativism should concur between anthropology and intercultural communication can be explored, but even this is somewhat limited. For example, on the one hand, one might assume that if the same language is being used, and the same general intellectual traditions, the logic for idea development should be indeed consistent. If this is the case, the logic of scientists of the same background should be the same, even between fields of study. But even here, 
the lack of discussion in the intercultural literature is restrictive.

On the other hand, perhaps fields of study can benefit from multiple forms of logic, or at least some degree of variation. This question is especially important in light of the fact that people from many cultural backgrounds are involved in the social sciences. Do they adhere to a uniform logic system intrinsic to "social science" or to each social science discipline, or do they contribute variations of logics? What about the research and application of intercultural communication and anthropology carried out in different cultures and in different languages? Is the logic of that culture employed? What happens to the "logic" of, for example, cultural relativism?

These questions are quite pertinent to intercultural communication because of the self-reflexive nature of this area of study. It has the potential, for example, of asking questions about other cultures' perspectives which, in turn, can render a different picture of itself.

The extent to which multicultural perspectives on cultural relativism exist cannot be determined from the scanty literature on cultural relativism in intercultural communication. However, because intercultural communication involves in its work the understanding of different cultural perspectives, the extent to which such multiplicity operates within its own theory is certainly important to pursue. 
Were one to have such information, the first question regarding the similarity, or difference, between the logic of anthropology and that of intercultural communication could be addressed more informatively and accurately. Cultural relativism might prove to be a highly flexible and useful concept cross-culturally. On the other hand, whatever usefulness, if any, it is perceived as having may be found to be culture-bound.

Clearly, this is a rich area for further study. The literature review reveals that too few authors have defined cultural relativism, let alone discussed their assumptions and their goals, for any analysis to be done at this time. Cultural relativism may not be the only concept so cursorily addressed.

2. The Justification of Personal Acts. Two of the current anthropologists criticize cultural relativism for its use as a justification for personal acts. Dimen-schein (1977) says that this use of relativism for moral justification is ineffective because it does not address the conditions of choices of individuals. Relativism addresses issues of cultures. Hartung (1954) says cultural relativism takes away the authority of society and renders ethics a matter of personal taste.

The differences between these two views seems to be explained by how each perceives cultural relativism. DimenSchein defines relativism as the process of cultural 
constructs. Hartung defines it as the fact of the equal validity of cultures. Dimen-schein makes a point of saying that because culture is merely a conceptual construct, the issue of "equal validity of cultures", and hence, moral dilemmas, is non-existant. There are no cultures, per se, she says. We arbitrarily draw the boundaries. Hartung, on the other hand, sees distinct, cultural boundaries, and feels that the authority of the society we are in should have influence over our choices. He clearly does sees cultural relativism as not viable because, to him, it equalizes all cultures.

The early anthropologists views seem to reflect DimenSchein's position. Perhaps, because they focus on developing theory and methods for understanding cultures, cultural differences and people in relation to their cultures, they apply relativism in terms of cultures, not individuals. Herskovits states specifically that a relativistic, minimally-evaluative position is to be applied in the research context, not in the context of the anthropologists as citizen (1958).

In intercultural communication, cultural relativism does pertain to individuals. However, relativism pertaining to personal acts, and thus morality, is generally referred to as "ethical relativism" and, as such, is not included in this study. However, overlapping of definitions and applications of both terms can be found. 
The criticism of the justification of personal acts is not insignificant in terms of intercultural communication. However, in the intercultural communication literature, the multiplicity of choices rendered by a relativistic perspective is not seen as an excuse to justify any personal acts. Generally, the problem perceived is the dilemma of having several ethical choices which derive from different cultural contexts, where an individual cannot see a basis for choosing one to which a committment to act can be made. Bennett (1986) is one of the few authors who refers to ethical choice in the context of "cultural relativism" las opposed to "ethical relativism"). In his description of his "ethnocentrism-ethnorelativism continuum," he says that different stages of relativism involve different bases for personal acts. For example, a person at the "pluralistic" stage will likely see multiple bases for ethical decision making, not knowing how to choose. This stage somewhat reflects Hartung's concern. He says that such decisions are left to choice, with no authority from society for choosing. Bennett, however, says that a person must move through, and beyond, this stage to those where one is increasingly relativistic and, at the same time, able to make ethical committments. The key, he says, is that such committments are made on a basis other than ethnocentrism. other authors (such as Barnlund) echo Bennett's identification of problems of ethical choices, as well as 
his solution. However, while Bennett offers a conceptual scheme for understanding the correlation of problems with stages of cultural relativism, the solutions to these problems, especially those involving the non-ethnocentric basis for choices, need to be addressed more comprehensively. What basis is a non-ethnocentric basis? Why is it chosen? Why is it effective? What are its implications? Does a change in communication situations, and a change of communicators roles change the basis on which decisions are made? If the goals of the communication interaction change, can the ethical framework? These are questions for which answers are very much needed, because the basis upon which individuals justify their personal acts has implications for the ability of a person to act and also for those with whom one is interacting.

3. Reality as a Discernable entity vs Reality as a Cultural construct. From the writing of the early anthropologists, it appears that they all perceived "cultures" as reflecting differing perceptual screens which variably reflect a single, existing reality, a perspective which has been referred to as "multiplicity" (Perry 1970).

A different view of reality is "constructivism" (Berger and Luckman 1967). Certainly, throughout history, there have been philosophers who have referred to reality as a "conceptual construct." Reality is created conceptually; it is not based on any existing reality las opposed to the 
multiplistic idea that cultural realties are merely reflections of an existing "reality"). Berger and Luckman (1967) were largely responsible for drawing attention to this concept in the social sciences, and relating it to social science theory. This may explain why some of the more current writers have subscribed to this assumption, but the early anthropologists did not. On the other hand, had they considered such an idea about reality, perhaps they still might have chosen to take a multiplistic rather than a constructivistic view. Without a detailed study of their philasophical orientations, it would be difficult to say. With the exception of Dimen-Schein, the current anthropology authors seem to share a multiplistic philosophical position about reality. Jarvie focuses his criticism of cultural relativism on the problems he see emerging from a position which considers reality as a construct, such that multiple, differing realities exist. He says that such realities, with their context-bound beliefs, deny the possibility of debate about reality and truth.

Again, we are faced with the question of boundaries. Jarvie (1975) argues that relativism creates a situation where there is a myriad of beliefs which are context-bound, and hence, not applicable to other cultures. No discussion can occur because the beliefs are not meaningful across cultural boundaries. 
This position stands squarely opposite to that of intercultural communication, which is concerned with the very communication of beliefs across cultural boundaries. All intercultural communication authors address this. However, only some can be identified as having the constructivist perspective on reality which Jarvie challenges.

A constructivist perspective is not uncommon in the field of communication as a whole, and the very communication problem which Jarvie raises in the anthropology field, which does not typically address the communication process as part of its study, is addressed by some of the communication literature, as well as by works in the intercultural communication literature which support the constructivist perspective (i.e., Barnlund, 1975; Bennett 1986). That is, they address, from a constructivist perspective, the problem of communication across "cultural boundaries". When applied to intercultural communication, constructivism implies the active creation of alternative world-view aspects by individuals for the purpose of communication.

However, the bottom line is that Jarvie is not arguing the problems of communication about reality he sees in the constructivist position so much as he is arguing that there is, indeed, a reality. This is another issue altogether. It is an issue likely to be present in intercultural 
communication as well (multiplicity versus constructivism), but one not addressed in terms of the field as a whole.

3. Particularism vs Universalism. The early anthropologists, and the intercultural communication authors, seem to incorporate both particularistic and universalistic approaches into their work. Boas, for example, sought to first collect data from a myriad of cultures, and only when he had enough data which was analyzed in term of context, was he, then, interested in looking for possible universals. Barnlund, too, though concerned with understanding meaning in context, writes about the need for universals.

No apparent conflict seems to exist in either the works of the early anthropologists or in those of the intercultural communication authors between their emphasis on contextualism and the making of cross-cultural generalizations about communication behavior.

However, the current anthropologist, Clark (1970), says that contextualism (particularism) and universalism are at odds. He sees relativism as rejecting any basis of criteria for cross-cultural comparison, and the establishment of general, universal laws.

This discrepancy seems, again, to be one of definitions and boundaries. Clark defines relativism as contextualism, but, in light of his discussion, he seems to perceive cultural boundaries as impermeable and absolute. 
In contrast, one of the basic assumptions in intercultural communication is that communication can occur across cultural boundaries because cultural boundaries are conceptual, and hence, flexible.

The use of concepts cross-culturally in intercultural communication is possible because they are considered useful for organizing ideas about communication to facilitate the communication process itself and to identify variations of communication behavior within different cultural groups. They are not used for making comparisons or for ranking data. Thus, concepts about communication phenomena such as "non-verbal behavior" and "proximics" are applied universally, but the meaning of the behaviors thus identified is considered in the particular contexts. Another current anthropologist, Turner (1982), argues that particularism prevents the criticizing of cultural goals at a time when cultural goals can have global implications.

Interestingly, Boas and Benedict, advocates of the very concept Turner criticizes, would have agreed with Turner. Both sought cultural understanding based on the particularism of contextualism, but they also advocated for insight into commonalities of human behavior based on this information. Their universals (and they did not think these had to apply to all people everywhere, just represent a general trend) were approximations based on the temporary 
withholding of judgment. It is at this juncture that they saw anthropologists in a position to address the pressing, global problems of society. "Cultural relativism" is what brings them to this point. It was not seen by them as an end to itself.

However, these early anthropologists were amidst a world being rapidly reshaped by imperialism. They interpreted the central world problem to be the abuses of power based on unconscious, and strong, ethnocentrism. Decades later, Turner focuses on problems which have become aggravated to crisis proportions. But, here too, he sees anthropologists as able to make a contribution.

Like Boas and Benedict, many of the intercultural communication writers also present what they perceive as pressing global, social problems (Barnlund 1978). Many of them use cultural relativism to achieve certain interactive goals, but employ a different approach when they discuss solutions to world problems. Thus, a simultaneous use of particularism and universalism does not occur. This parallels Boas and Benedict. Smart (1968), for example, says we must move past cultural relativism, utilizing what insights about cultures we've gained from it, but then synthesizing them, and forming new judgments on a new basis.

Smart's development concept echoes Bennett's continuum of relativism, but the state he says is achieved by engaging in cultural relativism and then, leaving it behind, is the 
very place described by Bennett as the final stage of relativism, which, like smart's "beyond relativism" state, involves synthesis. For the purpose of clarity, it would help to know if the two authors are giving the same state two different labels or, if they are describing different states. However, the brevity of Smart's reference prevents further comparison.

In spite of examples of relativists who incorporate both particularist and universalist approaches, Turner's query still stands as to how both can occur at once. It is here suggested that the early anthropologists, and most of the intercultural communication authors, use (or try to use) cultural relativism as an approach to achieve certain goals such as successful intercultural communication interaction, or information about cultures. Do some maintain a relativistic perspective while engaging in value formation and committment in terms of themselves and society, or do they all change approaches at this point like smart does?

Using Bennett's model as a possible explanatory tool for the moment, one could speculate that the ability to achieve particularism and universalism simultaneously, if it is possible, may well depend on the degree of cultural relativism one has developed.

Is current anthropologist, Turner (1982), correct on faulting those relativists who do shift approaches when their goals change? For instance, if someone calls the 
shift "relativism" when it is not, then Turner's point of inconsistency is accurate. But, the question begs another. What form of relativism are we talking about? What if the person simply shifts degrees of relativism, as Bennett's model indicates can occur? Then, inconsistency does not occur.

A final point is helpful pertaining to the particularism/universalism theme. Is it legitimate to shift from using relativism for some goals but not others? Again, this depends on one's interpretation of relativism. If it is a moral guide, then there might be an argument for the need for consistency. However, if relativism is an approach to understanding differences, then it seems there is no "immorality" or inconsistency in changing approaches.

In sum, Clark's and Turner's points may have relevance, but within their assumptive and definitional framework of cultural relativism. As we have seen, many authors' uses of relativism fall outside this framework.

4. Reverse Ethnocentrism. This disadvantage theme is mentioned in the early and current anthropology literature. Three of the current anthropologists charge relativists with devaluing their own cultures and positively valuing other cultures, instead of being "tolerant" of all cultures as relativists claim others should be. Benedict referred to this phenomenon and said that, while attractive in the 
frenzy of modern life to view other cultures as better, in actuality, this viewpoint is detrimental to the ethnologist. While both she and Boas draw attention to the ethnocentric dangers of powerful countries as well as the merits of the then non-industrial cultures, their focus on the negative aspects of the former, and some of the positive aspects of the latter, are clearly a matter of the emphasis which they felt was necessary to combat the misconceptions about culture they perceived prevailing in their own societies.

Bennett (1986) refers to reverse ethnocentrism also, describing it as one of the possible reactions a person can experience when exposed to cultural difference. However, he views it as one of the defensive stages of ethnocentricism, not as a state reflecting degrees of acceptance of difference, which he terms "ethnorelativism."

These references indicate that the three current anthropologists are, indeed, not alone in observing this attitudinal phenomenon. However, the criteria used by these authors for determining whether or not various anthropologists truly are reverse ethnocentric, and the extent to which they see this attitude as pervasive, is not known. A review of the intercuitural communication literature on cultural relativism indicates that this is not characteristic of intercultural communication relativists at all. However, most of the references to relativism are so 
brief, that further study would have to be done to determine if, and how many, intercultural communication authors are reverse ethnocentric.

\section{CONCLUDING REMARKS}

From the research of the intercultural communication literature, the original concern of this study was substantiated. The concept of cultural relativism is extensively used in the intercultural communication literature, but it is explicitly defined by only a small percentage of authors, and those definitions are inconsistent. Authors refer to it in all of the various applications of the field (training, intercultural interactions, and research), but the exact role relativism plays in the methods of each of these is articulated by only a few authors. That almost every intercultural communication author viewed cultural relativism as useful for intercultural communication is highly suggestive that a positive orientation is characteristic of the area of intercultural communication literature, in general. However, whether or not practitioners of intercultural communication concur is another matter, and a very important one. If practitioners do not perceive cultural relativism to be viable, then a serious split between theory and practice exists within intercultural communication. Further study of the degree to which authors and practitioners 
concur on their views of cultural relativism would help the clarification and development of intercultural theory which is so very much needed.

The review of the early anthropology literature done in this study suggested strong theoretical connections between this and the intercultural communication literature. However, no mention was found in the intercultural communicaton literature as to how cultural relativism became a part of intercultural theory, or what its theoretical roots are. This is a serious gap in the literature, and one that needs to be addressed in order to have some kind of grounding of the conceptual framework of intercultural communication. As previously noted in this chapter, such historical research, by revealing connections with already established theory, could help fill in some of the theoretical gaps in the intercultural communication literature, or would at least identify areas needing discussion.

The review of the current anthropology literature which criticizes cultural relativism, had two, overall results. First, the focus of the criticisms, such as logic, and the challenging of various concepts, revealed areas in the intercultural communication literature which were weak in presentation of the intercultural use and definition of concepts, or which were absent entirely. Thus, such concepts as "reality" and "boundaries" and "culture" which 
are key to the use of cultural relativism in intercultural communication came into relief as concepts needing clarification. Without a picture of the assumptive and conceptual basis of authors, confusion as to what they mean, and potential for criticism, prevails.

A second result was that, by contrasting some of the anthropological literature with the intercultural

literature, a better understanding of the differences between the two areas emerged. These differences included the kinds of topics considered within the fields, the methods used, the goals sought, and the varying roles perceived for the social scientist. In addition, similar views were found between the fields, suggesting that similar methodological and theoretical issues exist in both.

The only absolute difference found in the two literature groups pertained to goals. Some of the anthropologists felt that implicit in their discipline was the evaluation and resulting comparison of data. This was not found as a goal within the intercultural communication literature reviewed for this study, which is likely representative of intercultural communication in general.

The other differences occurred largely in emphasis. But this is significant because it suggests that each of the areas has much to offer the other, at least, pertaining to the cultural relativism issue. Thus, for those anthropologists who ponder how communication can occur 
across cultural boundaries within a relativistic perspective, he or she can look to the research in intercultural communication for some insights. Conversely, anthropology, as the study of culture, is a rich resource for those in intercultural communication who need in-depth understanding of cultures.

Finally, questions pertaining to the responsibilities of social scientists, in theory making, in research, and in interactive situations, apply to people in both areas. As we have seen, each of the areas, early anthropology, intercultural communication, and current anthropology, vary in their goals and emphasis. This could prove mutually beneficial as ethical concerns emerge pertaining to topios not emphasized in one area of study, but addressed extensively in another. For example, the research focus of anthropology has generated extensive discussion on cultural relativism, ethics and research. As far as the literature reviewed for this study indicates, similar discussion has not occurred in intercultural communication. But, because research is part of the intercultural communication area, questions on ethical issues, though maybe not the same ones as in anthropology, should be asked and discussed as well. The ground already covered in anthropology could well prove helpful to intercultural communication.

Similarly, intercultural communication could provide anthropologists with some insights pertaining to 
intercultural interactions which would help them address communication issues.

If intercultural communication specialists engaged in dialogue with anthropologists about cultural relativism for the purpose of clarifying the perimeters of cultural relativism for each field, different questions emerging out of the particular orientation of each field may provide new insights for the other field, and new directions of inquiry. As demonstrated by this study, "cultural relativism" has been used in the intercultural communication literature, and in both the early and current anthropology literature, to refer to many different concepts, each of which has been used in different ways, with varying advantages and disadvantages associated with them. Rather than perpetuating the confusion which has resulted from the multiple definitions, uses and evaluations of cultural relativism, a beneficial step in both intercultural communication and anthropology would be the renaming of the many concepts which have been assigned the label of "cultural relativism." For example, cultural relativism defined as contextualism could be called "contextualism." Cultural relativism defined as cultural diversity could be called "cultural diversity." While this may seem like a trivial point, the sorting out, and relabeling, of concepts has very specific advantages. 
First, a discussion specifically about "contextualism" (as opposed to "cultural relativism"), for example, could actually pursue the merits and applications of contextualism, rather than wallow in a muddle of confusion, because each communicator would know the other is talking about contextualism. If two people discuss "cultural relativism", at the present, one is very likely to be talking about contextualism, and the other about cultural diversity.

Second, as we have seen from the discussion of the disadvantages of cultural relativism, the disadvantages relate directly to an author's particular definition of cultural relativism. Authors who does not define cultural relativism as "equal cultural validity," for example, may find themselves being criticized for a supposed fault of "equal cultural validity" such as the disallowing of the evaluation of data, a criticism which does not necessarily apply if, in fact, those authors are actually using a different definition such as "attitudes toward difference."

The cataloging and renaming of concepts would make it possible to focus on the uses and merits, and the legitimacy of the assumptions of, each concept, in light of the particular goals and methods of a particular discipline.

In intercultural communication, in particular, this would alleviate both the unfortunate confusion which surrounds the term "cultural relativism," and the criticisms 
which may not be relevant to the specific definition of cultural relativism chosen for the purposes of intercultural communication. An example of such a definition of cultural relativism for intercultural communication might look like the following:

cultural relativism: the potentiality of the variability of meaning between differing communication contexts

This definition is based on the intercultural communication principle that "culture" is a perceived group whose members bond through shared meaning created, sustained, and changed by, group members. "Culture" is considered, here, as communication at 1 arge.

Some of the other concepts now being used as definitions of "cultural relativism" could be termed as follows :

1. Neutral or positive attitudes toward difference-"ethnorelativism" (in contrast to negative attitudes toward difference which would be "ethnocentrism")

2. The interconnectedness of cultural elements-"contextualism"

3. The fact of cultural diversity--"cultural diversity"

4. The perceiving and understanding on the part of an individual in terms of a "perceptual screen" comprised of both personal and cultural dimensions--"subjectivism 
5. The workability (viability) of cultures--"cultural validity"

6. The equal "goodness" of all cultures--"cultural equality"

7. Culture as ongoing, created, contingent process-"cultural process"

A very different definition than the one suggested here for "cultural relativism" may be selected for the area of intercultural communication, but failure to specifically define cultural relativism, at all, will leave those involved in the area of intercultural communication with no focus, amidst a multitude of questions about cultural relativism, such as:

Is cultural relativism a concept, a theory, a method, a doctrine, a thesis, a proposition, an assumption, an ethical guide, or what? Is it a "fact," or an attitude which can be experienced in degrees? Are we to call it epistemological relativism, ethnorelativism, ethical relativism, moral relativism, extreme relativism, or what? Is it applicable to research, to interpersonal relations, to geo-political strategies, or to philosophy? Is it moral, conceptual, or empirical? Does it mean the same thing if we use the term "relative," "relativistic," "relativism," or "relativity?" For whom is it useful? under what conditions? why? 
The current anthropologist, Hippler, says:

...we must simply for the sake of intellectual honesty bring our old rangga of cultural relativism out into the light of day where we can see it for the threadbare rag that it is (1981, 397).

Herskovits champions relativism and says it is:

...the most fruitful approach to the problem of the nature and significance of differential values in culture that has yet been devised (1951, 31).

The debate in anthropology land in other areas as well, such as psychology and philosophy) about cultural relativism has been, and seems to continue to be, lively. None exists in intercultural communication. Yet, it seems important to explore the question of whether or not the challenges to relativism are indeed relevant to intercultural communication. If they are, the implications strike the very assumptive and methodological core of training and theory in intercultural communication. If, however, upon careful analysis, the criticisms can be persuasively met, whereby cultural relativism is persuasively defended, the area of intercultural communication may prove to have some insights and perspectives with which to help clarify and validate cultural relativism elsewhere.

The goal of this study was not to argue a position, one way or another. The burden of proof as to the relevence of cultural relativism for the intercultural communication area rests on future studies. "Descriptive approaches often 
provide concrete facts describing the situation on the basis of which reasonably definite plans can be made for further action" (Helmstadter 1970). It is hoped this study has taken an effective step toward this end in describing and assessing the status quo of cultural relativism in the intercultural communication literature. 


\section{REFERENCES}

Adler, Peter S. 1974. Beyond cultural identity: Reflections on cultural and multicultural man. Topics in Culture Learning (August): 23-40.

An-náim, Abdullahi A. 1987. Religious minorities under Islamic law and the limits of cultural relativism. Human Rights Quarterly 9 (1): 1-18.

Asuncion-Landé, Nobleza c. 1975. Implications of intercultural communication for bilingual and bicultural education. International and Intercultural Communication Annual 2: $62-73$.

Barna, Laray M. 1976. Intercultural communication stumbling blocks. In Intercultural communication: A Reader, ed. Larry Samovar and Richard E. Porter. 291-298. Belmont, Ca.: Wadsworth Publishing Co.

- 1979. Ethics and intercultural communication education. Paper presented at the Annual Conference of the Society for Intercultural Education, Training and Research, Mexico City, Mexico, 2-9 March.

Barnlund, Dean C. 1968. Communication: The context of change. In Perspectives on communication, ad. C. E. Larson and F.E. X. Dance, 5-27. Madison, Wis.: Helix Press.

- 1975. Communication in a global village. In Intercultural communication: A reader, by Larry $A$. Samovar and Richard E. Porter, 5th ed., 5-14. Belmont, Ca.: Wadsworth Publishing Co., Inc. 1988. - 1978. The cross-cultural arena: An ethical void. In Ethical perspectives and critical issues in intercultural communication, ed. Nobleza C. Asuncion-Landé, 8-13. Falls Church, Va.: Speech Communication Association. Photocopied.

Barnlund, Dean C. and Naoki Nomura. 1985. Decentering, convergence and cross-cultural understanding. In Intercultural communication: A reader, by Larry $A$. Samovar and Richard E. Porter, 3rd ed. , 347-366. Belmont, Ca.: Wadsworth Publishing Co., 1985. 
Beattie, J. H. M. 1984. Objectivity and cultural divergence. In objectivity and social anthropology, ed. S. C. Brown, 1-20. Cambridge, England: Cambridge University Press.

Becker, Samuel L. 1969. Directions for intercultural communication research. Central states Journal 20 (Spring): 4. Quoted in Barbara Wilhoite Holmes. An exploratory study of the intercultural contacts of Americans in other cultures, 19. Ph.D. diss.. University of Michigan, 1978.

Benedict, Ruth. 1934. Patterns of culture. Cambridge, Mass.: Houghton, Miffin Co.

- 1946. Self-discipline in Japanese culture. In Ruth Benedict, by Margaret Mead, 146-165. New York and London: Columbia University Fress, 1974.

- 1947. Anthropology and the humanities. In Ruth Benedict, by Margaret Mead, 165-176. New York and London: Columbia University Press, 1974.

Bennett, Janet Marie. 1385. Intercultural communication training in self-awareness for study abroad. Ph.D. diss. Ann Arbor, Mich.: University Microfilms International.

Bennett, Milton J. 1977. Formingifeeling process: communication of boundaries and perception of patterns. Ph.D. diss., University of Minnesota.

- 1986. Towards ethnorelativism: A developmental model of intercultural sensitivity. In Cross-cultural orientations: New conceptualizations and applications, ed. Michael R. Paige, 27-69. Lanham, Md.: University Press of America, Inc.

Bidney, D. 1979. Cultural relativism and the value of the human. Humanitas 15 (2): 153-160.

Boas, Franz. 1938. The mind of primitive man. Rev. ed. With a Foreward by M.J. Herskovits. New York: The Free Press, a division of Macmillan Publishing Co. Inc.; London: Collier Macmillan Publishers.

- 1940. Race, language and culture. New York: The Free Press.

1962. Anthropology and modern life. New York:

W. W. Norton \& Company, Inc. 
Bochner, Stephen. 1973. The mediating man and cultural diversity. Topics in Culture Learning 1 (August): 23-37.

1981a. Intercultural mediation: A continuing inguiry. In The mediating person: bridges between cultures, ed. Stephen Bochner, 301-309. Cambridge, Mass.: Schenkman Publishing Co.

- 1981b. Introduction to The mediating person: bridges between cultures, 3-5. Cambridge, Mass.: Schenkman Publishing Co.

- 1981c. The social psychology of cultural mediation. In the mediating person: Bridges between cultures, ed. Stephen Bochner, 6-36. Cambridge, Mass.: Shenkman Publishing Co.

Bose, N. K. 1969. Cultural relativism. Man in India 49 (1): $1-9$.

Bourdillon, M.F.C. 1986. Teaching the anthropology of religion. Anthropology Today 2 (August): 11-14.

Brislin, Richard W. 1981. Cross-cultural encounters: Face-to-face interaction. New York: Pergamon Press.

Brislin, Richard W., Dan Landis and Mary E. Brandt. 1983. Conceptualizations of intercultural behavior and training. In Handbook of intercultural training. Vol.1, Issues in theory and design, eds. Richard $W$ Brislin and Dan Landis, 1-35. New York: Pergamon Press.

Clark, J. J. 1970. On the unity and diversity of cultural values. American Anthropologist 72 (June): 545-554.

Cooper, Harris M. 1984. The integrative research review: A systematic approach, Vol 2. Applied Social Research Method Series. Beverly Hills, Ca.: SAGE Publications, Inc.

Dimen-Schein, Muriel. 1977. The anthropological imagination. New York: McGraw-Hill Book Company.

Donnelly, Jack. 1984. Cultural relativism and universal human rights. Human Rights Quarterly 6 (4): 400-419.

Ferguson, Henry. 1977. Manual for multi-cultural and ethnic studies. La Grange Park: Intercultural Network, Inc. 
Fox, Robin. 1985. Anthropology. In The Social Science Encyclopedia, ed. Adam Kuper and Jessica Kuper, 2732. London: Routledge \& Kegan Paul.

Furnham, Adrian and Stephen Bochner. 1986. Culture shock. New York: Methuen Co.

Geertz, Clifford. 1984. Distinguished lecture: Anti Antirelativism. American Anthropologist 86 (June): 263-278.

Glenn, Edmund, with Christina G. Glenn. 1981. Man and Mankind: Conflict and communication between cultures. Norwood, N.J.: Áblex Publishing Corp.

Good, Carter V. and Douglas E. Scates. 1354. Methods of research. New York: Appleton-Century Crafts, Inc.

Gudykunst, William B. 1977. Toward a theoretical framework for the study of intercultural communication. Paper presented at the convention of the speech Communication Association, Washington, D.C., December. Photocopied.

Gudykunst, william B. and Young Yun Kim. 1984. Communicating with strangers: An approach to intercultural communication. Reading, Mass.: Addison-Wesley.

Hanson, Allan F. and Rex Martin. 1973. The problem of other cultures. Philosophy of the Social sciences

3 (Spring): 191-208.

Harris, Philip R, and Robert T. Moran. 1979. Managing cultural differences. Houston: Gulf Publishing Co.

Hartung, Frank E. 1954. Cultural relativity and moral judgments. The Philosophy of Science 21 (April): $118-126$.

Hatch, Elvin. 1983. Culture and morality: The relativity of values in anthropology. New York: Columbia University Press.

Helmstadter, G. C. 1970. Research concepts in human behavior. New York: Meredith Corporation.

Herskovits, Melville J. 1948. Man and his works: The science of cultural anthropology. New York: Alfred A. Knoph.

- 1951. Tender and Tough-minded anthropology and the study of values in culture. Southwestern Journal of Anthropology $7,22-31$. 
1958. Some further comments on cultural

relativism. American Anthropologist 60 (April): 266-273

- 1972. Cultural relativism: Perspectives in cultural pluralism. New York: Random House.

Hippler, A. E. 1981. The Yolngu and cultural relativism - A response note. American Anthropologist 83 (2):

393-397.

Hofstede, Geert. 1978. Value systems in forty countries: Interpretation, validation and consequences for

theory. In cross-cultural contributions to psychology. Selected papers from the 4 th

International conference of the International

Association for Cross-Cultural Psychology, Munich, Federal Republic of Germany, July 28-August 5, ed. L. Eckensberger, W. Lonner and Y. H. Poortinga, 389406. Lisse, Netherlands: Swets and Zeitlinger, B.V. for The International Association for Cross-cultural Psychology, 1979.

- 1983. The cultural relativity of organizational practices and theories. Journal of International Business Studies 14 (2): 75-89.

- 1984. The cultural relativity of the quality of life concept. Academy of Management Journal 9 (3): $389-398$.

Howell, William S. 1977. Can intercultural communication be taught in a classroom? In Readings in intercultural communication. Vol. 2, Teaching intercultural communication, ed. David S. Hoopes, 3-8. Pittsburgh: Society for Intercultural Education, Training and Research, Intercultural Network, Inc.

Isaac, Stephen and William Michael. 1971. Handbook in research and evaluation. San Diego, Ca.: Edits Publishers.

Isomura, Hisanori and Edward Stewart. 1976. Discussion. In Intercultural encounters with Japan: Communication contact and conflict: Perspectives from the International conference on communication across cultures held at International Christian University in Tokyo, ed. John C. Condon and Mitsuko Saito, 115116. Tokyo: Simul Press. 
Jarvie, I. E. 1975. Cultural relativism again. Philosophy of the Social Sciences 5 (3): 343-353.

Jimenez, Jose. 1981. The search for meaning. Dialectics and Humanism 8 (Spring): 85-92.

Kuttner, Robert E. 1970. Ethical relativism: The rise and ruin of an anthropological dogma. The Mankind Quarterly 10: 219-224.

Littlejohn, stephen W. 1983. Theories of human communication. Belmont, Ca.: Wadsworth Publishing Co.

Mayer, James C. 1980. Toward a test for ethnocentrism and ethnorelativism based upon reference group orientation. M.A. thesis., Portland State University.

Mcleod, Beverly. 1981. The mediating person and cultural identity. In The mediating person: Bridges between cultures, ed. Stephen Bochner, 37-52. Cambridge, Mass.: Schenkman Publishing Co.

Mortensen, C. David. 1972. Communication Postulates. Chap. in The study of human interaction. New York: MCGrawHill Book Co.

Neki, J. S. 1976. Examination of cultural relativism of dependence as a dynamic of social and therapeutic relationships. British Journal of Medicale Psychology $49($ March $): 1-10$.

Nowell-Smith, P. H. 1971. Cultural relativism. Philosophy of the Social Sciences 1 (January): 1-17.

Opler, M. E. 1968. Cultural relativity, modern research and M. Herskovits. American Anthropologist 70 (3): 563 .

Owen, William F. 1979. Interpersonal communication competence: A transcultural model. Speech Education Journal of the Communication Association of the Eacific - Japan 7 (September): 1-12.

Paige, R. Michael and Judith N. Martin. 1983. Ethical issues and ethics in cross-cultural training. In Handbook of intercultural training. Vol. 1, Issues in theory and design, ed. Richard w. Brislin and Dan Landis, 36-37. New York: Pergamon Press.

Pastner, C. M. Comment on Hippler's response to Reser. 1982. American Anthropologist 84 (2): 404-406. 
Pedersen, Paul. 1974. Translating therapy to the client's culture. In International and Intercultural communication annual 1 (December): 54-64.

Perry, William G., Jr. 1970. Forms of intellectual and ethical development in the college years. New York: Holt, Rinehart \& Winston.

Porter, Richard E. and Larry A. Samovar. 1988. Approaching intercultural communication. In Intercultural communication: A reader, by the authors. 5 th ed., 1530. Belmont, Ca.: Wadsworth Publishing Co.

Pusch, Margaret D. 1981. Multicultural education: A crosscultural training approach. Chicago: Intercultural Network, Inc.

Reser, Joseph. 1981. Australian aboriginal man's inhumanity to man: A case of cultural distortion. American Anthropologist 83 (2): 387-393.

- 1982. Cultural relativity or cultural bias: A response to Hippler. American Anthropologist 84 (2): 399-404.

Samovar, Larry A. and Richard E. Porter. 1976. Communicating interculturally. In Intercultural communication: $A$ Reader, by the authors. 2d ed., 4-24. Belmont, Ca.: Wadsworth Publishing Co.

1988. Epilogue. In Intercultural communication: A Reader, by the authors. 5th ed., 386-88. Belmont, Ca.: Wadsworth Publishing Co.

Sitaram, K. S., and Roy T. Cogdell. 1976. Foundations of intercultural communication. Columbus, Ohio: C. E. Merrill Publishing Co.

Sitaram, R. S., and Lawrence W. Haapanen. 1979. The role of values in intercultural communication. In Handbook of intercultural communication, ed. Molefi Asante, Eileen Newmark and Cecil A. Blake, 147-160. Beverly Hills, Ca.: SAGE Publications.

Smart, Reginald. 1968. Global village conversation: Bridges and barriers to communications between persons of different cultures. North Conway, N. H.: North Conway Publishing, Inc. 
Stein, Howard F. 1986. Cultural relativism as the central organizing resistance in cultural anthropology. Journal of Psychoanalitic Anthropology 9 (Spring): $157-175$.

Stewart, Edward C. 1972. American cultural patterns: A cross-cultural perspective. Chicago: Intercultural Press, Inc.

Stewart, Edward C., Jack Danielson and Robert J. Foster. 1979. Simulating intercultural communication through role playing. In Intercultural Sourcebook: Cross-cultural training methodologies, ed. David s. Hoopes and Paul Ventura, 44-61. Chicago, I1l.: Intercultural press, Ine.

Szalay, Lorand B. 1974. Adapting communication research to the needs of international and intercultural communications. In International and Intercultural Communication Annual 1: 1-16.

Taft, Ronald. 1981. The role and personality of the mediator. In The mediating person: Bridges between cultures, ed. Stephen Bochner, 53-88. Cambridge, Mass.: Schenkman Publishing Co.

Tai, Eiko. 1986. Modification of the Western approach to intercultural communication for the Japanese context. M.A. thesis., Portland State University.

Taylor, Robert B. 1969. Cultural Ways: A compact introduction to cultural anthropology. Boston: Allyn \& Bacon, Inc.

Teson, F. R. 1985. International human rights and cultural relativism. Virginia Journal of International Law 25 (4): $869-898$.

Tucker, Raymond R., Richard L. Weaver, II, and Cynthia Berryman-Fink. 1981. Research in speech communication. Englewood Clifs, N.J.: Prentice-Hall, Inc.

Turner, P. R. 1982. Anthropological value positions. Human organization 41 (Spring): 76-80.

Tzeng, Oliver C. S. 1983. The use of the atlas of affective meanings in intercultural training. In Handbook of intercultural training. Vol. 1 , Issues in Theory and design, ed. Richard $w$. Brislin and Dan Landis, 224252. New York: Pergamon Press. 
Wendt, Jon R. 1982. Uncle Sam and the bad news bears: Human rights as intercultural communication. In

Communication Yearbook 5, ed. M. Burgoon, 571-589. New Brunswick, N. J.: Transaction Books.

Whitney, Frederick Lamson. 1950. The elements of research.

3d ed. New York: Prentice-Hall, Inc. 